University of Arkansas, Fayetteville

ScholarWorks@UARK

Graduate Theses and Dissertations

$5-2014$

\title{
The Use of Recollection Rejection in the Misinformation Paradigm
}

\author{
Kara Moore \\ University of Arkansas, Fayetteville
}

Follow this and additional works at: https://scholarworks.uark.edu/etd

Part of the Cognitive Psychology Commons

\section{Citation}

Moore, K. (2014). The Use of Recollection Rejection in the Misinformation Paradigm. Graduate Theses and Dissertations Retrieved from https://scholarworks.uark.edu/etd/2252

This Thesis is brought to you for free and open access by ScholarWorks@UARK. It has been accepted for inclusion in Graduate Theses and Dissertations by an authorized administrator of ScholarWorks@UARK. For more information, please contact scholar@uark.edu. 
The Use of Recollection Rejection in the Misinformation Paradigm 
The Use of Recollection Rejection in the Misinformation Paradigm

A thesis submitted in partial fulfillment of the requirements for the degree of

Master of Arts in Psychology

by

\author{
Kara Moore \\ University of Texas at Arlington \\ Bachelor of Arts in Psychology, 2012
}

May 2014

University of Arkansas

This thesis is approved for recommendation to the Graduate Council.

Dr. James Lampinen

Thesis Director

Dr. Bill Levine

Dr. Denise Beike

Committee Member

Committee Member 


\begin{abstract}
Across three experiments, I investigated the role of recollection rejection in rejecting false suggestions using the misinformation paradigm. The use of model-based measurement of recollection rejection was extended to the misinformation paradigm. I manipulated two factors, delay and feedback, that are known to influence the use of recollection rejection. Recollection rejection was used to reject false suggestions in the misinformation paradigm. Manipulating delay time did not affect the acceptance of misinformation or the use of recollection rejection. Warning participants about false information reduced misinformation acceptance but did not lead to increased rates of recollection rejection. Collectively, these findings suggest an important role for recollection rejection in rejecting misleading suggestions about events.
\end{abstract}




\section{Acknowledgements}

I would like to thank my major advisor, Dr. James Lampinen, for his help and support on this project. Dr. Lampinen helped to ignite my interest in recollection rejection and apply it to another interest, the misinformation effect. Without his encouragement, patience, and ability to impart knowledge I would not have been able to complete this project. The members of my thesis committee, Dr. Denise Beike and Dr. Bill Levine, have been supportive and very incredibly insightful through my masters training and the course of this project.

I would like to thank the members of the Psychology and Law lab for their encouragement and support throughout this process. Special thanks to the 8 research assistants who helped collect and code all of the data for this project.

I am privileged to have an incredibly helpful support system of family and friends who have encouraged and motivated me throughout this project. 


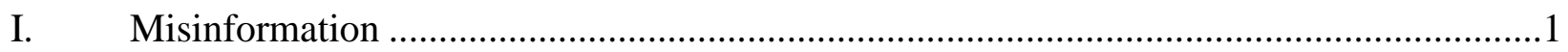

The Fate of the Original Memory ……………………...................................................

Summary: What leads to the acceptance of misinformation? ...........................................11

What Leads to The Rejection of Misinformation? ……………........................................12

II. Strategies Used to Discern True From False Information .................................................12

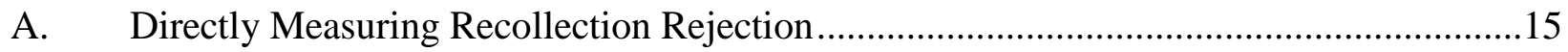

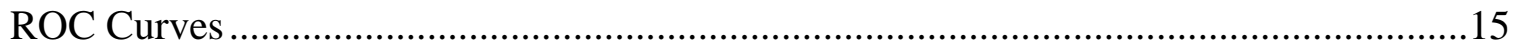

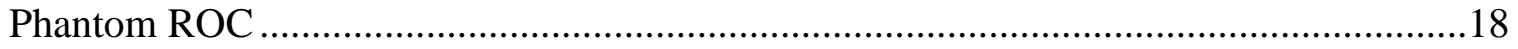

Related Lures in the Phantom ROC Model ..................................................................19

Target Recognition in the Phantom ROC Model.............................................................21

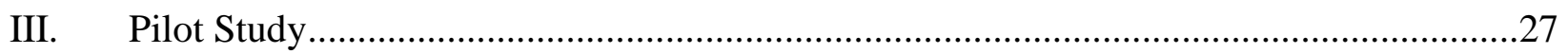

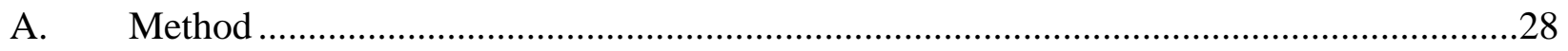

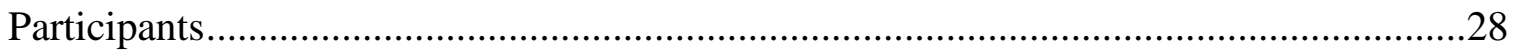

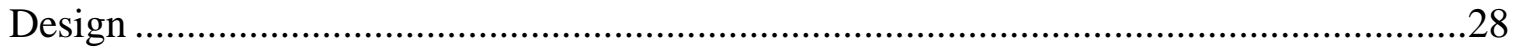

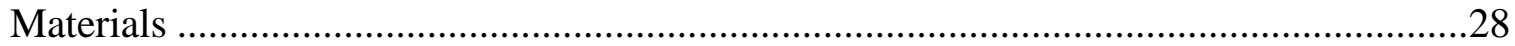

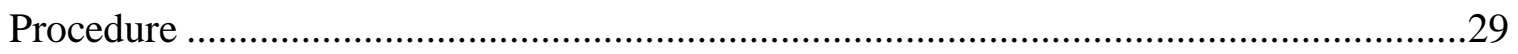

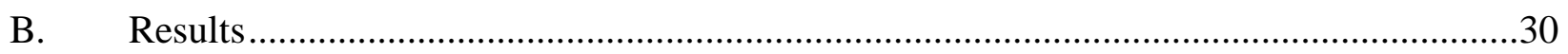

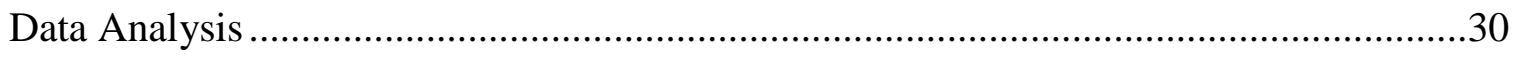

Misinformation Effects .............................................................................................30

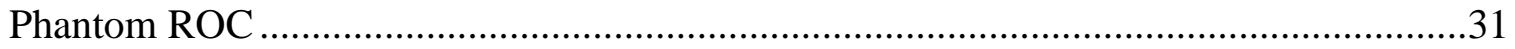

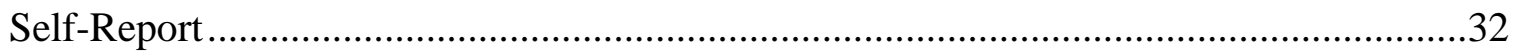

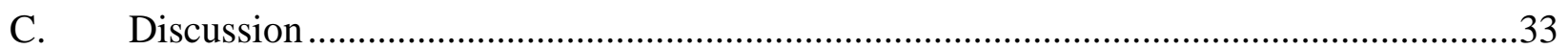

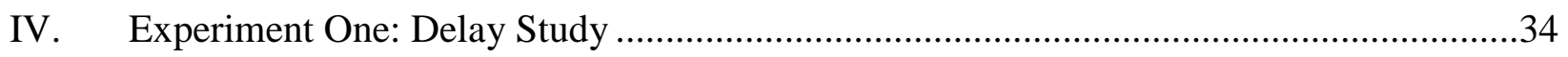

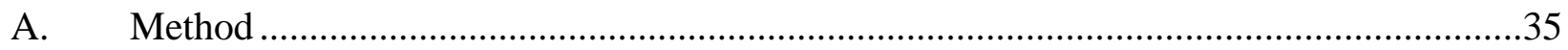

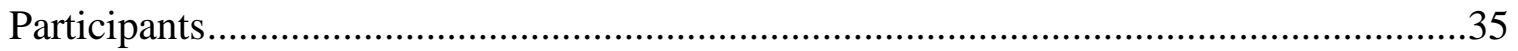

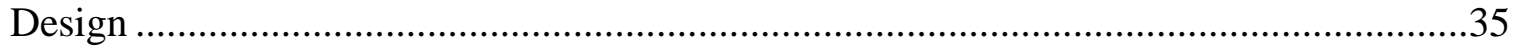

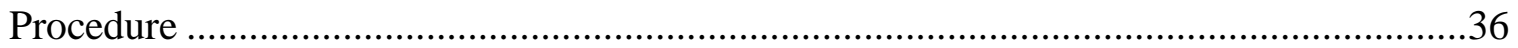

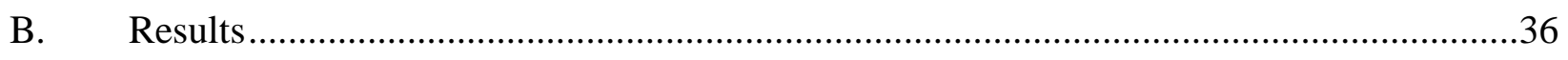

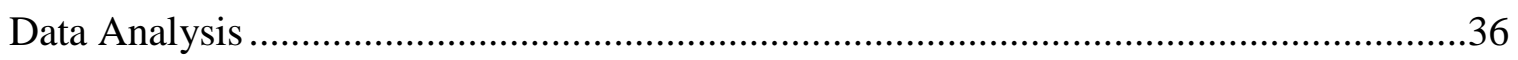

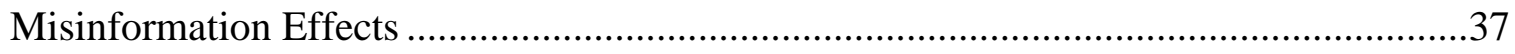

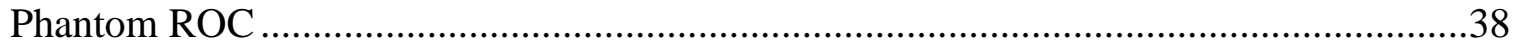




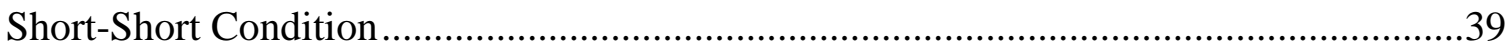

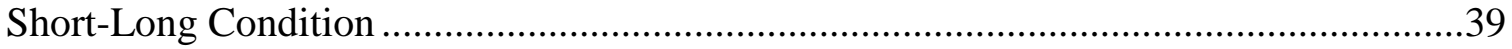

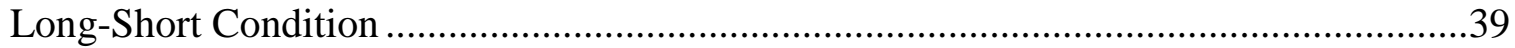

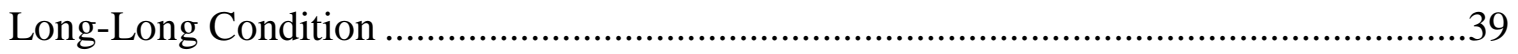

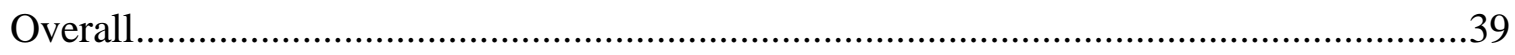

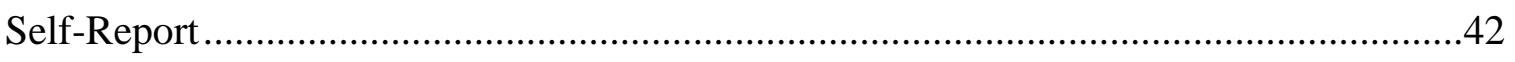

Short-Short Condition ...........................................................................................42

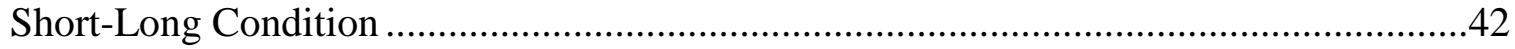

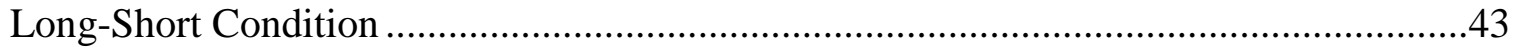

Long-Long Condition .........................................................................................

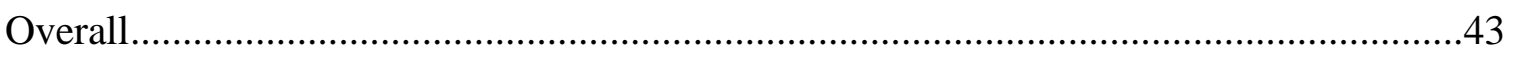

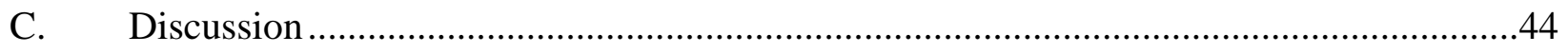

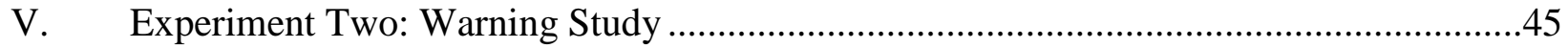

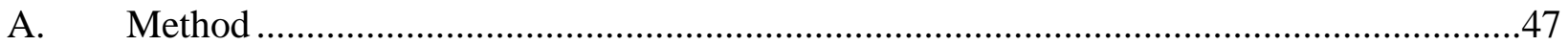

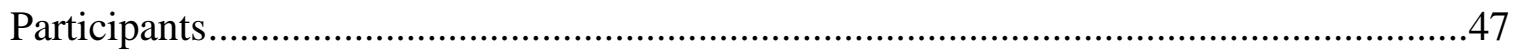

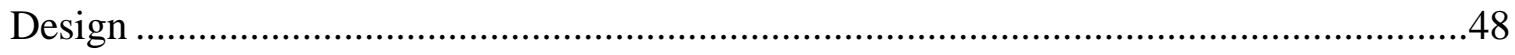

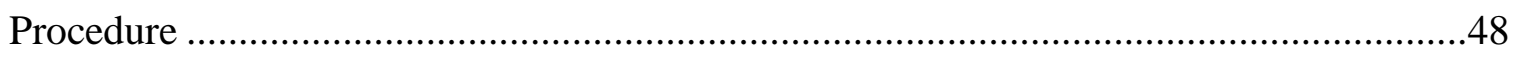

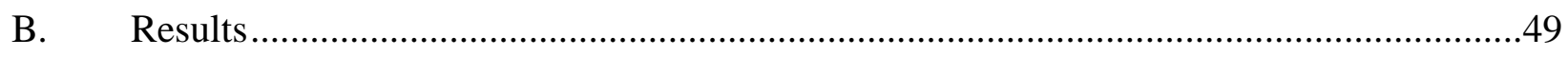

Data Analysis ....................................................................................................

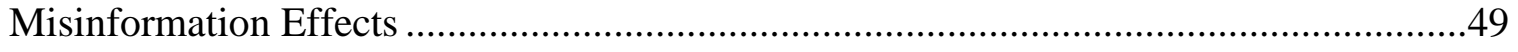

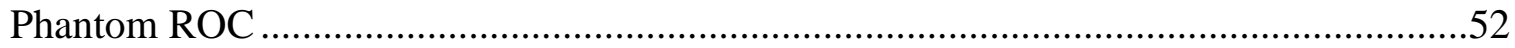

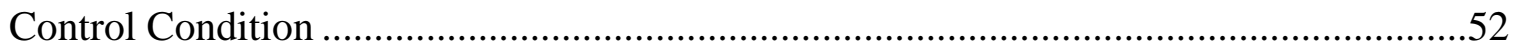

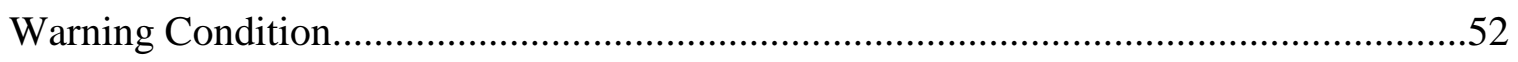

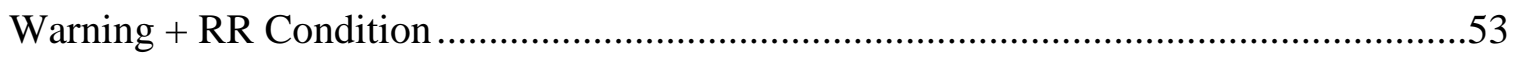

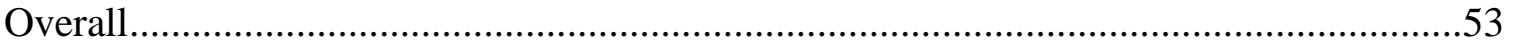

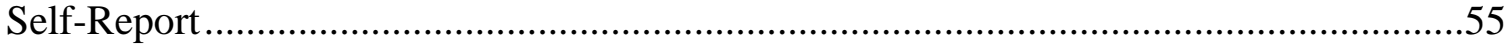

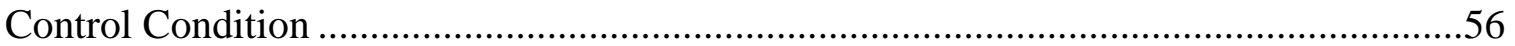

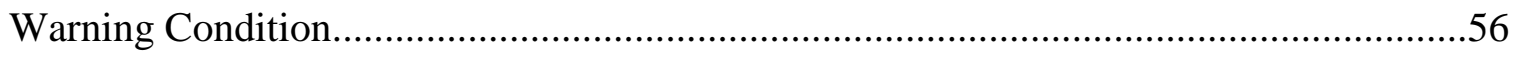

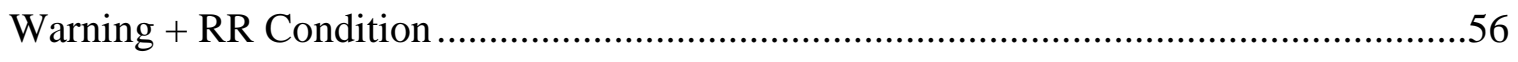

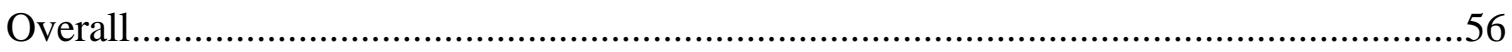

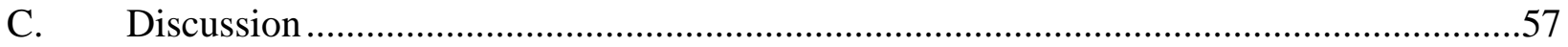

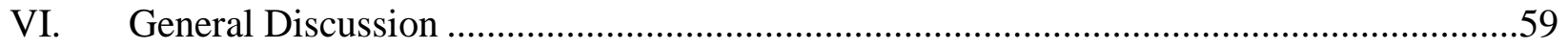

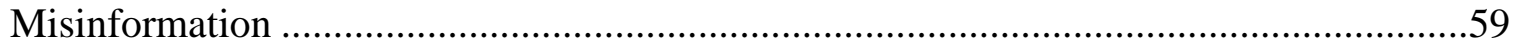




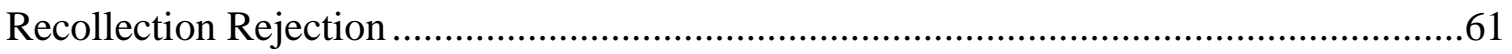

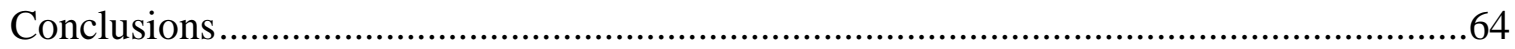

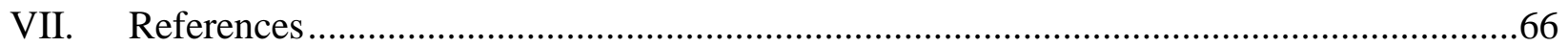

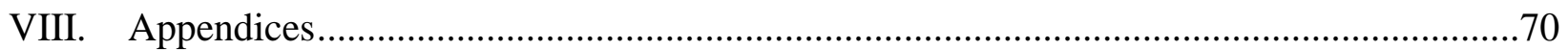

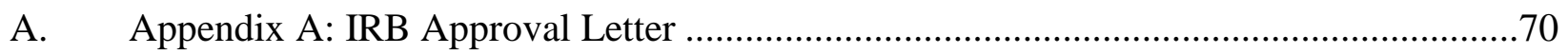

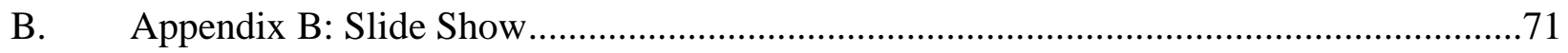

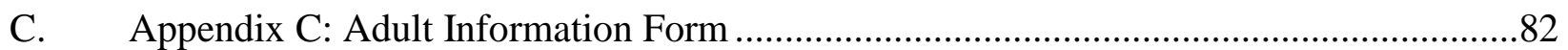

D. Appendix D: Critical Item Counterbalance …….........................................................83

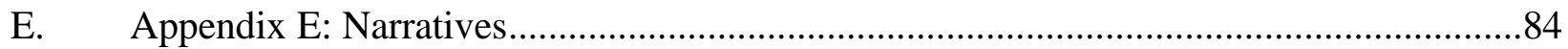

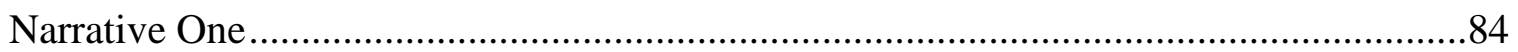

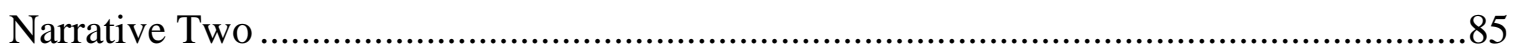

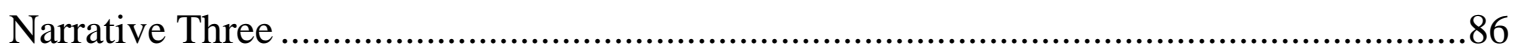

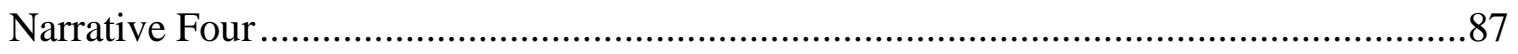

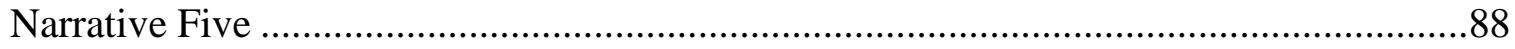

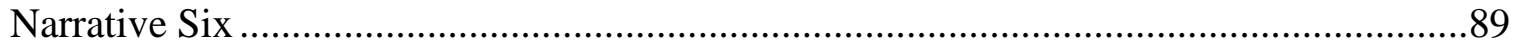

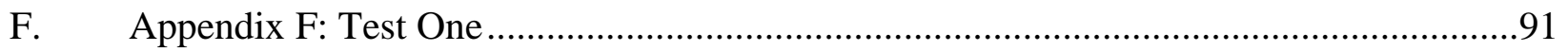

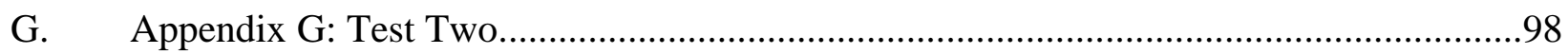

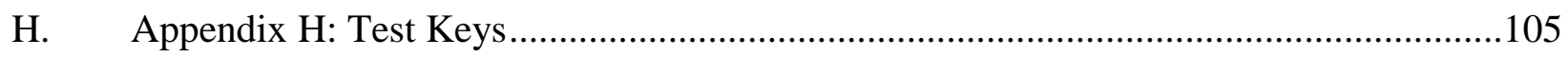

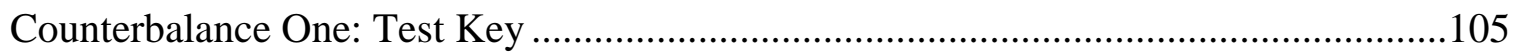

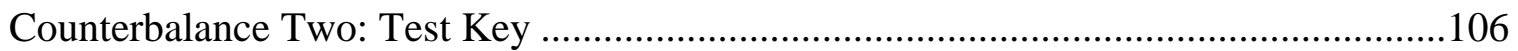

Counterbalance Three: Test Key ...............................................................................107

Counterbalance Four: Test Key ............................................................................108

Counterbalance Five: Test Key.................................................................................

Counterbalance Six: Test Key ..............................................................................110

I. Appendix I: Self-Report Survey ………………...........................................111

J. Appendix J: Warning Scripts ...........................................................................112 
Misinformation

Sometimes after a person has witnessed an event they receive false information about some of the details of the event. For instance, if the event was a crime, police officers may ask leading questions of the witness or the witness may discuss with a co-witness details of the crime that are not completely accurate. A phenomenon known as the misinformation effect occurs when these false details are incorporated into the witness's memory of the original event (Loftus, 1974). Over the years, researchers have discovered many reasons why people come to report misinformation (e.g., memory impairment - Loftus, Miller, \& Burns 1978; misinformation acceptance - McCloskey \& Zaragoza, 1985; and source misattribution errors - Lindsay \& Johnson, 1987). However, little work has been done to address the issue of how people come to reject misinformation. One way that misinformation may be rejected is through the use of a memory editing strategy called recollection rejection. Recollection rejection occurs when the memory for an item or event disqualifies the possibility of another item or event having occurred. Due to the fact that participants are often misinformed about a detail that is mutually exclusive from the detail they saw, they may be able to use recollection rejection to reject misinformation. The purpose of the current studies is to determine the nature of the use of recollection rejection in the misinformation paradigm.

There are multiple ways in which a person may be introduced to false information after witnessing an event. For instance, the witness may be interviewed by a police officer who unintentionally suggests false information. Imagine that a police officer interviews two witnesses who have witnessed a robbery. If the first witness reports that the robber was armed, when the police officer interviews the second witness, he or she may ask "What did the armed robber look like?" when in fact the second witness did not see a weapon. This question may lead the witness 
to incorporate the memory of a weapon into his or her memory of the robbery. Another way that misinformation can be encountered is through co-witness discussion. One witness may correctly remember seeing the robber with a gun, but if another witness mentions that the robber had a knife instead, this can lead to the incorporation of these false details into the memory of the crime.

In laboratory settings, the misinformation paradigm usually involves showing participants a video or a set of slides, later suggesting false information about the video or slides, and then administering a recognition test. The recognition test examines whether participant's memory of the original event has been affected by the false information. Researchers have used a second set of altered slides, a narrative about the slides, a co-witness to the event, or an interview about the event in order to introduce false information (Gabbert, Memon, \& Allan, 2003; Loftus, 1975; Takarangi, Parker, \& Garry; 2006). Interviews and co-witness discussions about the event are the most common ways that a person could potentially encounter false information in the real world after witnessing a crime. On average, people report around $30 \%$ of the false information as having occurred in the witnessed event (Loftus, 2005).

There are two types of misleading information that have been used to elicit the misinformation effect. In some studies, contradictory misinformation, false information that directly contradicts a piece of original event information, is used to elicit the misinformation effect (Loftus, 1978). In other studies, additive misinformation, new misinformation which does not contradict any of the information shown in the event, is used to induce the misinformation effect (Loftus, 1975). Both types of misinformation have successfully elicited the misinformation effect (Loftus, 1975; 1978). Loftus (1978) used contradictory postevent information to induce the misinformation effect. In this study, the researchers showed people a set of slides involving a car 
at either a stop sign or yield sign. After viewing the slides, participants filled out a questionnaire that had a question that suggested that the car was at either a stop sign or a yield sign, whichever piece of information that was the opposite of what they witnessed. Participants given contradictory information (e.g., yield sign when they saw a stop sign) were more likely to choose the contradictory information than participants given consistent information (e.g., stop sign when they saw a stop sign).

Misleading information may also be introduced that supplants information in the original event but does not contradict it. For instance, participants may be told that the man in the slide show had a knife when in fact he did not have a weapon at all. Misleading information of this type is known as additive misinformation. Loftus (1975) conducted a misinformation study that involved giving participants additive misinformation. Participants were informed that they were partaking in a study about a car accident. The additive piece of false information was that the car passed a barn while driving along a road when in fact this was not in the slide show. Participants in the control condition were asked "How fast was the white sports car going while driving along the country road?" Participants in the misinformation condition were asked "How fast was the white sports car going when it passed the barn while driving along the country road?" (Loftus, 1975). All participants were asked if they saw the car pass a barn a week later, the participants who received the misinformation indicated that they had seen a barn more than participants in the control condition.

Misinformation effects have been effectively established for both additive and contradictory misinformation but when misinformation is contradictory, participants may be able to employ a memory editing strategy called recollection rejection to reject the misinformation (Brainerd, Reyna, Wright, \& Mojardin, 2003). Recollection rejection occurs when the memory 
for an item or event excludes the possibility of another item or event having occurred. For example, a participant using recollection rejection to reject contradictory misinformation may say "I know that the man did not have a knife because I saw him with a gun." In this example, the presence of one weapon excludes the presence of another weapon. When additive misinformation is presented, there is no memory for another weapon (i.e., a gun) that could be used to reject the claim that the man had a knife. Frost (2000) examined the differences in accepting contradictory and additive misinformation. He found greater false memory for additive misinformation in comparison to contradictory misinformation; however, delay was also manipulated in this study. Participant's acceptance of misinformation was not measured until a week after they witnessed the event and encountered postevent information. One explanation for this finding is that participants used recollection rejection to reject contradictory misinformation. Nemeth and Belli (2006) also compared the effects of contradictory and additive misinformation but on schematic knowledge. The researchers found no differences between the acceptance of contradictory and additive misinformation and cite the short retention interval (i.e., 10 minutes) as an explanation for why they did not find a difference between the acceptance of contradictory and additive misinformation effects. Participants may be so good at detecting discrepancies between the original event and postevent information soon after the information is presented that differences between additive and contradictory misinformation cannot be detected. In order to test these effects, the researchers administered a remember/know paradigm to participants. Participants reported more 'know' responses for additive items than for contradictory items, so it may be that this effect was eliminated because of the type of test used to measure it. 
The Fate of the Original Memory

Soon after the initial research on the misinformation effect was published, researchers began asking what reporting misinformation meant for the original memory. One possibility is that the original memory remains intact even though misinformation is reported on the final test. If the original memory is intact, why wouldn't it be reported? Some researchers believed that people report misinformation due to social pressures even though they remember the original information (Smith \& Ellsworth, 1987). Alternatively, researchers have proposed that encoding misinformation causes the original memory to be impaired. Loftus and Greene (1980) tested this hypothesis using a lineup study. In these studies, participants were shown either a picture of a man, a video of a man, or a live presentation of a man. Participants then received misinformation in the form of a picture or video of another man. In this study, a misinformation effect was found for face memory. The point of interest is that after participants were debriefed, they were asked to choose the face they originally saw. Ninety percent of the participants who originally selected the "misinformed" face stuck with their decision. Similarly, a later study by Loftus et al. (1978) warned participants that they may have been exposed to false information. After receiving the warning, participants were asked about their memory for the misinformation and the majority of participants still claimed that they saw the misinformation in the original event. The researchers concluded that these findings supported the hypothesis that misinformation impairs or damages the original memory. This idea has come to be known as the memory impairment hypothesis.

Two versions of the memory impairment hypothesis were proposed. According to the destructive updating view, misleading information damages or completely destroys the memory trace for the original event in storage (Loftus, 1979). One implication of the destructive updating account is that once the memory trace is damaged, the damage cannot be undone. It is as if there 
were data on a hard drive that has been completely wiped clean. The alternate version of the memory impairment hypothesis was the interference account (Christiaansen \& Ochalek, 1983). According to this view, misleading information impairs retrieval of details from the original event, but those original details still remain in memory storage. One way this could occur is through blocking. In blocking, a search of memory stops as soon as information relevant to the answer is found. Because the misleading information was presented more recently, it is relatively more accessible than the original event information. When the misleading information is retrieved on the memory test, it blocks out retrieval of the original event information.

McCloskey and Zaragoza (1985) argued that Loftus' claim that misinformation impaired the memory of the original event was unwarranted. They argued that misinformation provides people who forget the original event with a choice on the final test. They stated that in the event the original memory is not remembered, misinformation does not interfere with the memory of the original event but instead is the only source of information available. Additionally, McCloskey and Zaragoza argued that sometimes participants may remember both the original event information and the false postevent information, but choose the postevent information because they believe that the researcher, who suggested the false information, must know his or her own study better than the participant.

To demonstrate this, consider a hypothetical study based on Loftus's (1977) study in which she suggested that a green car that was involved in an automobile accident was actually blue. In the car color experiment, some control participants will remember that the car was green. According to McCloskey and Zaragoza (1985), these participants should all choose the correct response on the final test (i.e., the car was green). It is possible that the control participants will not remember that the car was green. This can occur if participants did not encode the 
information or if they forgot it between the event and test. When control participants forget information, it cannot be attributed to the interference of postevent information because control participants do not encounter postevent information. When asked if the color of the car was green or blue, the control participants who do not remember would be forced to guess. Since there are two options on the test, control participants who guess should be accurate $50 \%$ of the time and inaccurate the other $50 \%$ of the time.

Consider a hypothetical experiment where $40 \%$ of the control participants remember the car was green and 60\% do not, the overall percent correct will be 70\% (40\% who remember plus half of the participants who are guessing $30 \%$ ). The misinformation effect is detected by comparing the difference in the percentages of original information recognized on the recognition test between the mislead condition and control condition. Given the example provided above about the control participants, less than $40 \%$ of the misled participants should remember that the car was green if the postevent information actually impaired the memory for the original information. Performance on the recognition test would be worse in the misled condition than the control condition if fewer misled participants remember the original information. McCloskey and Zaragoza (1985) argue that even if both groups remember the original information at the same rate, the mislead condition would still perform worse than the control condition.

If postevent information does not affect mislead participants' original memory, $40 \%$ of participants will remember that the car is green and $60 \%$ will not. These would be the same rates as the control condition. Just like control participants, assume that the mislead participants who remember that the car was green will choose the correct response on the test. What about the mislead participants who do not remember that the car was green? They are no longer limited to 
guessing. Participants who do not remember the original event information (green car) but do remember the postevent information (blue car) will presumably choose 'blue car' on the test and therefore be incorrect. Participants who do not remember the original or postevent information will be limited to guessing on the recognition test. If any of the participants forget the original information (green car) but remember the postevent information (blue car), the accuracy rate of misled participants will be lower compared to control participants. By introducing an additional source of information, accuracy rates will be lower in the misled condition. This reduction in accuracy does not have to be attributed to the memory impairment hypothesis.

In order to test for these possibilities, McCloskey and Zaragoza (1985) developed a "modified" final test. In the traditional final test, participants must choose from the piece of misinformation (e.g., hammer) and the correct information (e.g., screwdriver), and the misinformation effect is said to have occurred when the misinformed condition accepts more misinformation than the control condition. On the "modified" final test, participants were asked to choose between the original event information (e.g., screwdriver) and a new piece of information (e.g., wrench). The idea was that if memory was impaired by the misinformation, then people should do more poorly even on a test where the misinformation was not an option. If misinformation destructively updates memory for the original item in storage, then it is hypothesized that the original event detail is no longer available for retrieval. Therefore, on a modified recognition test, participants should do more poorly because the memory is no longer accessible. With the exception of the modified final test, participants in these studies were tested in the same way that Loftus tested participants. The results showed that the misled condition did not differ from the control condition on reporting the novel items. Based on these findings, the 
researchers claimed that the memory of the original event was not impaired by misleading postevent information.

Ceci, Ross, and Toglia (1987; Experiments 3 and 4) tested whether misinformation could affect children's memory using a) the traditional misinformation paradigm and b) the modified final test (Loftus, 1975; McCloskey \& Zaragoza, 1985). As expected, the misinformation effect was found using the traditional misinformation paradigm; however, somewhat surprisingly, the misinformation effect was also found using the modified final test. Belli (1989) also conducted a misinformation experiment, this time using a yes/no recognition test instead of a forced choice recognition test, which controlled for McCloskey and Zaragoza (1985)'s concern about response bias. On the yes/no recognition test, participants were presented with items and instructed to say "yes" when the items were presented in the original event and "no" if they were not. There were three types of items on this test: a) targets, items that were presented at study, b) postevent information, false information presented after the original event, and c) novel information that was not mentioned during or after the event. Belli (1989) found that when misinformation was introduced, the recognition of items from the original event decreased. This finding provided evidence that postevent information interferes with or impairs the memory for the original event. Tversky and Tuchin (1989) conducted a similar study using a yes/no recognition test. The researchers' found that participants performed worse on items for which they were misled about in comparison to items they were not. The researchers took these findings as evidence that misleading information affects the memory of the original information. However, participants in this study sometimes accepted both the original information and postevent information, which suggests that the memory for the original information is not always impaired. Additionally, Belli, 
Windschitl, McCarthy, and Winfrey (1992) found memory impairments on the modified test after a long retention interval (5-7 days) but not a short retention interval (15 minutes).

Lindsay and Johnson (1987) proposed that misinformation may be accepted because people incorrectly attribute misinformation as having occurred in the original event. They called this misattribution a source monitoring error. A source monitoring error is committed when participants remember the original event information and the postevent information but confuse the sources, leading them to report that the postevent information occurred in the original event (Johnson, Hashtroudi, \& Lindsey, 1993; Johnson \& Raye, 1981).

Zaragoza and Lane (1994) sought to determine whether people actually confuse postevent information with their memories of the original event. To test this, participants were asked to make overt source judgments on the final test. Additive postevent information was used in order to reduce the chances of participants detecting discrepancies between the original and the postevent information. Participants were instructed to indicate whether they "saw", "read" or "both" saw and read about an item. Some participants indicated that they "saw" the postevent information in the original event. This finding provides evidence that participants believed that postevent information was shown in the original event.

Loftus and Hoffman (1989) stated that misinformation acceptance and memory impairment are both involved in accepting misinformation. They discussed how misinformation acceptance, memory impairment, and source misattribution can all lead participants to report misinformation. The researchers continued to uphold the claim that memory impairment can and does occur while embracing the idea that misinformation acceptance plays a role in the misinformation effect. In accordance with their conclusion, evidence has been found for each of 
the following theories: misinformation acceptance, memory impairment, and source misattribution. It is possible that within a study or paradigm that all three of these types of misinformation acceptances could occur. For instance, a participant could have seen a man drink a Coke in a video but received postevent information that the man drank Pepsi. On the final test, he or she could be confused as to whether they saw Pepsi or Coke in the video. Another participant may recall the source of both the Coke and Pepsi but think that the experimenter who provided the postevent information is more likely to know what happened. This may lead the participant to report that the man drank a Pepsi in the video. Finally, another participant's memory for the video may have been impaired by encountering the postevent information about the man drinking a Pepsi.

Summary: What leads to the acceptance of misinformation?

During the memory impairment debate, researchers found several causes of the misinformation effect. These causes fall into three broad categories: memory impairment, misinformation acceptance, and response bias. One cause of choosing misinformation on a final test occurs when a person is exposed to postevent information and it leads to the impairment of memory for the original event (Loftus, 1979; Loftus \& Loftus, 1980). This phenomenon has been called memory impairment. Lindsay and Johnson $(1987,1989)$ discovered another cause for accepting misinformation which is known as source monitoring errors. Source monitoring errors are a form of memory impairment that occur when a person remembers both the original event and misinformation, but remembers the misinformation as having occurred during the original event. Misinformation acceptance occurs when participants who remember both sources of information choose the postevent information. Another form of misinformation acceptance occurs when the participant chooses the postevent information because he or she does not 
remember the original information but does remember the postevent information. Lastly, in some cases the participant may forget both the original event and the misinformation in which case they resort to guessing.

What leads to the rejection of false information?

There are three main reasons why participants would reject misinformation. One reason a participant may reject misinformation is because he or she remembers the original event information, the postevent information, and their respective sources. Rejecting misinformation in this fashion is akin to recollection rejection. Next, a person may be led to reject misinformation because he or she remembers the original information and forgets the postevent information. Finally, the person may forget both the original information and the postevent information and make a guess.

Strategies Used to Discern True From False Information

There are a number of strategies that can be used to accept or reject information. Tousignant, Hall, and Loftus (1986; Loftus, 1992) suggest discrepancy detection is one mechanism used to accept or reject misinformation. Discrepancy detection occurs when a participant detects a discrepancy between the original event and the postevent information at the time the postevent information is encountered. When a person encounters information about a witnessed event, they use discrepancy detection to identify differences between what they remember witnessing and the information being provided to them. The quality of a person's memory affects their ability to use discrepancy detection (Tousignant et al., 1986). If a person cannot remember an event well, they will struggle to detect differences between what they witnessed and the postevent information they received, because there is less information to 
compare the new information to. The discrepancy detection principle states that "recollections are more likely to change if a person does not immediately detect discrepancies between postevent information and memory for the original event" (Loftus, 1992; p121). As a result, discrepancies between the two sources are less likely to be detected when original event information and postevent information are spread apart further in time. Tousignant et al. (1986) sought to provide direct evidence for the use of discrepancy detection in the misinformation paradigm. They believed that discrepancy detection could explain people's responses to warnings, delays in misinformation, and the strength of misinformation. To test for evidence of discrepancy detection in Experiment 1, the researchers measured how quickly participants read postevent information. The researchers hypothesized that if a discrepancy was detected, participants would read or think over the postevent information, taking more time to come to a resolution of what they witnessed. In Experiment 2, discrepancy detection was directly measured by asking participants to report when they detected a discrepancy in addition to measuring reading speed (Tousignant et al., 1986). Slower reading times were found to be associated with reduced acceptance of false information. It follows that quicker reading times were associated with higher acceptance rates of false information. In another experiment, reading speed was experimentally manipulated by instructing participants to read the postevent information quickly or slowly. This was done in order to confirm that slower reading times, not people prone to slow reading, were associated with a decrease in the acceptance of misinformation (Tousignant et al., 1986). These studies confirmed that slower reading times were associated with higher levels of discrepancy detection and accuracy. Other research found that participants whose attention is divided during the encoding of postevent information are more likely to report misinformation than participants whose attention was not divided (Zaragoza \& Lane, 1998; Lane, 2006). These 
studies provided evidence that the resources necessary to detect discrepancies between two sources of information are not available to participants who are distracted.

Another strategy that may be used to accept or reject misinformation is recollection rejection. Recollection rejection is a memory editing strategy that reduces rates of false recognition (Brainerd et al., 2003) through comparing possible events when only one could have actually occurred. When one of these events is recognized, the others can be rejected. For example, if a person can remember parking their car in the parking lot at work they can reject the idea that they took a bus or a place to work because it is only possible to take one of mode of transportation.

The Deese-Roediger-McDermott lists have been used to examine recollection rejection (Deese, 1959; Roediger \& McDermott, 1995). The DRM paradigm consists of lists of words that all relate to one critical unpresented word, which is known as a critical lure. For example, one list consists of words related to royalty. Royalty is the critical lure so it is not presented at study but a number of people recall it at test because it is so similar to the other words they have studied. When recollection rejection occurs in the context of the DRM paradigm, people compare their memory for one word (i.e., king) to other related words (i.e., princess, royalty, etc.).

There are a number of findings to support the idea that people are more likely to falsely accept a related item that was not presented at study than an unrelated item that was not presented at study (Roediger \& McDermott, 1995). When people's memory of the DRM lists is tested, they accept the critical lure as part of the studied word list at very high rates (Lampinen, Meier, Anal, \& Leding, 2005; Lampinen, Odegard, Blackshear, \& Toglia, 2005). In addition to strong evidence for these findings, researchers have found that under certain circumstances people are more likely to falsely accept an unrelated word than a related word (Brainerd, Reyna, 
\& Kneer, 1995). These findings have been explained by the use of recollection rejection, which allows people to compare related items or events in memory to determine what happened. If someone can remember that the word horse (target) was presented, they can be more confident that the word pony (related lure) was not presented, whereas they would be less confident that pony was not presented if they did not remember the word horse. If someone is asked if the word сир (unrelated lure) was presented but they have no recollection of another related word (i.e., glass), they may say "it's possible that the word cup was presented, because I do not recall a related word being presented." Recollection rejection has been thoroughly investigated using words, pictures, and statements; however, no research has examined whether people can use recollection rejection to reject false postevent information like that used in the misinformation paradigm (Gallo, Bell, Beier, \& Scharcter, 2006; Reyna \& Kiernan, 1995). There are a number of ways studies have measured recollection rejection. I thought that using receiver operating characteristics to measure recollection rejection was a fitting choice for the misinformation paradigm.

Directly Measuring Recollection Rejection

\section{ROC Curves}

Receiver operator characteristic curves are scatterplots of the proportion of correct recognitions and the proportion of false recognitions at varying confidence levels (Yonelinas, 1997). These values are obtained through old/new recognition tests. An "old" judgment indicates the belief that an item was studied; a "new" judgment indicates the belief that an item was not studied. On the x-axis, the probability of accepting an item that was not studied (unrelated items on one plot and related items on another plot) at various confidence levels are plotted. On the y- 
axis, the probability of accepting targets at various confidence levels is plotted. The furthest point on the left of the graph shows the rate at which the most confidently remembered items, old (on the y axis) and new (on the x axis) are accepted as "sure-old". The next point, "maybe-old" includes the rate at which old and new items are accepted as "sure-old" and "maybe-old". This continues until the final point, "sure-new" which incorporates the rate at which old and new items are accepted as "sure-new" and all of the other possible judgments. The point on the yintercept that the curve intersects represents "sure-old" the amount of recollection occurring because at this point, signal detection process is maximally conservative (Lampinen et al., 2005). When the upper x-intercept of the "old-similar" (related lure) data is higher than the upper xintercept of the "old-new" (unrelated lure) data, recollection rejection has occurred. The difference between these two numbers provides a measure of how much recollection rejection is occurring. The symmetry of ROC curves contributes to their ability to provide a measure of recollection rejection. When only familiarity processes account for recognition decisions and the distribution of recognition is normal and of equal variance, symmetrical ROCs will occur (Brainerd et al. 2003). Yonelinas (1994) found that these plots are skewed when measuring recognition; this occurs when distributions of familiarity values are not normal or have unequal variances.

Rotello, Macmillian, and Van Tassel (2000) demonstrated that (ROC) curves are useful in determining the use of recollection rejection in recognition tasks, assuming a dual-process model of recognition. The researchers propose a model of recognition involving both familiarity and recollection. In such cases, the y-intercept of the ROC curve will be greater than zero and the slope will be decreasing. The decreasing slope is due to the distribution of familiarity. When "old-similar" ROCs are plotted, instead of "old-new", they have a slight curve (Rotello et al. 
2000). Rotello et al. (2000) argued that recollection rejection occurs when distractors are placed in the "sure-new" category and no old items are placed into the "sure-new" category. This causes the ROC curve to hit the upper $\mathrm{x}$-axis when the false alarm rate is less than 1 . The researchers argue that this occurrence represents recollection rejection (Figure 1).

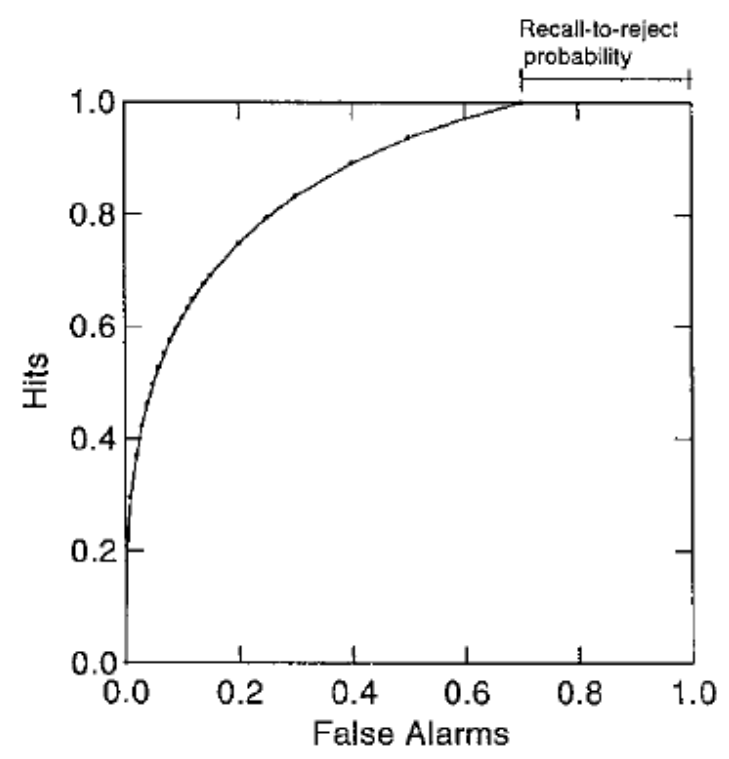

Figure One: Hypothetical ROC curve that indicates the presence of both familiarity and recall-to-reject processing ${ }^{1}$

${ }^{1}$ Rotello et al. (2000)

In a series of experiments, Lampinen, Odegard, Blackshear, and Toglia (2005) tested whether ROC curves would show evidence for recollection rejection by presenting participants with a list of words. Participants were tested over their memory for words that were presented, related words that were not presented, and unrelated words that were not presented. When target recognition was regressed onto false recognition for related words, they found the upper xintercept to be about .71 which indicates that about $29 \%$ of the related words were rejected by recollection rejection. 


\section{Phantom ROC}

A phantom ROC model was devised to examine phantom recollection and recollection rejection using ROC curves (Lampinen et al., 2005). Phantom recollection is a phenomenon that occurs when a person experiences a false recognition as compellingly as he or she experiences true memories. When phantom recollection occurs, it can lead to erroneous recollection rejection, which is the rejection of a target item. The phantom ROC model retains some of the assumptions of Brainerd, Wright, Reyna, and Mojardin (2001) phantom recollection model and Yonelinas (1999) dual process model. Lampinen et al. (2005) assumed that familiarity is not an all-or-none, but a graded process like Yonelinas. Yonelinas used ROC curves to model recollection and familiarity $(1994 ; 1997)$. The phantom ROC model builds off of this by using ROC curves to estimate additional memory processes influenced by recollection and familiarity (e.g., recollection rejection and phantom recollection).

The phantom ROC model uses ROC plots of target recognition against related lures and unrelated lures like Rotello et al. (2000), to examine recollection rejection. The phantom ROC model adds the measurement of phantom recollection and phantom recollection rejection to form a complete model. Brainerd et al. (2001) also accounted for phantom recollection and phantom recollection rejection but instead used a conjoint recognition model.

The phantom ROC model measures two high confidence, all-or-none processes: recollection rejection and phantom recollection. Finally, familiarity for targets and familiarity for related items, which are graded processes, are measured. 
Table 1. Parameters estimated by the phantom ROC model.

\begin{tabular}{|l|l|}
\hline Parameter & Description \\
\hline $\mathrm{R}_{\mathrm{t}}:$ & Recollection of targets \\
\hline $\mathrm{ER}_{\mathrm{t}}:$ & Phantom recollection rejection for targets \\
\hline $\mathrm{d}^{\prime}{ }_{\mathrm{t}}:$ & Memory strength for targets based on familiarity \\
\hline $\mathrm{P}_{\mathrm{r}}:$ & Phantom recollection for related lures \\
\hline $\mathrm{R}_{\mathrm{r}}:$ & Recollection rejection for related lures \\
\hline $\mathrm{d}_{\mathrm{r}}:$ & Memory strength for related lures based on familiarity \\
\hline
\end{tabular}

Related Lures in the Phantom ROC model.

There are a number of reasons a participant may accept or reject a related lure. If the participant uses recollection rejection, he or she will reject a related lure because they remember an item that disqualifies the related lure from having occurred. If phantom recollection occurs, the participant will accept the related lure on the basis that they believe that the target did not occur. Finally, a participant may accept a related lure because the item is familiar to the participant. The probability of these different memory processes is estimated by the phantom recollection model by fitting a multinomial model. Phantom recollection and recollection rejection are estimated by fitting an ROC curve that plots cumulative recognition of related lures against cumulative recognition of unrelated lures. Familiarity for related lures is expressed in terms of the sensitivity (i.e., d'r) of the underlying signal detection model.

The equations for the related lure ROC curve are as follows, where $\mathrm{c}_{\mathrm{j}}$ refers to the shifting response criterion: 


$$
\begin{aligned}
& P(\text { related })=\left(1-R_{r}\right) P_{r}+\left(1-R_{r}\right)\left(1-P_{r}\right) \varnothing\left(d^{\prime}{ }_{r}-C_{j}\right) \\
& P(\text { unrelated })=\varnothing\left(-C_{j}\right)
\end{aligned}
$$

Figure 2 is a hypothetical ROC curve using the phantom ROC model (Lampinen et al., 2005). The equations for related and unrelated lures indicate that the signal detection process only comes into play if both recollection rejection and phantom recollection rejection fail to occur. When the signal detection process is maximally conservative, the equations are the following:

$\mathrm{P}($ related $)=\left(1-\mathrm{R}_{\mathrm{r}}\right) \mathrm{P}_{\mathrm{r}}$ $\mathrm{P}($ unrelated $)=0$

When the signal detection process is maximally conservative, the y-intercept in the model is $\left(1-R_{r}\right) P_{r}$. One assumption of the phantom ROC model is that recollection rejection overpowers phantom recollection. Therefore, the y-intercept represents the probability of phantom recollection occurring.

If the response criterion is more liberal, the ROC curve should cross the diagonal representing chance performance and therefore should intercept below $(1,1)$ on the curve. When signal detection is maximally liberal, the equations simplify to:

$\mathrm{P}($ unrelated $)=1$

$P($ related $)=\varnothing\left(d^{\prime}{ }_{r}-C_{j}\right)$

If any recollection rejection occurs, the ROC curves should cross the diagonal and intercept somewhere below $(1,1)$. Recollection rejection can be estimated by determining how far below $(1,1)$ the ROC curve is. 


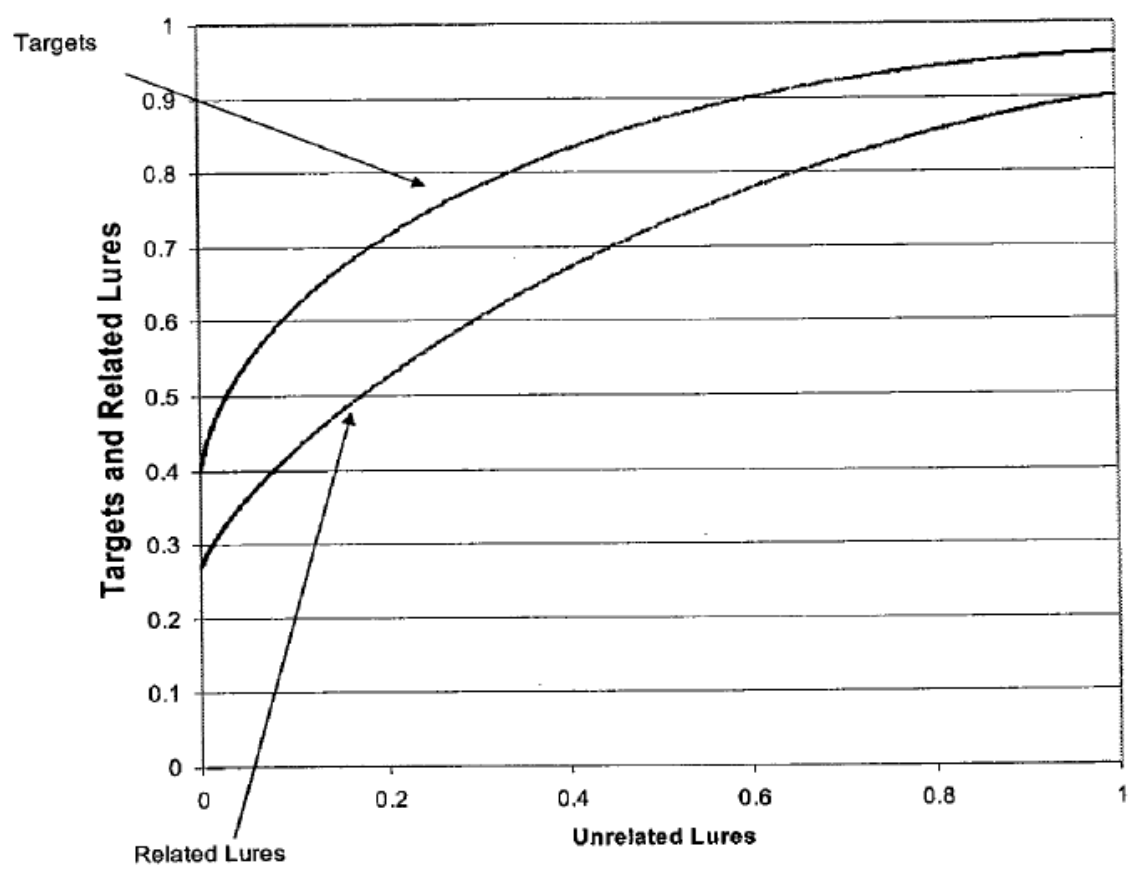

Figure Two: Hypothetical ROC Curve Illustrating

Target Recognition Under Phantom ROC ${ }^{2}$

${ }^{2}$ Lampinen et al. (2005)

Target recognition in the Phantom ROC model.

Recollections occur when a participant accepts targets because they match the participants' exact memory trace. Targets can also be accepted because they are familiar. Participants can mistakenly reject a target because they "remember" the related lure as having occurred, as in the case of phantom recollection.

Recollection, phantom recollection, and familiarity are all estimated from the ROC curve. Familiarity for targets is expressed in terms of the sensitivity (i.e., $d^{\prime}{ }_{t}$ ) of the underlying signal detection model.

The equations for the ROC curve for target recognition are:

$P(\operatorname{target})=R_{t}+\left(1-R_{t}\right)\left(1-E R_{t}\right) \varnothing\left(d^{\prime}{ }_{t}-C_{j}\right)$ 
$\mathrm{P}($ unrelated $)=\emptyset\left(-\mathrm{C}_{\mathrm{j}}\right)$

Recollection estimates are provided by the y-intercept of the ROC curve.

$\mathrm{P}($ target $)=\mathrm{R}_{\mathrm{t}}$

$\mathrm{P}($ unrelated $)=1$

Thus, phantom recollection will only occur if a recollection does not occur according to the phantom recollection model.

In Experiment 1, Lampinen et al. (2005) tested Brainerd's et al. (2001) prediction that phantom recollection would be more likely to occur when the related lure is a good match for the underlying gist memory trace of the target. Phantom recollection for critical lures and missing exemplars were compared because when an item is closely related to the gist traces for the target, such as critical lures, phantom recollection should be higher in comparison to when an item is less closely related to the gist trace for the target, such as missing exemplars. In the DRM paradigm, critical lures are words that all of the presented words are related to. The critical lure is a word that is not presented at study but represents the gist of the word list. Missing exemplars are words that are not presented on the study lists; however, these words were generated to be related to critical lures but are not related to the whole list of words. Therefore, missing exemplars are less closely related to the list than the critical lures.

In this experiment, participants studied multiple DRM lists. After the study phase, they took an old/new recognition test and ranked the confidence of their responses on a 4 point scale ranging from "not at all confident" to "extremely confident". To make these yes/no judgments, participants were either instructed use to target instructions, related instructions, or target and 
related instructions (Brainerd et al., 2001). Additionally, half of participants were asked to make remember/know responses for each item. Remember judgments map onto recollection while know judgments map onto familiarity. For "new" judgments, participants were asked to indicate "remember" if they could remember information that made them believe that the item was not presented during the study phase.

As predicted, phantom recollection of critical lures was higher than the phantom recollection of missing exemplars. This occurred because critical lures provided a stronger cue for target items than missing exemplars. ROC analyses found that remember-based responses were more common for targets than critical lures. The remember/know judgments which were considered as support for self-reported recollection rejection did not match up with ROC estimates of recollection rejection. The researchers hypothesize that this occurred because the instructions for the task may not have been clear enough.

In Experiment 2, study list length was varied in order to manipulate gist strength. It has been hypothesized that longer lists are more likely to induce gist representations (Brainerd et al., 2001). The method in this experiment was the same as that in Experiment 1.

The phantom recollection rejection of targets did not differ from recollection rejection of critical lures. Performance differences for target recognition, phantom recollection rejection, and recollection rejection were not found between list lengths. It was predicted that long lists would cause greater similarity for targets and critical lures, but this result was not found.

Regarding false memories, the researchers found that ROC curves that plot related lures against unrelated lures intercepted the $\mathrm{Y}$-axis above 0 . This occurrence provides evidence for recollection and phantom recollection. These studies supported the prediction that when gist 
trace is strong, phantom recollection will occur. In Experiment 1, this was evidenced by the greater y-intercept for critical lures than missing exemplars. In Experiment 2, this was evidenced by the greater y-intercept for long list lures compared to short list lures.

The use of the phantom ROC model to measure recollection rejection and other memory editing processes has several benefits. The phantom ROC model is able to measure the parameters of the model with the use of only one instructional condition. Brainerd et al.'s (2001) conjoint recognition model of phantom recollection requires three different instructional conditions and therefore more participants to obtain the same estimates. Additionally, the phantom ROC model clearly predicts that if any recollection rejection is occurring, the ROC curves should cross the diagonal and intercept somewhere below (1,1) (Lampinen et al. 2005). Additionally, the rate of recollection rejection is provided by the amount below $(1,1)$ that the ROC curve falls.

Lampinen, Watkins, and Odegard (2006) examined dual process predictions about recollection rejection using the phantom ROC model (three process model). Participants studied and were tested over their memory for pictures. On the test, there were targets, related lures, and unrelated lures. Targets were pictures that were presented during study, related lures were pictures of the target items taken at a different angle, and unrelated lures were pictures that are unrelated to targets and were not presented during study. The test included instructions that were similar to the conjoint recognition model's test instructions. The first set of instructions was designed to elicit gist memory and the second set of instructions was designed to elicit verbatim memory. In the first set of instructions, the "meaning question" instructed participants to say 'yes' if they saw the item in the study phase even if at study it was at a different angle (i.e., a photo of a dog head on versus a photo of a dog in profile view). In the second set of instructions, 
participants were asked to respond 'yes' only if they saw the exact photo on the "standard recognition question". Confidence ratings for the responses to both question types were obtained. In addition, attention was manipulated in order to determine its effect on recollection rejection rates. Half of participants were assigned to the divided attention condition. These participants were asked to count backwards by $3 \mathrm{~s}$ during the study phase. The other half of participants completed the study phase without any distractions.

The researchers had three specific predictions. One prediction was that related lure ROC curves would be deflected below the diagonal when substantial recollection rejection occurred. This should occur because recollection rejection can provide a more certain basis for rejecting an item than a lack of familiarity. Target recognition, familiarity, and erroneous recollection rejection were estimated by ROC curves in which targets and unrelated lure probabilities were plotted. When meaning instructions were given, it was predicted that related items would be accepted; however, when standard instructions were given, it was predicted that they would be rejected. This prediction is based on the findings that recollection leads to the acceptance of related items under gist instructions but not under verbatim instructions. Finally, it was hypothesized that high confidence flip flops would occur if participants were asked both standard and meaning questions for the same item. High confidence flip flops occur when the high confidence rejection of related lures under one set of instructions (standard) becomes high confidence acceptances of those same items under the opposite set of instructions (meaning).

ROC curves for related lures were deflected below the diagonal as predicted, indicating that substantial recollection rejection occurred. There was less of a downward deflection on the target ROC curve, which provides evidence that recollection rejection of related lures was more common than erroneous recollection rejection of targets. The y-intercept of the target ROC curve 
was much lower for participants who were distracted than for participants who were not. Participants who were distracted at study therefore made fewer recollection-based acceptances than participants who were not distracted. High confidence flip flops occurred more often for related lures than targets or unrelated lures. The data on high confidence flips flops indicate that there was a lot of recollection rejection of related lures. The data also show the erroneous recollection rejection of targets by participants.

In Experiment 2, half of participants were informed that the photos were mutually exclusive, while the other half of participants were told that it was possible to have seen pictures from two different camera angles (i.e., the items were not exclusive). Instructions about exclusivity were manipulated because using recollection rejection should be easier when a participant is alerted to the exclusive nature of items.

For the standard instruction ROC curve, there was a downward deflection of both the mutually exclusive curve and the non-exclusive curve. This indicates that all participants used recollection rejection to accept targets and reject related lures. Erroneous recollection rejection of targets did not occur as often as recollection rejection, evidenced by the fact that the target standard instruction ROC curve did not have much of a downward deflection. Similar to the results found in experiment one, high confidence flip flops were more common for related lures than for targets, which were more common than unrelated lures. Mutual exclusivity instructions did not seem to have an effect on participants' judgments. Lampinen et al. (2006) proposed that the instructions may not have affected participants' choices because participants are already very capable of using recollection rejection without instructions. Alternatively, other researchers have proposed that recollection rejection may be unconscious and therefore unaffected by metacognitive control (Brainerd et al., 2003). This research supported the hypothesis that ROC 
curves would be reflected below the diagonal when recollection rejection occurs. As predicted, recollection caused people to be confident that some proportion of the related lures were not presented during the study. This is what causes the ROC curve to be reflected below the diagonal. The ROC curve was lower on the right side when using standard instructions and higher when using the meaning instructions. This is due to the fact that acceptance of related lures occurred under meaning instructions but was rejected under standard instructions. Both experiments provided evidence for the prediction that high confidence flip flops would occur for related lures. Phantom ROC, a three process model, closely follows the findings and predictions of the two process models discussed above. The new component that this model added to the dual process models (conjoint recognition and ROC) is the measurement of phantom recollection using ROC curves.

In the current studies, I examined the use of recollection rejection in the misinformation paradigm. The goal of these studies was to determine if and how recollection rejection is used a) when someone has witnessed a crime and b) when he or she received false information (related and unrelated to the event) about the crime. This research has important implications for determining how often recollection rejection is used in real life scenarios.

\section{Pilot Study}

Hypothesis One: The acceptance of additive misinformation should be higher than the acceptance of contradictory misinformation because people can use recollection rejection to reject contradictory misinformation but not additive misinformation. 
Hypothesis Two: People will report using recollection rejection less than the other measures (e.g., pROC curves, contradictory vs. additive misinformation) because recollection rejection is not always a conscious process.

Methods

Participants

One hundred and thirty-six general psychology students from the University of Arkansas participated for course credit. Participants who indicated they knew the true nature of the study were excluded from analyses. Participants who personally knew the person in the slide show were excluded from analyses. Fourteen participants indicated knowledge about the study or recognized the subject of the slide show. Therefore, one hundred and twenty-two participants' data were analyzed. The sample was predominately Caucasian (90.2\%, 4.92\% African American, 1.64\% Hispanic, $1.64 \%$ Asian, 1.64\% Bi-racial), and 63\% female, and the average age was 19.22 years $(\mathrm{SD}=1.61$, Range $=18-27)$.

\section{Design}

The study manipulated item type (e.g., foil, additive, contradictory) in order to establish misinformation effects for both contradictory and additive item types.

Materials

Participants viewed a slide show of a handy man snooping around a client's house while the client is away, similar to materials created by Takarangi, Parker, and Garry (2006). Three different versions of the slide show were constructed. There were a total of nine critical items which were split up into additive, contradictory, and unrelated items. The critical items all served 
as each item type in one of the slide shows. A narrative about each slide show was constructed. The narrative detailed all of the events that occurred in the slide show. Additive items were items that were not shown in the slide shows but were mentioned in the text. Therefore, additive items were misinformation items that were presented only in the narrative. Contradictory items were items in the narrative that contradicted the footage in the slide show. For example, the man was shown drinking a Pepsi in the slide show but in the narrative it is suggested that he drank a CocaCola. Unrelated items were items that were not shown in the slide show or mentioned in the narrative, but were asked about on a final test. There were also true and false filler items on the final test. The final test was an old/new recognition judgment test. On the first page of the test, there were explicit instructions asking participants to respond according to what they saw in the slide show. When an item was viewed in the slide show, participants were instructed to indicate "yes". When an item was not viewed in the slide show, participants were instructed to indicate "no". The test consisted of 24 items: 15 fillers, 3 unrelated, 3 contradictory, and 3 additive items. In addition to indicating whether they saw the item in the slide show, participants were asked to rank their confidence in their responses. Confidence rankings were "extremely confident", "moderately confident", "somewhat confident", and "not at all confident". Self-report judgments were collected from participants by asking them to "explain your response" to each question. Lampinen, Odegard, and Neuschatz (2004) used this self-report method as an estimate of recollection rejection as well as other acceptance and rejection strategies.

Procedure

Participants were informed that they would be participating in a study examining memory for normal everyday events. Participants consented to participate before the study began. First, participants viewed a slide show and then they took part in a 4 minute filler task. After the filler 
task, participants read a narrative about the slide show that was "written by a police officer". After this, participants took part in a 2 minute filler task. Participants then completed an old/new recognition test. Prior to recognition test administration, the experimenter instructed the participant on how to complete the test.

Results

Data Analysis

For each participant, accuracy on the 3 types of critical items (unrelated items, contradictory items, and additive items) was coded and analyzed using a one way repeated measures ANOVA. The confidence-accuracy data for the critical items was fit to the phantom ROC model using procedures outlined in Lampinen et al. (2005). The model parameters were compared to the self-reported rates of recollection rejection. The self-report data was coded by two RAs in order to obtain an inter-rater reliability score. We chose Pearson's $r$ as a measure of correlation between our two coders. Each self-report response was coded for recollection rejection, distinctiveness, discrepancy detection, video recall, narrative recall, guessing, familiarity, and memory. I was primarily interested in recollection rejection for the purposes of these studies, so those are the only self-report analyses reported in this manuscript.

The purpose of this study was to learn about the use of recollection rejection in the misinformation paradigm. The results are divided into three sections: misinformation results, phantom ROC, and the self-report of recollection rejection. Unless otherwise specified, all results were considered significant at $p<.05$ (two-tailed).

Misinformation Results. Accuracy rates for the critical items are presented in Figure Three. A one way ANOVA revealed that the three types of critical items (unrelated, additive, and 
contradictory) differed significantly, $F(2,270)=3.05, p=.05, \eta_{p}^{2}=.022$. Pairwise comparisons revealed that unrelated item accuracy $(M=.86, S D=.24)$ was significantly higher than additive item accuracy $(M=.67, S D=.35)$ and contradictory item accuracy $(M=.73, S D=.32), p$ 's<.001.

I hypothesized that additive misinformation acceptance would be higher than contradictory misinformation acceptance. Contradictory misinformation is exclusive from a corresponding piece of original information (i.e., Coke vs. Pepsi) but additive misinformation is not exclusive. Therefore, people should be able to use recollection rejection to reject contradictory misinformation but not additive misinformation. Consistent with this hypothesis, pairwise comparisons revealed that accuracy on contradictory items $(M=.73, S D=.32)$ was higher than accuracy on additive items $(M=.67, S D=.35), p=.035$.

Figure Three: Pilot Study

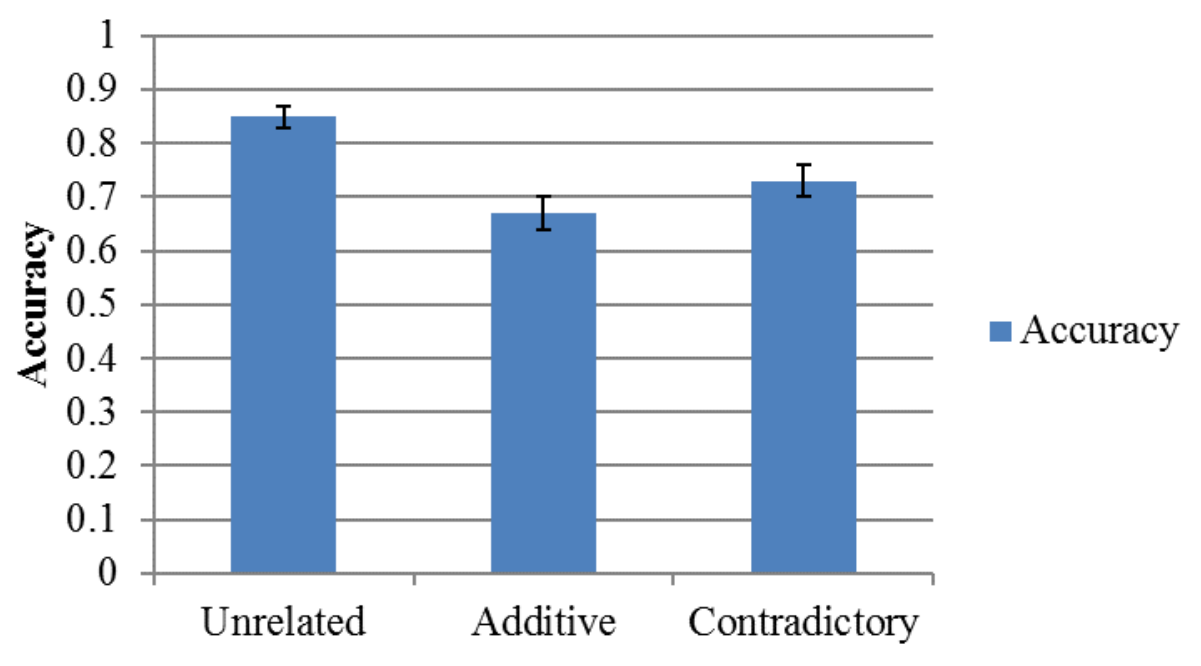

Phantom ROC. The data was analyzed by fitting ROC curves using the phantom ROC model. As in prior work by Yonelinas (1997) and Lampinen et al. (2005), we used the Solver add-in to Excel to obtain parameter estimates by minimizing the sum of squared errors associated with the model. The best fitting ROC curves are shown in Figure 4 and parameter estimates for 
the model are shown in Table 2. Overall, the model provided an excellent fit, accounting for $99.997 \%$ of the variance.

For additive items, estimates of recollection rejection were approximately $6 \%$ and estimates of phantom recollection were at $14 \%$. For contradictory items, estimates of recollection rejection were at $42 \%$ and estimates of phantom recollection were at $26 \%$.

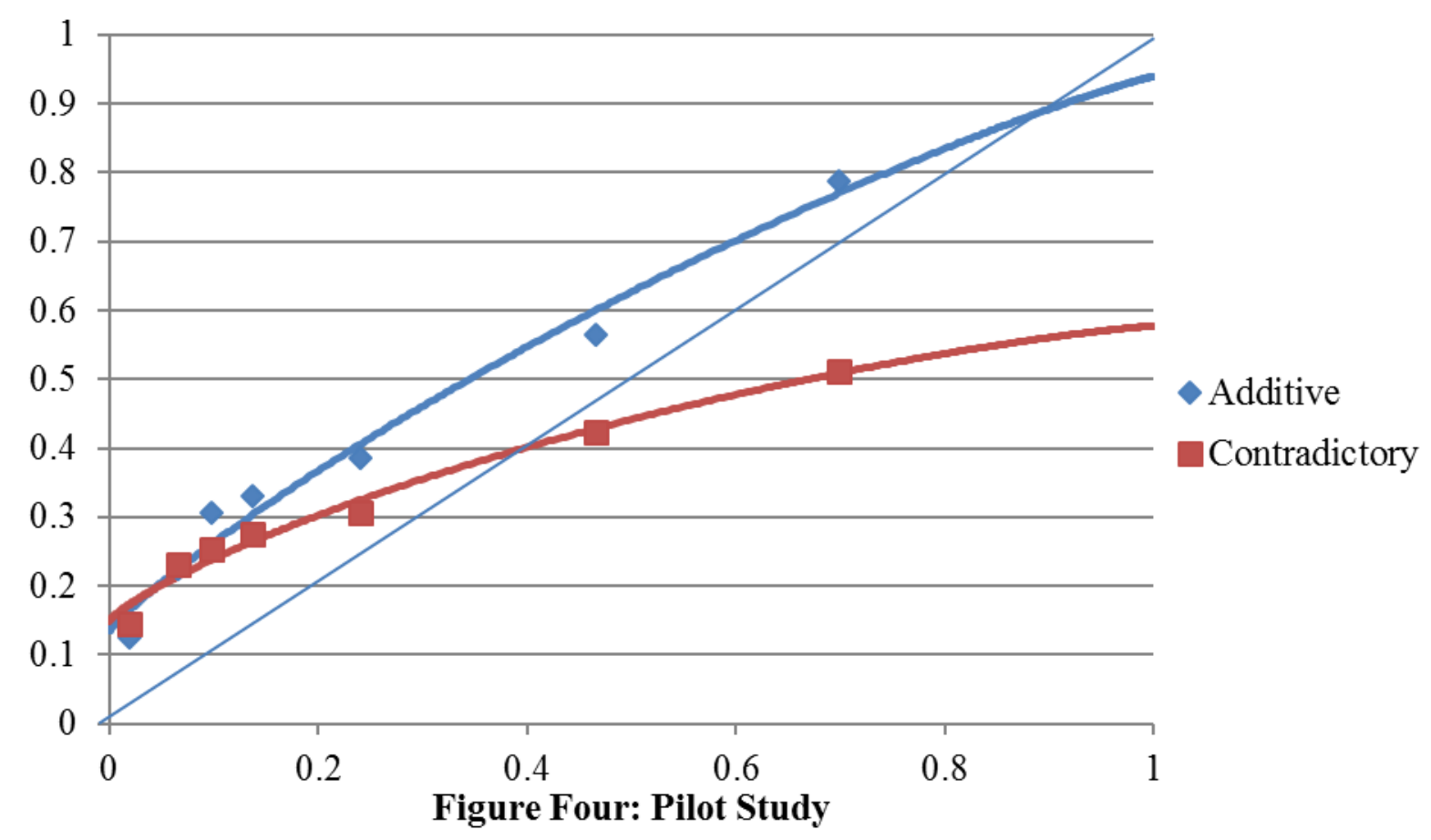

Table Two.

\begin{tabular}{|c|c|c|c|c|c|c|c|c|c|c|c|c|}
\hline \multicolumn{9}{|c|}{ Parameters } & \multicolumn{3}{c|}{ Additive Items } & \multicolumn{3}{|c|}{ Contradictory Items } \\
\hline & & & & & & & & & & & & \\
c1 & $\mathrm{c} 2$ & $\mathrm{c} 3$ & $\mathrm{c} 4$ & $\mathrm{c} 5$ & $\mathrm{c} 6$ & $\mathrm{c} 7$ & $\mathrm{RR}$ & $\mathrm{PhR}$ & $\mathrm{d}$ & $\mathrm{RR}$ & $\mathrm{PhR}$ & $\mathrm{d}$ \\
\hline 6.41 & 1.47 & 1.17 & 1.03 & 0.75 & 0.13 & -0.54 & 0.06 & 0.14 & 0.28 & 0.42 & 0.25 & 0.48 \\
\hline
\end{tabular}

Self-Report. In order to establish inter-rater reliability, two research assistants coded the self-report data. Regarding recollection rejection, the agreement between RA1 $(M=.68, S D=.7)$ and RA2 $(M=.42, S D=.65)$ was $r(136)=.74, p<.001$. On unrelated items, the agreement was 
$\mathrm{r}(136)=.55, \mathrm{p}<.001$. On contradictory items, the agreement between RA1 $(M=1.64, S D=.92)$ and RA2 $(M=1.58, S D=.93)$ was $r(136)=.86, p<.001$. On additive items, the agreement between RA1 $(M=.47, S D=.6)$ and RA2 $(M=.35, S D=.55)$ was $r(136)=.64, p<.001$.

The self-reported rate of recollection rejection for contradictory items was $55 \%$. The selfreported rate of recollection rejection for additive items was $15 \%$. The self-reported rate of recollection rejection for unrelated items was $18 \%$.

A one way ANOVA was conducted to determine the differences in self-reported recollection rejection by item type. The main effect of item type was significant, $F(2,242)$ $=108.48, p<.001, \eta_{p}^{2}=.473$. Pairwise comparisons revealed that participants self-reported recollection rejection more on contradictory items $(M=.55, S E=.03)$ than additive $(M=.15, S E=$ $.02)$ or unrelated items $(M=.18, S E=.02), p$ 's<.001.

Discussion

In this study, I examined the use of recollection rejection in an ecologically valid way using the misinformation paradigm. The goals of this study were to a) establish whether our materials would replicate the effects of previous misinformation research and b) determine if or to what extent people use recollection rejection to reject event-based suggestions. I found support for the use of recollection rejection through the three methods used to measure it in the misinformation paradigm.

A misinformation effect was found for both the contradictory and additive misinformation. Consistent with my hypothesis, I found that additive misinformation was accepted more than contradictory misinformation. Evidence for this hypothesis also came from the ROC curves for additive and contradictory misinformation items. The ROC analysis for the 
contradictory items indicated the recollection rejection occurred $42 \%$ of the time. In comparison, recollection rejection for additive items occurred $6 \%$ of the time.

I expected that the self-reported rates of recollection rejection may be lower than the other measures of recollection rejection indicated. This was not the case. The self-reported rate of recollection rejection was $54 \%$ for the contradictory items. In comparison, the estimate of recollection rejection of the contradictory items by the phantom ROC model was $43 \%$. Although these differences are likely not significantly different, the rate of self-reported recollection rejection was definitely not lower than the other estimates. Perhaps using recollection rejection to reject items encountered in the environment (i.e., narrative) is more overt and conscious than rejecting items such as words.

Experiment One: Delay Study

Hypothesis 1: Participants who receive shorter delays will accept less postevent information than participants with longer delays.

Hypothesis 2: Participants who receive shorter delays will be more likely to use recollection rejection than participants who receive longer delays.

Due to the fact that there are mixed findings on delay times in misinformation studies, it is important to test the effects of manipulating delay times on the acceptance of the two types of misinformation and the use of recollection rejection. Using recollection rejection should be easier with short retention intervals because participants have to remember the original event information and postevent information for less time. Additionally, I am interested in the effects of manipulating delay time on the acceptance of additive and contradictory misinformation. Researchers using short delays have found no difference in the acceptance of additive versus 
contradictory misinformation (Nemeth \& Belli, 2006), whereas research using long delays has found that contradictory misinformation is accepted less often than additive misinformation (Frost, 2000). This may be because additive misinformation is especially distinctive immediately after viewing the original event. However, it should also be easier to use recollection rejection immediately after viewing the original event.

\section{Method}

Participants

Two hundred and thirty-nine general psychology students from the University of Arkansas participated for course credit. Participants who indicated that they knew that the study was about the misinformation effect were excluded from analyses. Participants who personally knew the subject of the slide show were excluded from analyses. Thirteen participants indicated knowledge about the study or recognized the subject of the slide show. Two hundred and twentysix participants were included for analyses. The sample was predominately Caucasian $(84.1 \%$, 6.19\% African American, 2.65\% Hispanic, 3.54\% Asian, 2.21\% Native American, .04\% Biracial, $1.32 \%$ unreported), $62.4 \%$ female, and the average age was 19.17 years $(S D=1.29$, Range $=18-29$ )

Design

The study was a 3 (item type: foil, additive, contradictory) x 2 (first delay: short, long) x 2 (second delay: short, long) mixed factorial design with delay lengths as between subjects factors. The materials used for this study were the same as the materials for the pilot study. 
Procedure

Participants were informed that they would be participating in a study examining memory for normal everyday events. Participants consented to participate before the study began. First, participants viewed a slide show then they took part in a 2 (short) or 14 (long) minute filler task. After the filler task, participants read a narrative about the slide show that was "written by a police officer". After this, participants took part in another 2 (short) or 14 (long) minute filler task. Participants then completed an old/new recognition test. Prior to recognition test administration, the experimenter instructed the participant on how to complete the test.

\section{Results}

Data Analysis

For each participant, accuracy on the 3 types of critical items (unrelated items, contradictory items, and additive items) was coded and analyzed using a 3 (critical items: unrelated items, contradictory items, and additive items) x 2 (first delay: short, long) x 2 (second delay: short, long) ANOVA to determine the effects of item type and differing delay lengths. The confidence-accuracy data for the critical items was fit to the phantom ROC model. The model was compared to the self-report data. According to dual process theory, the ROC curves will be deflected below the diagonal when recollection rejection is occurring. Since recollection rejection can be used for contradictory misinformation, I expected the ROC curve to be deflected below the diagonal for the contradictory items. Since recollection rejection cannot be used for additive misinformation I did not expect the ROC curve to be deflected below the diagonal for the additive items. The self-report data was coded by two RAs to obtain an inter-rater reliability 
score. I was primarily interested in recollection rejection for the purposes of these studies so those are the only self-report analyses reported in this manuscript.

The purpose of this study was to learn about the effect of delays on use of recollection rejection in the misinformation paradigm. The results are divided into three sections: misinformation results, phantom ROC, and the self-report of recollection rejection. Unless otherwise specified, all results were considered significant at $p<.05$ (two-tailed).

Misinformation Results. Data from the misinformation results are presented in Figure 5. In order to analyze misinformation effects and the effects of delays a 3 (item: unrelated, contradictory, additive) x 2 (first delay: short, long) x 2 (second delay: short, long) ANOVA was conducted. The ANOVA revealed a main effect of item type, $F(2,442)=42.26, p<.001, \eta_{p}^{2}=$ .16. Pairwise comparisons revealed that unrelated item accuracy $(M=.84, S D=.24)$ was significantly higher than additive item accuracy $(M=.61, S D=.35)$ and contradictory item accuracy $(M=.75, S D=.29), p ` s<.001$.

I hypothesized that additive misinformation acceptance would be higher than contradictory misinformation acceptance because contradictory items are more conducive to the use of recollection rejection. Pairwise comparisons revealed that contradictory item accuracy $(M=.75, S D=.29)$ was significantly higher than additive item accuracy $(M=.61, S D=.35), p<.001$, providing evidence for my hypothesis.

The ANOVA revealed no effect of delay one on accuracy, $F(1,221)=.63, p=.43, \eta^{2}{ }_{p}=$ .003 , no effect of delay two on accuracy, $F(1,221)=.35, p=.56, \eta_{p}^{2}=.002$, no interaction between delay one and delay two, $F(1,221)=.58, p=.45, \eta_{p}^{2}=.003$, no interaction between delay one and item type, $F(2,442)=1.47, p=.23, \eta_{p}^{2}=.007$, no interaction between delay two and 
item type, $F(2,442)=.34, p=.71, \eta_{p}^{2}=.002$, and no three way interaction between item type, delay one, and delay two, $F(6,442)=.3, p=.74, \eta_{p}^{2}=.001$.

There were no group differences in the misinformation effects for contradictory or additive misinformation items.

\section{Figure Five: Delay Study}

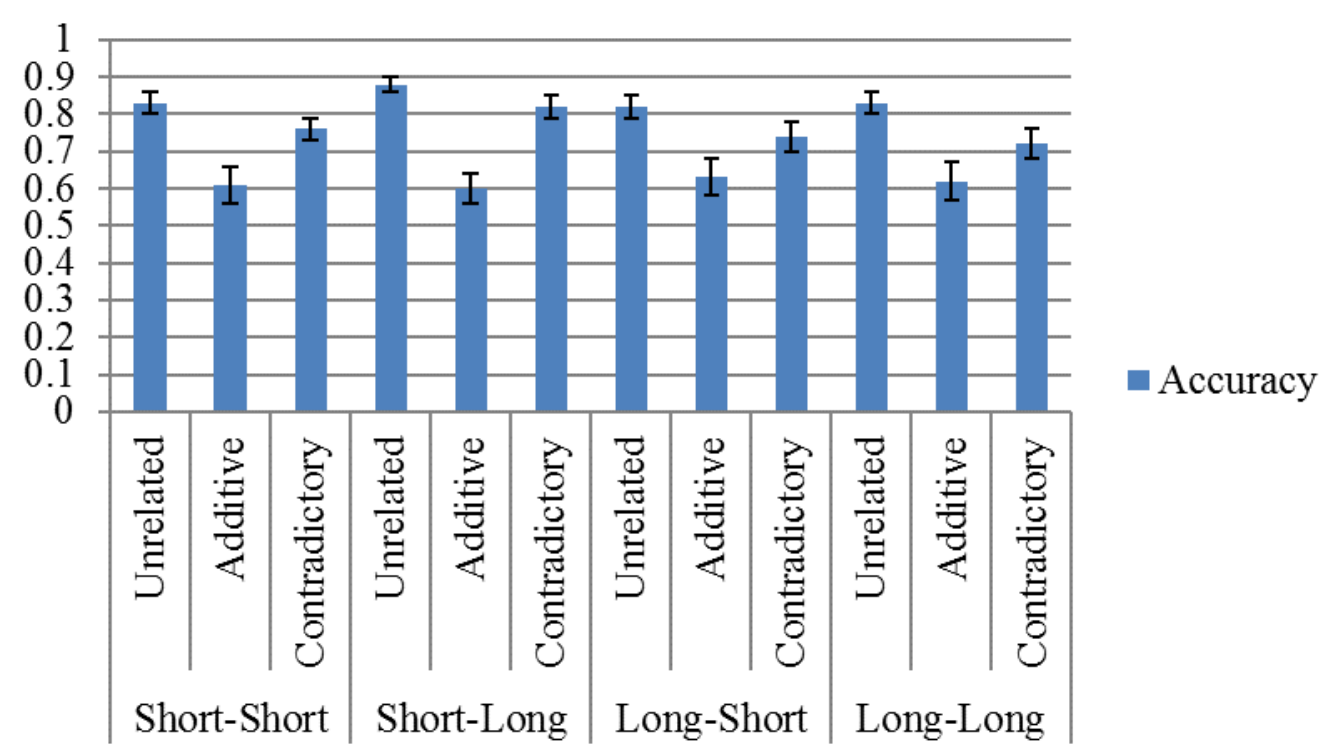

Phantom ROC. We analyzed the data by fitting ROC curves using the phantom ROC model. As in prior work by Yonelinas and Lampinen, we used the Solver add-in to Excel to obtain parameter estimates by minimizing the sum of squared errors associated with the model. The best fitting ROC curves are shown in Figures 6-9 and parameter estimates for the model are shown in Table 3. Overall, the models provided an excellent fit, accounting for $99.4 \%$ of the variance for the long-long condition, $99.8 \%$ of the variance for the long-short condition, $99.2 \%$ of the variance for the short-long condition, and $99.8 \%$ of the variance for the short-short condition. 
Short-Short Condition. For additive items, recollection rejection was used approximately $2 \%$ of the time and phantom recollection was used approximately $16 \%$ of the time. For contradictory items, recollection rejection was used approximately $40 \%$ of the time and phantom recollection was used $21 \%$ of the time.

Short-Long Condition. For additive items, recollection rejection was used approximately $7 \%$ of the time and phantom recollection was used approximately $16 \%$ of the time. For contradictory items, recollection rejection was used approximately $35 \%$ of the time and phantom recollection was used $17 \%$ of the time.

Long-Short Condition. For additive items, recollection rejection was used approximately $0 \%$ of the time and phantom recollection was used approximately $0 \%$ of the time. For contradictory items, recollection rejection was used approximately $40 \%$ of the time and phantom recollection was used $15 \%$ of the time.

Long-Long Condition. For additive items, recollection rejection was used approximately $0 \%$ of the time and phantom recollection was used approximately $0 \%$ of the time. For contradictory items, recollection rejection was used approximately $48 \%$ of the time and phantom recollection was used $15 \%$ of the time.

Overall. For additive items, recollection rejection rates did not differ across conditions but phantom recollection rates decreased when the first delay was long $(0 \%, 0 \%)$ instead of short $(16 \%, 16 \%)$. For contradictory items, recollection rejection rates were highest in the longest delay condition, long-long, and lowest in the short-long delay condition. For contradictory items, phantom recollection rates did not differ across delay conditions. 


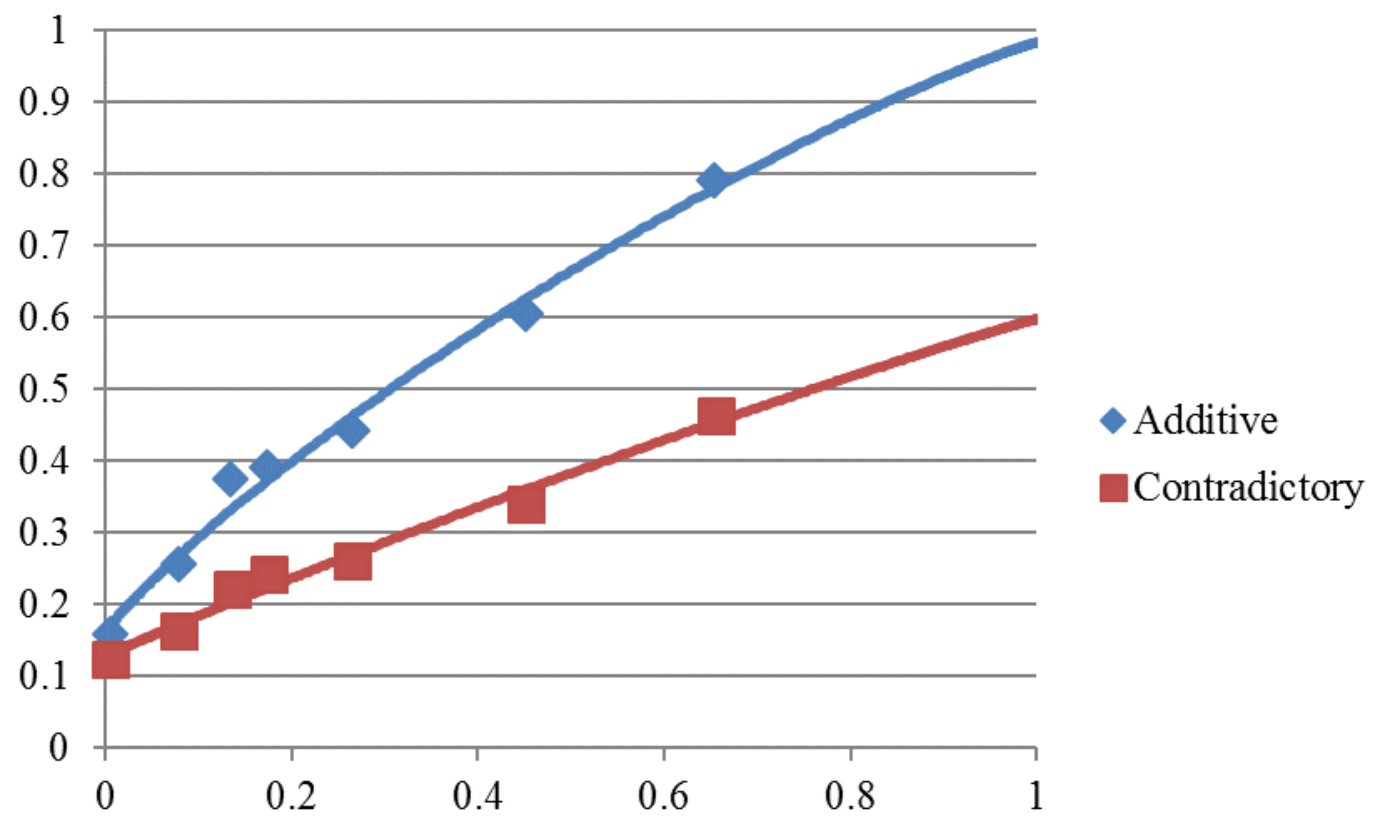

Figure Six: Delay Study ROC curves Short-Short Condition

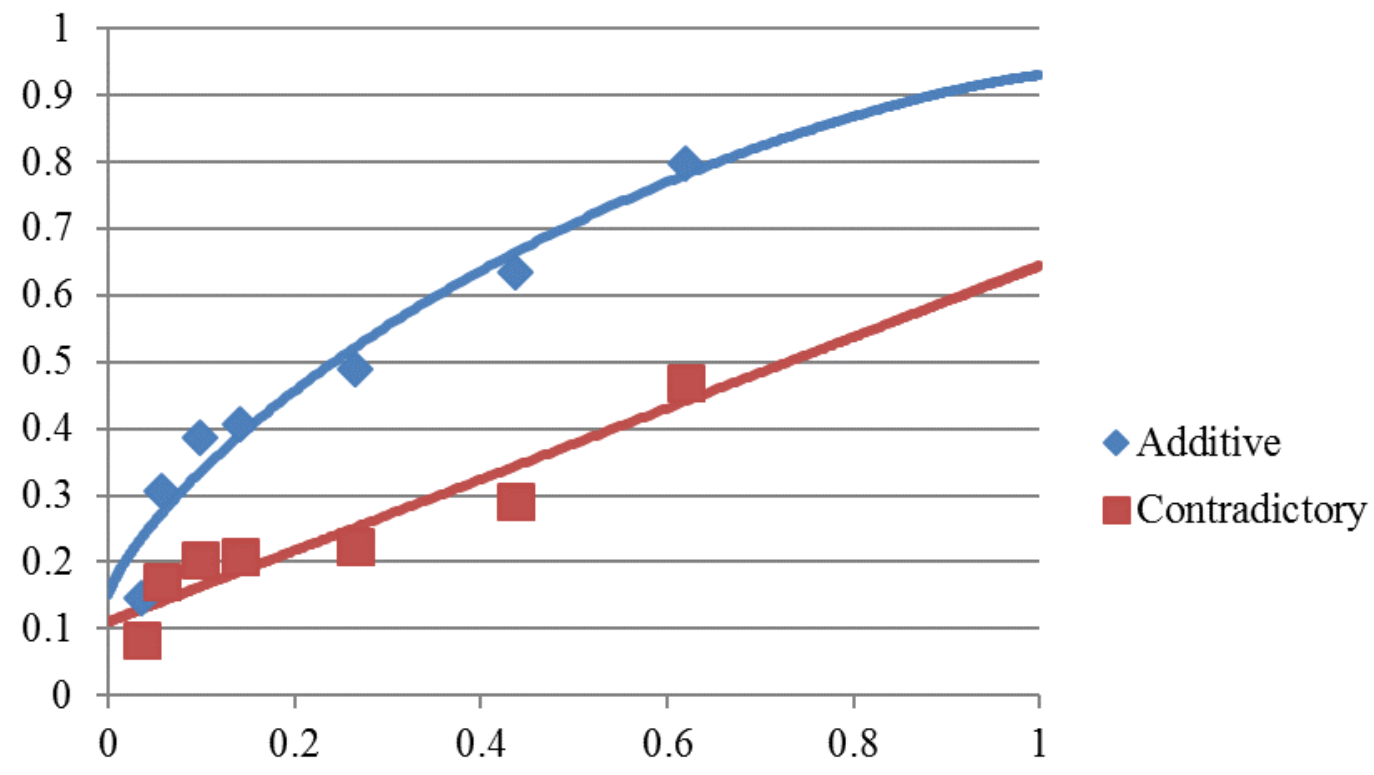

Figure Seven: Delay Study ROC curves Short-Long Condition 


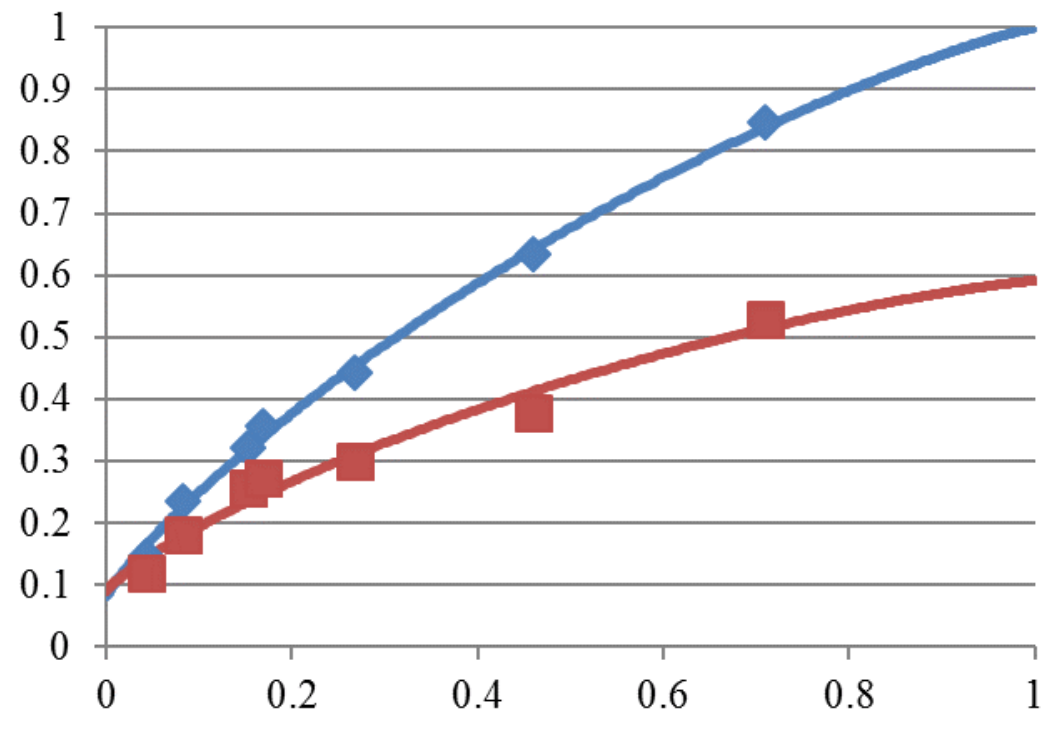

Figure Eight: Delay Study ROC curves Long-Short Condition
Additive

Contradictory

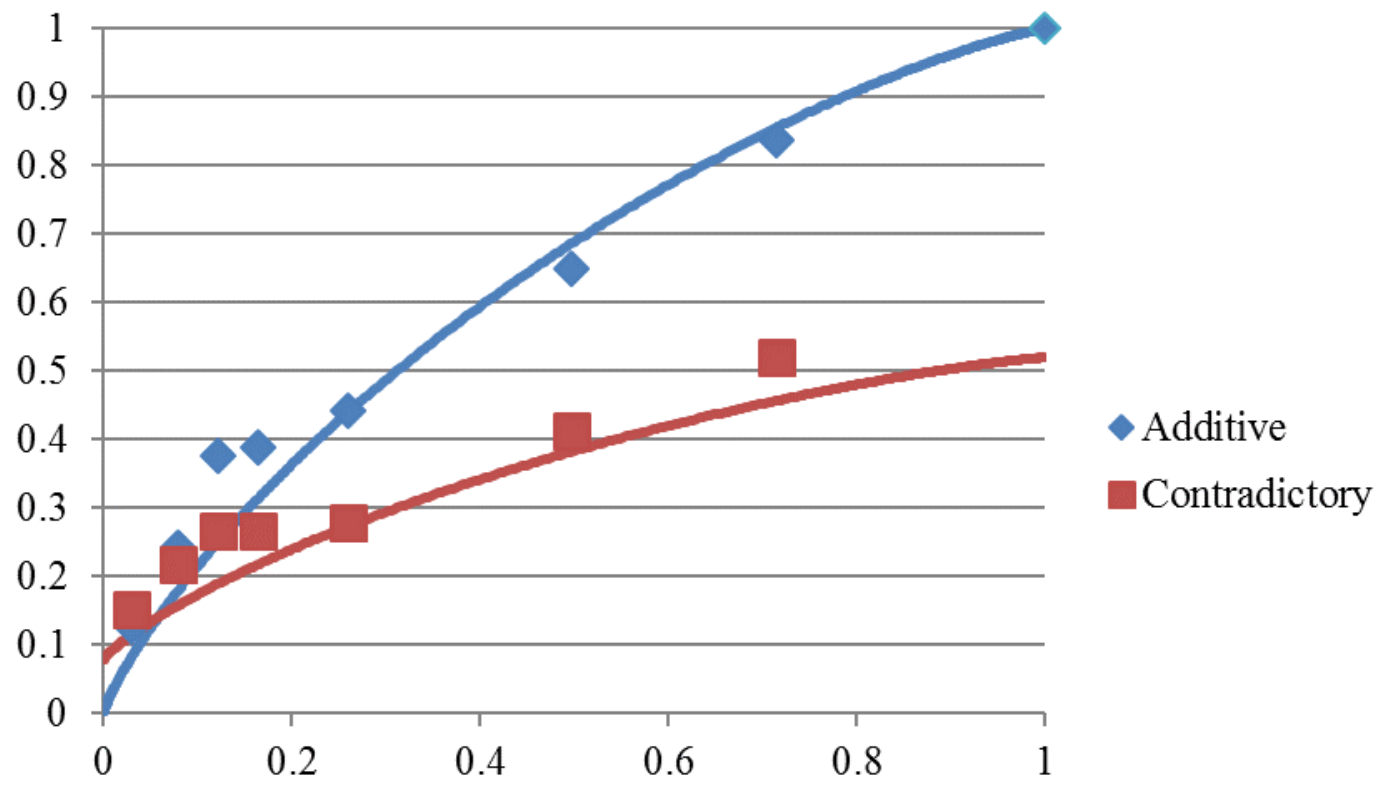

Figure Nine: Delay Study ROC curves Long-Long Condition 
Table Three.

\begin{tabular}{|c|c|c|c|c|c|c|c|c|c|c|c|c|}
\hline \multicolumn{7}{|c|}{ Parameters } & \multicolumn{3}{|c|}{ Additive Items } & \multicolumn{3}{|c|}{ Contradictory Items } \\
\hline \multicolumn{13}{|c|}{ Short-Short } \\
\hline $\mathrm{c} 1$ & $\mathrm{c} 2$ & $\mathrm{c} 3$ & $\mathrm{c} 4$ & $\mathrm{c} 5$ & c6 & c7 & $\mathrm{RR}$ & $\mathrm{PhR}$ & $\mathrm{d}^{\prime}$ & RR & $\mathrm{PhR}$ & $\mathrm{d}^{\prime}$ \\
\hline 4.43 & 1.47 & 1.01 & 0.89 & 0.66 & 0.15 & -0.42 & 0.01 & 0.16 & 0.29 & 0.40 & 0.21 & 0.11 \\
\hline \multicolumn{13}{|c|}{ Short-Long } \\
\hline $\mathrm{c} 1$ & $\mathrm{c} 2$ & $\mathrm{c} 3$ & $\mathrm{c} 4$ & $\mathrm{c5}$ & c6 & c7 & $\mathrm{RR}$ & $\mathrm{PhR}$ & $\mathrm{d}^{\prime}$ & RR & $\mathrm{PhR}$ & $\mathrm{d}^{\prime}$ \\
\hline 5.48 & 1.43 & 1.14 & 1.03 & 0.69 & 0.22 & -0.34 & 0.06 & 0.16 & 0.57 & 0.35 & 0.17 & 0 \\
\hline \multicolumn{13}{|c|}{ Long-Short } \\
\hline $\mathrm{c} 1$ & $\mathrm{c} 2$ & c3 & $\mathrm{c} 4$ & $\mathrm{c} 5$ & c6 & c7 & RR & $\mathrm{PhR}$ & $\mathrm{d}^{\prime}$ & RR & $\mathrm{PhR}$ & $\mathrm{d}^{\prime}$ \\
\hline 1.84 & 1.36 & 1 & 0.91 & 0.64 & 0.13 & -0.57 & 0 & 0.08 & 0.38 & 0.41 & 0.15 & 0.47 \\
\hline \multicolumn{13}{|c|}{ Long-Long } \\
\hline c1 & $\mathrm{c} 2$ & $\mathrm{c} 3$ & $\mathrm{c} 4$ & $c 5$ & c6 & c7 & $\mathrm{RR}$ & $\mathrm{PhR}$ & $\mathrm{d}^{\prime}$ & RR & $\mathrm{PhR}$ & $\mathrm{d}^{\prime}$ \\
\hline 1.51 & 1.12 & 0.84 & 0.78 & 0.62 & 0.11 & -0.34 & 0 & 0 & 0.49 & 0.48 & 0.15 & 0.5 \\
\hline
\end{tabular}

Self-Report. In order to establish inter-rater reliability, two research assistants coded the self-report data. Regarding recollection rejection, the agreement between RA1 $(M=2.63$, $S D=1.43)$ and RA2 $(M=2.85, S D=1.49)$ was $r(239)=.90, p<.001$. On unrelated items, the agreement between RA1 $(M=.48, S D=.65)$ and RA2 $(M=.61, S D=.75)$ was $r(239)=.83, p<.001$. On contradictory items, the agreement between RA1 $(M=1.69, S D=.96)$ and RA2 $(M=1.72$, $S D=.97)$ was $r(239)=.94, p<.001$. On additive items, the agreement between RA1 $(M=.46$, $S D=.67)$ and RA2 $(M=.52, S D=.67)$ was $r(239)=.89, p<.001$.

Short-Short Condition. The self-reported rate of recollection rejection for contradictory items was $61 \%$. The self-reported rate of recollection rejection for additive items was $19 \%$. The self-reported rate of recollection rejection for unrelated items was $17 \%$.

Short-Long Condition. The self-reported rate of recollection rejection for contradictory items was $64 \%$. The self-reported rate of recollection rejection for additive items was $14 \%$. The self-reported rate of recollection rejection for unrelated items was $18 \%$. 
Long-Short Condition. The self-reported rate of recollection rejection for contradictory items was $53 \%$. The self-reported rate of recollection rejection for additive items was $16 \%$. The self-reported rate of recollection rejection for unrelated items was $16 \%$.

Long-Long Condition. The self-reported rate of recollection rejection for contradictory items was $53 \%$. The self-reported rate of recollection rejection for additive items was $9 \%$. The self-reported rate of recollection rejection for unrelated items was $20 \%$.

Overall. The self-reported rate of recollection rejection for contradictory items was $58 \%$. The self-reported rate of recollection rejection for additive items was $15 \%$. The self-reported rate of recollection rejection for unrelated items was $18 \%$.

In order to determine the effects of item type and delay on self-reported rates of recollection rejection, a 3 (item: contradictory, additive, unrelated) x 2 (delay one: short, long) x 2 (delay two: short, long) ANOVA was conducted. The ANOVA revealed a main effect of item type, $F(2,444)=204.75, p<.001, \eta_{p}^{2}=.48$. Pairwise comparisons revealed that participants reported using recollection rejection more for contradictory items $(M=.58, S E=.02)$ than additive items $(M=.15, S E=.01)$ and unrelated items $(M=.18, S E=.02), p s<.001$. There was not a significant difference in self-reported recollection rejection for additive and unrelated items. There was a main effect of the first delay, $F(1,222)=4.72, p=.031, \eta^{2}{ }_{p}=.02$. Pairwise comparisons revealed that participants whose first delay was short $(M=.32, S E=.01)$ reported more recollection rejection than participants whose first delay was long $(M=.38, S E=.02)$, $p=.031$. No other results were significant at $p<.05$. 


\section{Discussion}

In this study, I manipulated the delay that participants received before and after they received misinformation. Misinformation effects were found for contradictory and additive misinformation item types, replicating the results found in the pilot study. The finding that additive misinformation was accepted more than contradictory misinformation was also replicated in this study.

The main manipulation in this study, delay, was not significant. It was hypothesized that participants would be less accurate when delays were longer and that they would be less likely to use recollection rejection. Participants' accuracy, however, did not vary with delays. One explanation for this is that the delays used were not long enough or different enough from one another. The experiment was constrained to a one hour time block, which constrained the longest delay times that we could use to two 14 minute delays. These delays seem relatively short in comparison to the delays in reporting a crime that may occur in real life (e.g., hours or days). In comparison, our short delay times were 2 minutes apiece. This means that the difference between the long-long delay condition and the short-short delay condition was 24 minutes. I thought that this time difference would be enough to elicit differences in accuracy scores, but this was not found to be true.

Almost all research on the misinformation effect involves delays both before and after receiving postevent information. While the length of the delay period varies across studies, almost no one has directly examined the effects of manipulating delay on the acceptance of misinformation. Belli, Windschitl, McCarthy, and Winfry (1992) examined the effects of manipulating the delay between receiving postevent information and taking the final test. They 
had a short delay (15 minutes) and a long delay (5-7 days). The researchers found that memory was more impaired when the test was delayed 5-7 days than when it was taken 15 minutes after receiving postevent information. Belli et al. (1992) did find an effect of delay but their delay manipulation was much stronger than ours. However, if we had manipulated the delay time across hours or days, I would expect that recollection rejection rates would decrease with a longer delay between postevent information and the test.

\section{Experiment Two: Warning Study}

In many recollection rejection studies, instructions about the use of recollection rejection have been provided to participants (Brainerd et al., 2003). Instructing participants about the exclusivity of items and the ability to use recollection rejection approximately doubles the use of recollection rejection (Rotello et al. 2000). In these studies, participants in the control condition who did not receive instructions used recollection rejection $13-14 \%$ of the time, whereas participants in the instruction condition used recollection rejection nearly $30 \%$ of the time.

In most recollection rejection studies, words are presented and participants are tested over studied words, related words that were not studied, and unrelated words that were not studied. Instructions introducing recollection rejection are presented to alert participants to the fact that there are item categories or that original information is somewhat exclusive from the postevent information. For example, in the traditional recollection rejection studies, participants may know that they did not hear the word 'ball' if they saw a picture of a 'ball' because the experimenter informed them that the item would be presented either as a word or a picture. In the misinformation paradigm, there are two sources that a piece of information could have come from: event and postevent information. When a piece of postevent information contradicts a 
piece of information from the original event, the participant may believe that the two pieces of information are exclusive (i.e., that the postevent information is wrong).

Warnings have been used in misinformation studies to reduce the acceptance of false postevent information (Greene, Flynn, \& Loftus, 1982; Tousignant et al. 1986; Christiaansen \& Ochalek, 1983). Greene et al. (1982) warned participants of misinformation in an attempt to get them to resist accepting misinformation on a final test. The researchers manipulated the placement of the warning: before the slides, before the postevent information, before the test, or no warning. In these misinformation warning studies, an explanation for why the source of the postevent information may be inaccurate is provided. In the first misinformation warning study, the researchers told participants that the police cadet who wrote the report "was inexperienced at detailing observed crimes, some of the information...may be inaccurate" (Greene et al. 1982; p.210). The researchers measured the time it took participants to read the postevent information as well as accuracy on the final memory test to assess the effect of the warnings. In comparison to people who did not receive a warning, people who received a warning between the event and the postevent information took longer to read sentences containing false information. People who received warnings immediately before the slides or immediately before the final test read sentences at the same rate as people who did not receive a warning. In Experiment 1, the researchers found that people warned before the postevent information were marginally more accurate on the final memory test than people who were not warned. A second experiment was conducted to replicate these findings. In the second study, warnings placed just before the postevent information led to significantly greater accuracy on the final memory test in comparison to people who did not receive a warning. This finding was later replicated by other researchers (Chambers \& Zaragoza, 2001). It is important to note, however, that the warning 
used by Greene et al. (1982) and warnings used in other research did not restore memory performance to levels of the control group who received no false information.

Warnings placed before the postevent information decrease the source monitoring and misinformation acceptance portions of the misinformation effect by increasing discrepancy detection. Therefore, successful recollection rejection rates should increase when participants are warned.

I was interested in measuring the use of recollection rejection in the misinformation paradigm, so I tested the effects of a misinformation warning with specific instructions about recollection rejection on misinformation acceptance. Providing instructions to participants should alter peoples' strategy, causing them to scrutinize postevent information more carefully, thereby increasing the chance that discrepancy detection will occur and recollection rejection will be used to reject false information.

Method

Participants

One hundred and seventy-nine general psychology students from the University of Arkansas participated for course credit. Participants who indicated that they knew that the study was about the misinformation effect were excluded from analyses. Participants who personally knew the subject of the slide show were also excluded from analyses. Five participants indicated knowledge about the study or recognized the subject of the slide show. This left us with one hundred and seventy-four participants. The sample was predominately Caucasian $(84.3 \%, 3.5 \%$ African American, 5.23\% Hispanic, 6.98\% Asian, 1.16\% Bi-racial), 66.9\% female, and the average age was 19.57 years $(S D=1.88$, Range $=18-29)$. 


\section{Design}

The study was a 3 (item type: foil, additive, contradictory) x 3 (warning: no warning, warning, warning + recollection rejection instructions) mixed factorial design with and warning as a between subjects factor. The materials for this study were the same as the materials for the pilot study with the addition of a warning.

Procedure

Participants were informed that they would be participating in a study examining memory for normal everyday events. Participants gave consent to participate before the study began. Participants were shown a slide show. Afterwards, participants completed a 14 minute filler task. Before reading a narrative about the slide show, participants in the warning conditions were warned about inaccurate details in the narrative. Participants were then given a narrative about the slide show to read that was "written by a police officer". Once they finished reading the narrative, participants performed another 14 minute filler task. After the filler, participants in the warning condition were reminded of possibility of inaccurate details in the narrative. Participants in the warning and recollection rejection instruction condition received a description of recollection rejection as well as an example of how it could be used. Participants then completed an old/new recognition test. Prior to recognition test administration, the experimenter instructed the participant on how to complete the test. 
Results

Data Analysis

For each participant, accuracy on the 3 types of critical items (unrelated items, contradictory items, and additive items) was coded. The data was analyzed using a 3 (critical items: unrelated items, contradictory items, and additive items) x 3 (warning: no warning, warning, warning and recollection rejection instructions) mixed factorial ANOVA to determine the effects of items type and warnings. The confidence-accuracy data for the critical items was fit using the phantom ROC model. Confidence data was plotted so that ROC curves could be fit to them. The model was compared to self-report data. According to dual process theory, the ROC curves should be deflected below the diagonal when recollection rejection is occurring. Since recollection rejection can be used for contradictory misinformation, we expected the ROC curve to be deflected below the diagonal for contradictory misinformation ROC curves. Since recollection rejection cannot be used for additive misinformation, we did not expect the ROC curve to be deflected below the diagonal for additive misinformation ROC curves. The selfreport data was coded by two RAs to obtain an inter-rater reliability score. I was primarily interested in recollection rejection for the purposes of these studies so those are the only selfreport analyses reported in this manuscript.

Misinformation Effects. Data from the misinformation results are presented in Figure 10. In order to analyze misinformation effects and the effects of warnings, a 3 (item: unrelated, contradictory, additive) x 3 (warning: no warning, warning, warning + RR) ANOVA was conducted. The ANOVA on these scores revealed a main effect of item type, $F(2,340)=16.74$, $p<.001, \eta^{2}{ }_{p}=.09$. Pairwise comparisons revealed that unrelated item accuracy was significantly 
higher than additive item accuracy, $p<.001$. This finding reveals that there was a misinformation effect for the additive misinformation. Pairwise comparisons revealed that unrelated item accuracy was significantly higher than contradictory item accuracy, $p=.002$. Therefore, there was a misinformation effect for both additive and contradictory items.

I hypothesized that additive misinformation acceptance would be higher than contradictory misinformation acceptance because contradictory items are more conducive to the use of recollection rejection Pairwise comparisons revealed that contradictory item accuracy was significantly higher than additive item accuracy, $p=.002$.

The ANOVA revealed a main effect of warning on accuracy, $F(2,170)=3.38, p=.036, \eta_{p}^{2}$ $=.038$ and an interaction between warning and item type, $F(4,340)=2.94, p=.027, \eta^{2}{ }_{p}=.033$. Pairwise comparisons using LSD test revealed that the control condition $(M=.7, S E=.02)$ was less accurate the warning condition $(M=.78, S E=.03)$ and the warning plus recollection rejection instructions condition $(M=.78, S E=.03), p=.023, p=.033$. The two warning conditions did not differ from one another on overall accuracy.

In order to examine the item $\mathrm{x}$ warning interaction one way ANOVAs were conducted for each item type. The one way ANOVA on unrelated items was not significant, $F(2,171)=1.98$, $p=.14, \eta^{2}{ }_{p}=.023$. The one way ANOVA on additive items was not significant, $F(2,171)=2.11$, $p=.13, \eta_{p}^{2}=.024$. The one way ANOVA on the contradictory items was significant, $F(2,171)=$ 5.04, $p=.007, \eta^{2}=.056$. Posthoc tests using LSD test revealed that accuracy on the contradictory items was significantly higher in the warning $+\mathrm{RR}$ instructions conditions $(M=.83, S E=.04)$ than the control condition $(M=.67, S E=.03)$. The fact that the warning $+\mathrm{RR}$ instructions improved performance on the contradictory items suggests that the instructions about the use of recollection rejection may have increased the use of recollection rejection. 
In order to examine the differences in misinformation effects for contradictory items across warning conditions a one way ANOVA was conducted on contradictory item difference scores. The difference score was calculated by subtracting the unrelated item accuracy from the contradictory item accuracy because this reflects the misinformation effect. The one way ANOVA on contradictory item difference score was significant, $F(2,170)=5.29, p=.006$.

Posthoc using LSD test revealed that there was a smaller misinformation effect in the warning + RR condition $(M=.04, S D=.38)$ compared to the control condition $(M=-.17, S D=.38), p=.002$. Posthoc tests also revealed that the misinformation effect in the warning + RR condition $(M=.04$, $S D=.38)$ was significantly smaller than the misinformation effect in the warning condition ( $M=$ $.13, S D=.32), p=.021$.

In order to examine the differences in misinformation effects for additive items across warning conditions, a one way ANOVA was conducted on additive item difference scores. The difference score was calculated by subtracting the unrelated item accuracy from the additive item accuracy because this reflects the misinformation effect. The one way ANOVA on the additive item difference score was not significant. 


\section{Figure Ten: Warning Study}

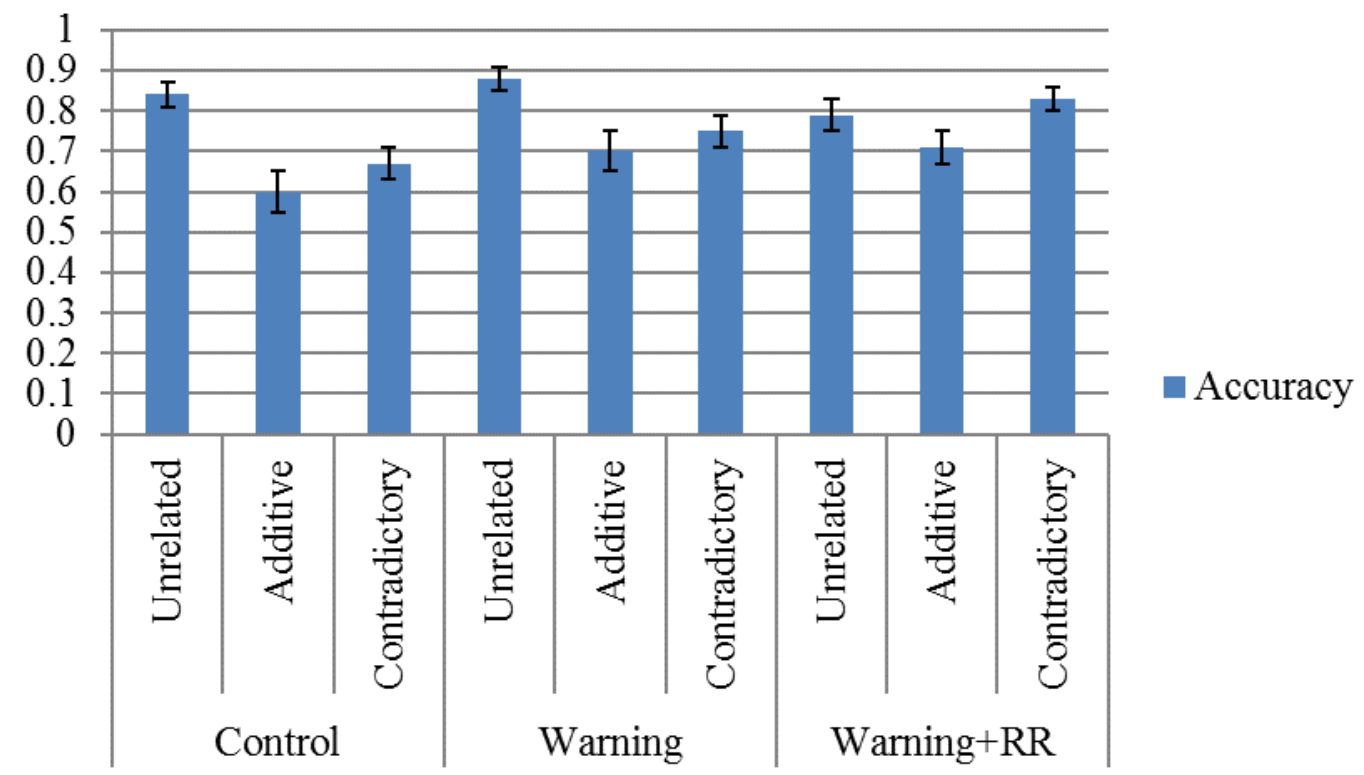

Phantom ROC. We analyzed the data by fitting ROC curves using the phantom ROC model. As in prior work by Yonelinas and Lampinen, we used the Solver add-in to Excel to obtain parameter estimates by minimizing the sum of squared errors associated with the model. The best fitting ROC curves are shown in Figures 11-13 and parameter estimates for the model are shown in Table 4. Overall, the model provided an excellent fit, accounting for $99.5 \%$ of the variance in the control condition, $99.91 \%$ of the variance in the warning condition, and $99.88 \%$ of the variance in the warning $+\mathrm{RR}$ condition.

Control Condition. For additive items, recollection rejection was used approximately $0 \%$ of the time and phantom recollection was used approximately $17 \%$ of the time. For contradictory items, recollection rejection was used approximately $41 \%$ of the time and phantom recollection was used $31 \%$ of the time.

Warning Condition. For additive items, recollection rejection was used approximately $3 \%$ of the time and phantom recollection was used approximately $0 \%$ of the time. For contradictory 
items, recollection rejection was used approximately $52 \%$ of the time and phantom recollection was used $20 \%$ of the time.

Warning $+R R$ Condition. For additive items, recollection rejection was used approximately $0 \%$ of the time and phantom recollection was used approximately $0 \%$ of the time. For contradictory items, recollection rejection was used approximately $41 \%$ of the time and phantom recollection was used $10 \%$ of the time.

Overall. For additive items, recollection rejection rates did not differ much across groups; however, phantom recollection was used $17 \%$ of the time in the control condition but estimates of phantom recollection decreased to $0 \%$ in the warning conditions. For contradictory items, recollection rejection rates were highest in the warning condition (52\%) but this difference is likely not significant from the $41 \%$ measured in the control and warning + RR condition. Phantom recollection decreased with condition (control $=31 \%$, warning $=20 \%$, warning $+\mathrm{RR}=$ $10 \%)$. For both types of misinformation, phantom recollection decreased with warnings but recollection rejection rates did not appear to be affected by warnings. 


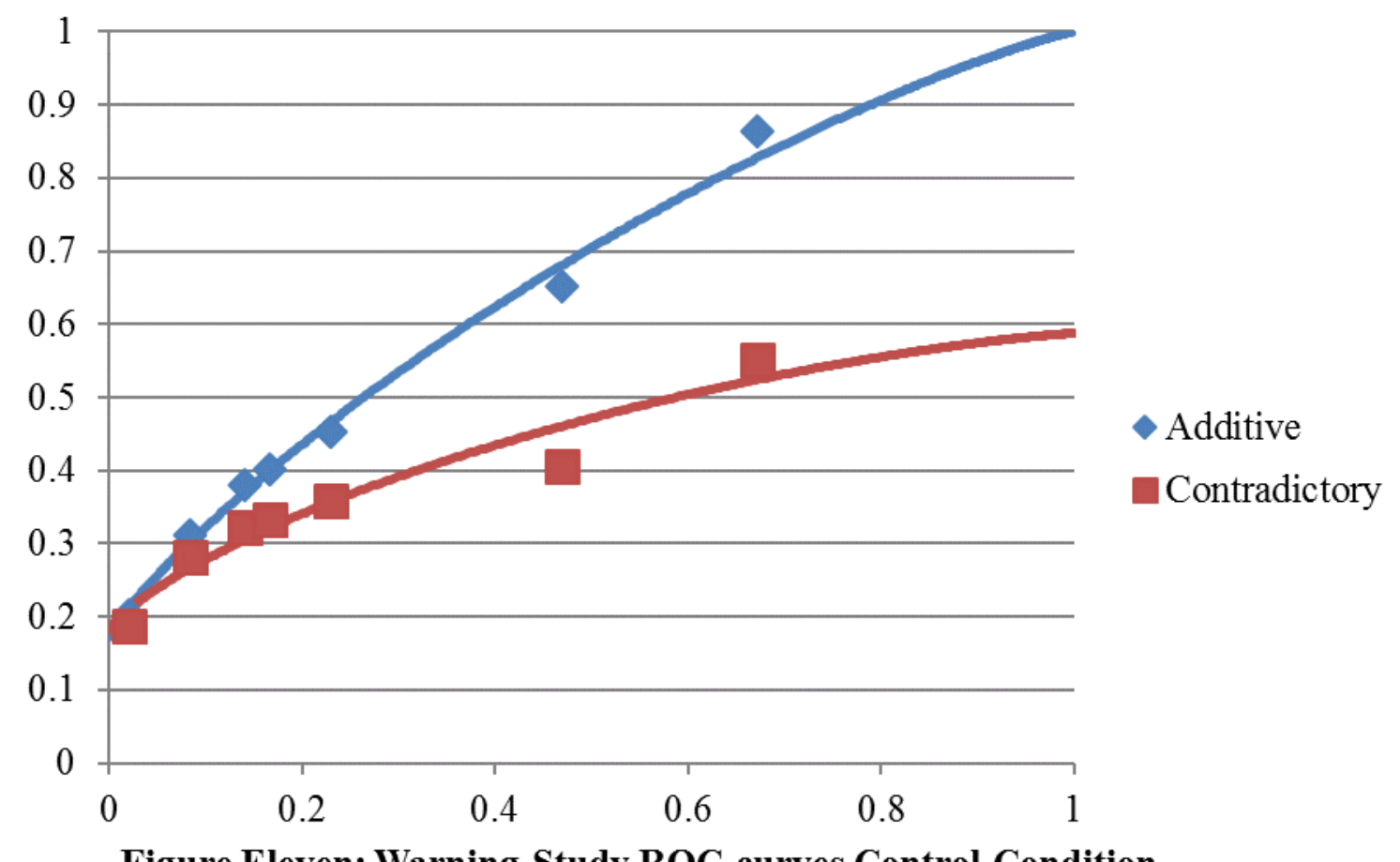

Figure Eleven: Warning Study ROC curves Control Condition

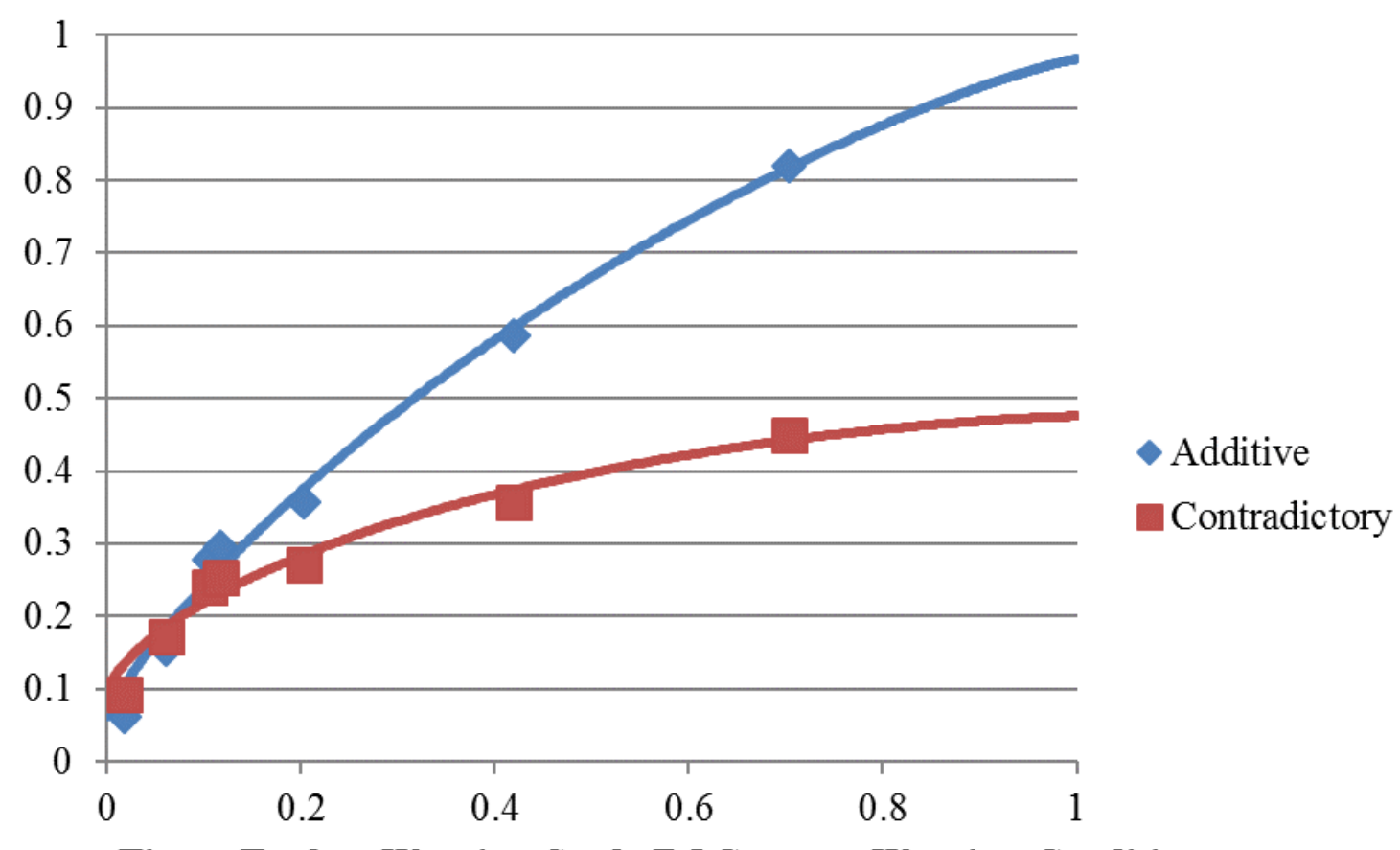

Figure Twelve: Warning Study ROC curves Warning Condition 


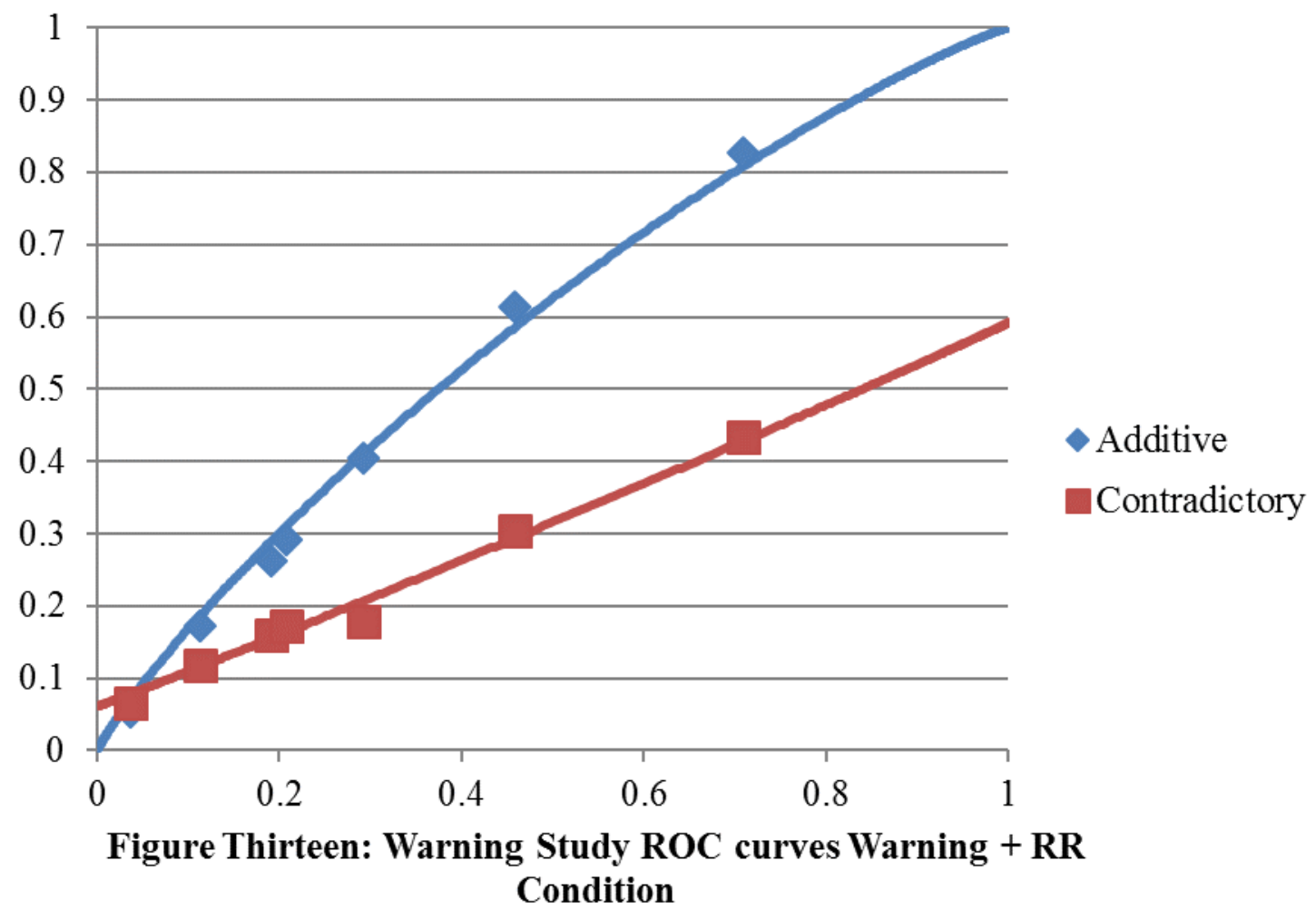

Table Four.

\begin{tabular}{|c|c|c|c|c|c|c|c|c|c|c|c|c|}
\hline \multicolumn{7}{|c|}{ Parameters } & \multicolumn{3}{|c|}{ Additive Items } & \multicolumn{3}{|c|}{ Contradictory Items } \\
\hline \multicolumn{13}{|c|}{ Control } \\
\hline $\mathrm{c} 1$ & $\mathrm{c} 2$ & c3 & $\mathrm{c} 4$ & c5 & c6 & c7 & $\mathrm{RR}$ & $\mathrm{PhR}$ & $\mathrm{d}^{\prime}$ & $\mathrm{RR}$ & $\mathrm{PhR}$ & $\mathrm{d}^{\prime}$ \\
\hline 2.24 & 1.33 & 1.04 & 0.95 & 0.758 & 0.14 & -0.5 & 0 & 0.17 & 0.37 & 0.41 & 0.31 & 0.57 \\
\hline \multicolumn{13}{|c|}{ Warning } \\
\hline $\mathrm{c} 1$ & c2 & $\mathrm{c} 3$ & $\mathrm{c} 4$ & $\mathrm{c5}$ & $\mathrm{c} 6$ & c7 & $\mathrm{RR}$ & $\mathrm{PhR}$ & $\mathrm{d}^{\prime}$ & $\mathrm{RR}$ & $\mathrm{PhR}$ & $\mathrm{d}^{\prime}$ \\
\hline 4.4 & 1.66 & 1.17 & 1.11 & 0.867 & 0.224 & -0.54 & 0.03 & 0.06 & 0.44 & 0.52 & 0.20 & 0.83 \\
\hline \multicolumn{13}{|c|}{ Warning + RR } \\
\hline $\mathrm{c} 1$ & $\mathrm{c} 2$ & c3 & c4 & $\mathrm{c} 5$ & c6 & c7 & $\mathrm{RR}$ & $\mathrm{PhR}$ & $\mathrm{d}^{\prime}$ & $\mathrm{RR}$ & $\mathrm{PhR}$ & $\mathrm{d}^{\prime}$ \\
\hline 1.91 & 1.24 & 0.92 & 0.84 & 0.572 & 0.068 & -0.58 & 0 & 0 & 0.32 & 0.41 & 0.10 & -0.05 \\
\hline
\end{tabular}

Self-Report. In order to establish inter-rater reliability, two research assistants coded the self-report data. Regarding recollection rejection, the agreement between RA1 $(M=2.6, S D=1.44)$ and RA2 $(M=3, S D=1.63)$ was $r(179)=.84, p<.001$. On unrelated items, the agreement between RA1 (M=.53, SD=.68) and RA2 $(M=.7, S D=.77)$ was $r(179)=.76, p<.001$. On contradictory 
items, the agreement between RA1 $(M=1.69, S D=.96)$ and RA2 $(M=1.7, S D=.97)$ was

$r(179)=.93, p<.001$. On additive items, the agreement between RA1 $(M=.39, S D=.58)$ and RA2 $(M=.6, S D=.71)$ was $r(179)=.73, p<.001$.

Control Condition. The self-reported rate of recollection rejection for contradictory items was $53 \%$. The self-reported rate of recollection rejection for additive items was $13 \%$. The selfreported rate of recollection rejection for unrelated items was $18 \%$.

Warning Condition. The self-reported rate of recollection rejection for contradictory items was $55 \%$. The self-reported rate of recollection rejection for additive items was $14 \%$. The self-reported rate of recollection rejection for unrelated items was $18 \%$.

Warning $+R R$ Condition. The self-reported rate of recollection rejection for contradictory items was $62 \%$. The self-reported rate of recollection rejection for additive items was $14 \%$. The self-reported rate of recollection rejection for unrelated items was $23 \%$.

Overall. The self-reported rate of recollection rejection for contradictory items was $56 \%$. The self-reported rate of recollection rejection for additive items was 13\%. The self-reported rate of recollection rejection for unrelated items was $20 \%$.

In order to determine the effects of item type and delays on self-reported rates of recollection rejection a 3 (item: contradictory, additive, unrelated) x 3 (feedback: no warning, warning, warning $+\mathrm{RR}$ ) ANOVA was conducted. The ANOVA revealed a main effect of item type, $F(2,342)=171.87, p<.001, \eta^{2}=.5$. Pairwise comparisons revealed that participants reported using recollection rejection more for contradictory items $(M=.57, S E=.02)$ than additive items $(M=.13, S E=.02)$ and unrelated items $(M=.2, S E=.02), p$ 's $<.001$. Pairwise comparisons revealed that participants reported using recollection rejection more for unrelated items $(M=.2$, 
$S E=.02)$ than for additive items $(M=.13, S E=.02), \mathrm{p}=.009$. There was no effect of feedback, $F(1$, $171)=1.75, p=.18, \eta_{p}^{2}=.02$. There was no interaction between the item type and warning, $F(4$, $342)=.59, p=.67, \eta_{p}^{2}=.007$

\section{Discussion}

I was interested in the effects that warnings and instructions about the use of recollection rejection would have on the use of recollection rejection in the misinformation paradigm. The findings of this study replicated the results of the previous studies in that misinformation effects were established, contradictory misinformation acceptance was lower than additive misinformation acceptance, and recollection rejection was used to reject false information.

However, my findings on warnings do not replicate previous research. In this study, only the warning in the warning plus recollection rejection instructions condition significantly reduced the misinformation effect. Simply warning participants in the warning-only condition failed to significantly reduce the misinformation effect. This finding contradicts the findings of Greene et al. (1982) who found that the misinformation effect was reduced when participants were only warned about misleading information before encountering it. There are a few explanations for my discrepant findings. Greene et al. (1982) used a multiple choice recognition test whereas I used an old/new recognition test. On Greene's test, participants were faced with three choices when confronted with critical items; the choices were a) what they saw in the slide show, b) the piece of misinformation, or c) a piece of novel information. On my test, participants were faced with one choice when confronted with critical items: to endorse the misinformation or not. It is possible that after receiving a warning that it was easier to recognize the false details and refute them by selecting an alternative on Greene's test whereas on my test participants 
could only recognize the false details. Secondly, participants partook in two 14 minute long filler tasks in my study, whereas Greene used two 5 minute filler tasks. Perhaps this amount of time allowed participants to forget more about what they had seen in the slide show, making it even harder to reject the false information on the final test. Finally, Greene et al.'s warning differed from mine in that Greene provided an explanation as to why there were inaccurate details in the story participants were about to read. Similar to Greene's study, participants in my study were told that the summary they were about to read was written by a police officer. In Greene's study, participants were told that "because the police cadet was inexperienced at detailing observed crimes, some of the information in the paragraph may be (have been) inaccurate" whereas in my study participants were told that "you should know that the summary contains some inaccurate details." Could it be that the lack of explanation for the inaccurate details made participants question the existence of or extent of the inaccuracies in the summary?

There was a decreased misinformation effect for the warning + RR condition. The difference between this condition and the warning condition were the instructions about the potential to use recollection rejection on the test. "You may be able to reject some of these inaccurate details by comparing what you saw in the slide show to other details when only one or the other could have occurred. For example, if you saw the man arrive at the house in a taxi and the test asked if he drove a car, you could reject the idea that he drove a car because you know he arrived in a taxi." Sticking with the lack of explanation for inaccurate details hypothesis, these instructions could have provided participants with a reason why the inaccurate details occurred.

With regards to the phantom recollection model and self-report results, I had expected to see increased rates of recollection rejection when participants were warned about misleading details. Unfortunately, this was not the case for either form of measurement. Instead, what we 
found using the phantom ROC model was that phantom recollection rates decreased for both additive and contradictory information in both warning conditions.

One reason why recollection rejection rates may not have increased in the warning conditions could be due to the placement of the warning. Participants were warned right before they encountered the misleading details, which may have caused participants not to incorporate misleading details information into memory in the first place - a process known as discrepancy detection. If misinformation acceptance was reduced by discrepancy detection, it could prevent an increase in recollection rejection rates because by the time recollection rejection could have occurred (at test), discrepancy detection (at the time postevent information is encountered) may have already taken place.

A second reason why recollection rejection rates may not have increased with the warning conditions could be that participants were already using recollection rejection as much as possible in the control condition. Our item types made the use of recollection rejection particularly easy in that our items were semantically related (i.e., Coke vs. Pepsi instead of Coke vs. apple or Coke vs. dog). Previous research has shown that when items are highly semantically related, recollection rejection is more likely to occur (Odegard, Lampinen, \& Toglia, 2005).

\section{General Discussion}

\section{Misinformation}

The primary aim of these studies was to examine the use of recollection rejection in the misinformation paradigm but these studies also provide some new evidence about the misinformation paradigm itself. In all three of my studies, I found that participants accepted additive misinformation more than contradictory misinformation. A previous study found that 
participants accepted more additive than contradictory misinformation after a one week delay (Frost, 2000) but to my knowledge mine are the first studies to demonstrate that participants accepted more additive misinformation than contradictory misinformation without a lengthy delay (which is how most misinformation studies are conducted). One previous study contradicted these results; however, Nemeth and Belli (2006) found that the acceptance of additive and contradictory misinformation did not differ for schemata knowledge. There are now four studies supporting the finding that additive misinformation is accepted significantly more than contradictory misinformation and only one which did not find support for this hypothesis. The study that did not find support for this hypothesis measured schemata knowledge in comparison to the other studies which measured memory for events. There may be something specific about schemata knowledge that eliminates the effect of rejecting more contradictory misinformation than additive misinformation. In addition, there is little theoretical basis to support the idea that additive and contradictory misinformation rates should be the same. Indeed, even Nemeth and Belli were surprised by the lack of difference in acceptance of additive and contradictory misinformation in their studies. They cited the short retention interval as a potential reason for their lack of findings; however, my research calls that explanation into question. In addition to this there is support for the hypothesis that additive misinformation should be accepted at higher rates than contradictory misinformation. Generally supporting this idea is the fact that there is already something specific in memory that can be used to reject contradictory misinformation. Specifically supporting this idea, there is proof for the use of memory editing strategies, such as recollection rejection, on contradictory misinformation but not so much for additive misinformation. Future research on this matter is required in order to be able to 
generalize the finding that additive misinformation is accepted more than contradictory misinformation.

There are important implications, for research in the misinformation paradigm, to draw from the differences in the acceptance of additive and contradictory misinformation. In the over 40 years of misinformation research, some studies have elicited the misinformation effect using contradictory misinformation (Loftus, 1978; Roediger, Jacoby, \& McDermott, 1996) and others have elicited the misinformation effect using additive misinformation (Lane \& Zaragoza, 1995; Loftus, 1975; Zaragoza \& Mitchell, 1996). In particular these two types of misinformation have not been treated as though they are different. Few publications have discussed the implications of using additive versus contradictory misinformation on the size of misinformation effects or there relation to actual eyewitness memory. Meta-analyses on misinformation studies should take the type of misinformation used in each study into account. In addition to this other researchers should take the type of misinformation used in other studies into account before comparing the results of their studies to others or before comparing the results two of separate studies.

\section{Recollection Rejection}

The finding that additive misinformation is accepted more than contradictory misinformation provides support that the higher rates of recollection rejection for contradictory items, as evidenced by the self-report results and the pROC model for my studies, caused the discrepancy in acceptance of additive and contradictory misinformation. It would appear that the use of recollection rejection on contradictory misinformation lead the rates of contradictory misinformation acceptance to decrease. 
It is important to point out that although the manipulations in my studies did not push around rates of recollection rejection that I did find consistent evidence for recollection rejection through three different measures in my studies. Across all three studies I found that participants accepted additive misinformation less than contradictory misinformation. While this does not provide direct evidence for the use of recollection rejection it does provide evidence that participants may have extra strategies available to them to reject contradictory misinformation in comparison to additive misinformation. In addition to this, I found evidence that participants self-reported the use of recollection rejection for contradictory misinformation more than for additive misinformation and that participants self-reported recollection rejection for additive misinformation no more than for unrelated items. Finally, the pROC curves for each of these studies indicated that participants used recollection rejection for contradictory misinformation. All together these measures provide solid evidence that people use recollection rejection when recollecting event details and in particular when misleading event details have an exclusive true detail that corresponds to them.

These data provide insight into the role of recollection rejection in remembering events. One conclusion to draw from this research is that people use recollection rejection to reject false suggestions about events that they have witnessed. Previous research has established that people use recollection rejection to reject false suggestions in the form of words, pictures, and for narratives, but to my knowledge this is the first study to identify recollection rejection in the memory for events. The phantom ROC model and self-report judgments both identified the use of recollection rejection in the misinformation paradigm. In addition, the misinformation effect was larger for the additive items than contradictory items as hypothesized, potentially because contradictory items allow for the use of recollection rejection. 
In Experiment 1, I varied the length of the delays that participants encountered in the misinformation paradigm. To my knowledge, this is the first time that the effects of short term delays on misinformation effects have been measured. Fortunately for the years of research on the misinformation effect that have mostly disregarded the potential for varying delay times to affect participants' memory, I did not find an effect of manipulating short term delays on the size of the misinformation effect. However, this was not the result hypothesized at the outset of this study. I believe now that the delay lengths were not long enough to identify an effect with the number of participants in the study, which led to inadequate power to detect differences. Similarly, I did not detect an effect of varying delays on the use of recollection rejection. I hypothesized that the reason for this is that the delay manipulation was not strong enough (i.e., the difference between delay lengths was not long enough). Previous research has found that manipulating delays on a larger timescale affects the ability to use recollection rejection, but my study revealed a diminished effect on shorter timescales (Brainerd, Reyna, and Kneer, 1995). Future research should examine the effects of delays of varying lengths from hours to days to establish when exactly delays start to affect misinformation acceptance and the use of recollection rejection.

In Experiment 2, I introduced warnings about misinformation and instructions about the ability to use recollection rejection. In past research, warnings about misinformation have reduced the acceptance of postevent information (Greene et al., 1982). Warnings placed after postevent information have sometimes been found to reduce the misinformation effect but this finding has been difficult to replicate. Therefore, I chose to place the warning where it has previously been effective: before encountering postevent information. Unfortunately, the warning only effectively reduced misinformation acceptance when accompanied by recollection 
rejection instructions. It may be possible that the recollection rejection instructions provided a reason for why inaccurate details were present leading participants to reject them whereas in the warning study participants only received the information that inaccurate details were present without an explanation. It may have been harder for participants to come to believe that false information was presented to them without an explanation as to why. Recollection rejection rates were not increased in the warning-only or warning + RR conditions. Previous research has found that giving participants instructions about the use of recollection rejection substantially increases their use of recollection rejection. There are a few reasons why recollection rejection instructions may not have inflated the use of recollection rejection in my study. One reason why recollection rejection rates may not have increased is that participants may have already been using recollection rejection to the best of their ability even before receiving instructions about the use of recollection rejection. In this case it would make it difficult to increase rates of recollection rejection. Another explanation is that there may not have been enough participants in the study to make it possible to detect the differences in the use of recollection rejection across feedback conditions. Future research should examine the effects of warnings about misinformation and recollection rejection instructions in order to determine their exact effects in memory for events.

\section{Conclusions}

This series of studies examined the use of recollection rejection in the misinformation paradigm and the differences between the acceptance of additive and contradictory misinformation. I found that participants use recollection rejection and report using recollection rejection to reject contradictory misinformation. Participants are also more likely to report additive misinformation than contradictory misinformation which provides some indication that recollection rejection may be an extra strategy available for rejecting contradictory 
misinformation. Future research should examine the use of memory editing strategies on event based memories in order to gain a clearer picture of when they are used and to what extent they are used. 
References

Belli, R. F. (1989). Influences of misleading postevent information: Misinformation interference and acceptance. Journal of Experimental Psychology: General, 118(1), 72.

Belli, R. F., Windschitl, P. D., McCarthy, T. T., \& Winfrey, S. E. (1992). Detecting memory impairment with a modified test procedure: Manipulating retention interval with centrally presented event items. Journal of Experimental Psychology: Learning, Memory, and Cognition, 18(2), 356.

Brainerd, C. J., Wright, R., Reyna, V. F., \& Mojardin, A. H. (2001). Conjoint recognition and phantom recollection. Journal of Experimental Psychology: Learning, Memory, and Cognition, 27(2), 307.

Brainerd, C. J., Reyna, V. F., Wright, R., \& Mojardin, A. H. (2003). Recollection rejection: false-memory editing in children and adults. Psychological review, 110(4), 762.

Brainerd, C. J., Reyna, V. F., \& Kneer, R. (1995). False-recognition reversal: When similarity is distinctive. Journal of Memory and Language, 34(2), 157-185.

Ceci, S. J., Ross, D. F., \& Toglia, M. P. (1987). Suggestibility of children's memory: Psycholegal implications. Journal of Experimental Psychology: General, 116(1), 38.

Chambers, K. L., \& Zaragoza, M. S. (2001). Intended and unintended effects of explicit warnings on eyewitness suggestibility: Evidence from source identification tests. Memory \& Cognition, 29(8), 1120-1129.

Christiaansen, R. E., \& Ochalek, K. (1983). Editing misleading information from memory: Evidence for the coexistence of original and postevent information. Memory \& Cognition, 11(5), 467-475.

Deese, J. (1959). On the prediction of occurrence of particular verbal intrusions in immediate recall. Journal of experimental psychology, 58(1), 17.

Frost, P. (2000). The quality of false memory over time: is memory for misinformation 'remembered' or 'known'? Psychonomic Bulletin \& Review, 7, 531-536.

Gabber, F., Memon, A., Allan, K. (2003). Memory Conformity: Can Eyewitnesses Influence Other's Memories for an Event? Applied Cognitive Psychology, 17, 533-543.

Gallo, D. A., Bell, D. M., Beier, J. S., \& Schacter, D. L. (2006). Two types of recollection-based monitoring in younger and older adults: Recall-to-reject and the distinctiveness heuristic. Memory, 14(6), 730-741.

Greene, E., Flynn, M. S., \& Loftus, E. F. (1982). Inducing resistance to misleading information. Journal of Verbal Learning and Verbal Behavior, 21(2), 207-219. 
Johnson, M. K., \& Raye, C. L. (1981). Reality monitoring. Psychological review, 88(1), 67.

Johnson, M. K., Hashtroudi, S., \& Lindsay, D. S. (1993). Source monitoring. Psychological bulletin, 114(1), 3.

Lampinen, J. M., Meier, C. R., Arnal, J. D., \& Leding, J. K. (2005). Compelling untruths: content borrowing and vivid false memories. Journal of Experimental Psychology: Learning, Memory, and Cognition, 31(5), 954.

Lampinen, J. M., Odegard, T. N., \& Neuschatz, J. S. (2004). Robust recollection rejection in the memory conjunction paradigm. Journal of Experimental Psychology: Learning, Memory, and Cognition, 30(2), 332.

Lampinen, J. M., Odegard, T. N., Blackshear, E., \& Toglia, M. P. (2005). Phantom ROC.In Trends in Experimental Psychology Research. (pp. 235- ). New York, NY: Nova Science Pub Inc.

Lampinen, J. M., Watkins, K. N., \& Odegard, T. N. (2006). Phantom ROC: Recollection rejection in a hybrid conjoint recognition signal detection model. Memory, 14(6), 655671.

Lane, S. M. (2006). Dividing attention during a witnessed event increases eyewitness suggestibility. Applied Cognitive Psychology, 20(2), 199-212.

Lane, S.M., \& Zaragoza, M.S. (1995). The recollective experience of cross-modality confusion errors. Memory \& Cognition, 23, 607-610.

Lindsay, D. S., \& Johnson, M. K. (1987). Reality monitoring and suggestibility: Children's ability to discriminate among memories from different sources. In Children's eyewitness memory (pp. 92-121). Springer US.

Lindsay, D. S., \& Johnson, M. K. (1989). The eyewitness suggestibility effect and memory for source. Memory \& Cognition, 17(3), 349-358.

Loftus, E. F. (1974). Reconstructing memory: The incredible eyewitness. Jurimetrics J., 15, 188.

Loftus, E. F. (1975). Leading questions and the eyewitness report. Cognitive psychology, 7(4), $560-572$.

Loftus, E. F. (1977). Shifting human color memory. Memory \& Cognition, 5(6), 696-699.

Loftus, E. F. (1979). The malleability of human memory: Information introduced after we view an incident can transform memory. American Scientist, 67(3), 312-320. 
Loftus, E. F. (1992). When a lie becomes memory's truth: Memory distortion after exposure to misinformation. Current Directions in Psychological Science, 1(4), 121-123.

Loftus, E. F. (2005). Planting misinformation in the human mind: A 30-year investigation of the malleability of memory. Learning \& Memory, 12(4), 361-366.

Loftus, E. F., Donders, K., Hoffman, H. G., \& Schooler, J. W. (1989). Creating new memories that are quickly accessed and confidently held. Memory \& Cognition, 17(5), 607-616.

Loftus, E. F., \& Greene, E. (1980). Warning: Even memory for faces may be contagious. Law and Human Behavior, 4(4), 323.

Loftus, E. F., \& Loftus, G. R. (1980). On the permanence of stored information in the human brain. American Psychologist, 35(5), 409.

Loftus, E. F., Miller, D. G., \& Burns, H. J. (1978). Semantic integration of verbal information into a visual memory. Journal of experimental psychology: Human learning and memory, 4(1), 19.

McCloskey, M., \& Zaragoza, M. (1985). Misleading postevent information and memory for events: arguments and evidence against memory impairment hypotheses. Journal of Experimental Psychology: General, 114(1), 1.

Odegard, T. N., Lampinen, J. M., \& Toglia, M. P. (2005). Meaning's moderating effect on recollection rejection. Journal of Memory and Language, 53(3), 416-429.

Nemeth, R. J., \& Belli, R. F. (2006). The influence of schematic knowledge on contradictory versus additive misinformation: False memory for typical and atypical items. Applied cognitive psychology, 20(5), 563-573.

Reyna, V. F., \& Kiernan, B. (1995). Children's memory and metaphorical interpretation. Metaphor and Symbol, 10(4), 309-331.

Roediger, H.L., III, Jacoby, J.D., \& McDermott, K.B. (1996) Misinformation effects in recall: Creating false memories through repeated retrieval. Journal of Memory \& Language, 35, 300-318.

Roediger, H. L., \& McDermott, K. B. (1995). Creating false memories: Remembering words not presented in lists. Journal of Experimental Psychology: Learning, Memory, and Cognition, 21(4), 803.

Rotello, C. M., \& Heit, E. (2000). Associative recognition: A case of recall-to-reject processing. Memory \& Cognition, 28(6), 907-922.

Rotello, C. M., Macmillan, N. A., \& Van Tassel, G. (2000). Recall-to-reject in recognition: Evidence from ROC curves. Journal of Memory and Language, 43(1), 67-88. 
Smith, V. L., \& Ellsworth, P. C. (1987). The social psychology of eyewitness accuracy: Misleading questions and communicator expertise. Journal of Applied Psychology, 72(2), 294.

Takarangi, M. K., Parker, S., \& Garry, M. (2006). Modernising the misinformation effect: The development of a new stimulus set. Applied Cognitive Psychology, 20(5), 583-590.

Tousignant, J. P., Hall, D., \& Loftus, E. F. (1986). Discrepancy detection and vulnerability to misleading postevent information. Memory \& Cognition, 14(4), 329-338.

Tversky, B., \& Tuchin, M. (1989). A reconciliation of the evidence on eyewitness testimony: Comments on McCloskey and Zaragoza. Journal of Experimental Psychology: General, $118(1), 86-91$.

Yonelinas, A. P. (1994). Receiver-operating characteristics in recognition memory: evidence for a dual-process model. Journal of Experimental Psychology: Learning, Memory, and Cognition, 20(6), 1341.

Yonelinas, A. P. (1997). Recognition memory ROCs for item and associative information: The contribution of recollection and familiarity. Memory \& Cognition, 25(6), 747-763.

Yonelinas, A. P. (1999). The contribution of recollection and familiarity to recognition and source-memory judgments: A formal dual-process model and an analysis of receiver operating characteristics. Journal of Experimental Psychology: Learning, Memory, and Cognition, 25(6), 1415.

Zaragoza, M. S., \& Lane, S. M. (1994). Source misattributions and the suggestibility of eyewitness memory. Journal of Experimental Psychology: Learning, Memory, and Cognition, 20(4), 934.

Zaragoza, M. S., \& Lane, S. M. (1998). Processing resources and eyewitness suggestibility. Legal and Criminological Psychology, 3(2), 305-320. 
Appendix A: IRB Approval Letter

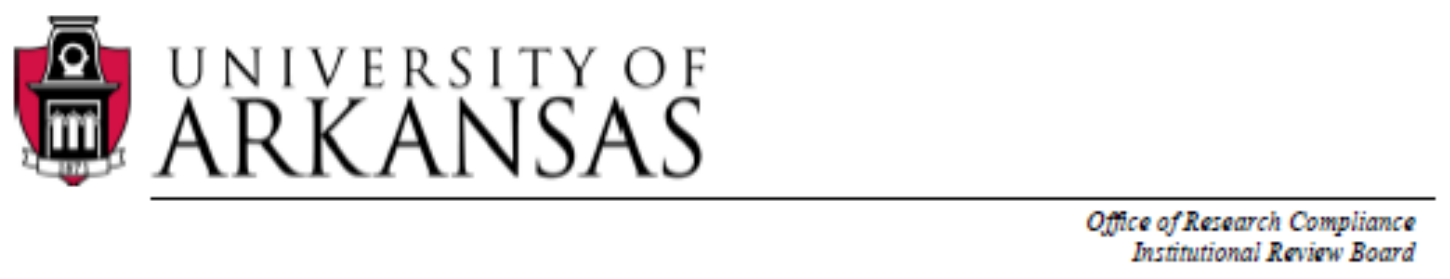

October 4, 2013

MEMORANDUM

TO:

Kara Moore

James Lampinen

FROM:

Ro Windwalker

IRB Coordinator

$\mathrm{RE}$ :

New Protocol Approval

IRB Protocol \#:

$13-09-125$

Protocol Title:

Memory for a Wimessed Event

Review Type:

$\triangle$ EXEMPT $\square$ EXPEDITED $\square$ FULL IRB

Approved Project Period:

Start Date: 10/04/2013 Expiration Date: 10/03/2014

Your protocol has been approved by the IRB. Protocols are approved for a maximum period of one year. If you wish to continue the project past the approved project period (see above), you must submit a request, using the form Continuing Review for IRB Approved Projects, prior to the expiration date. This form is available from the IRB Coordinator or on the Research Compliance website (http://vpred.uark.edu/210.php). As a courtesy, you will be sent a reminder two months in advance of that date. However, failure to receive a reminder does not negate your obligation to make the request in sufficient time for review and approval. Federal regulations prohibit retroactive approval of continuation. Failure to receive approval to continue the project prior to the expiration date will result in Termination of the protocol approval. The $\mathbb{R} B$ Coordinator can give you guidance on submission times.

This protocol has been approved for 1,200 participants. If you wish to make any modifications in the approved protocol, including enrolling more than this number, you must seek approval prior to implementing those changes. All modifications should be requested in writing (email is acceptable) and must provide sufficient detail to assess the impact of the change.

If you have questions or need any assistance from the IRB, please contact me at 210 Administration Building, 5-2208, or irb $@$ uark.edu.

210 Administration Building * 1 University of Arkansas * Fayetteville, AR. 72701 Voice (479) 575-2208 - Fax (479) 575-3846 • Email irb@uark edu

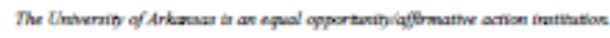




\section{Appendix B: Slide Show}

Slide One

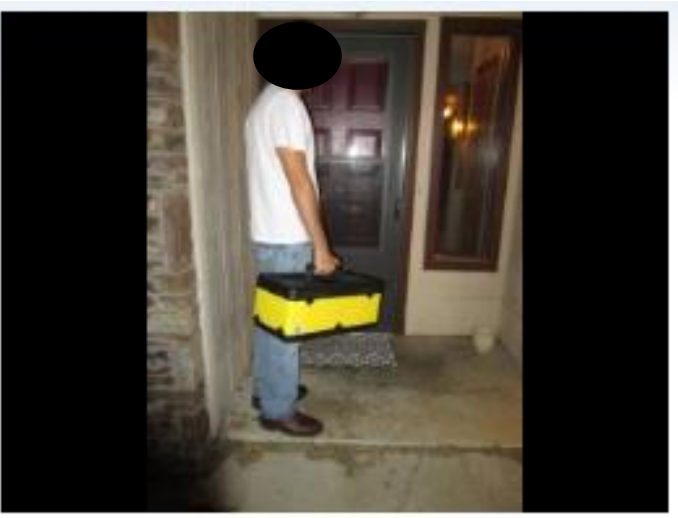

Contradictory Key Item A

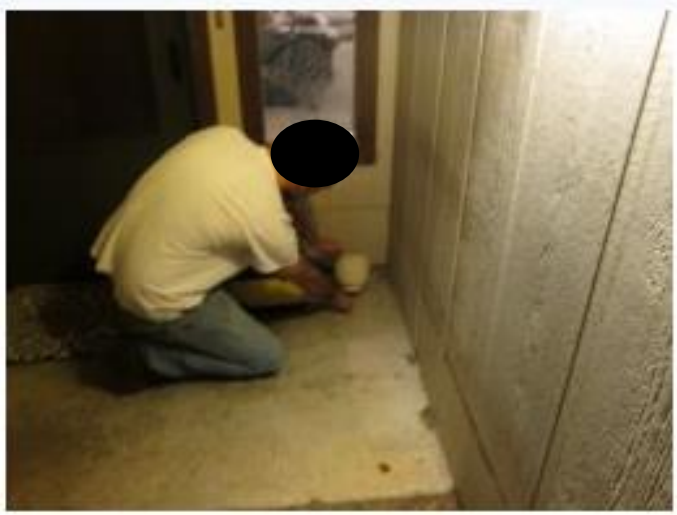

Contradictory Key Item B

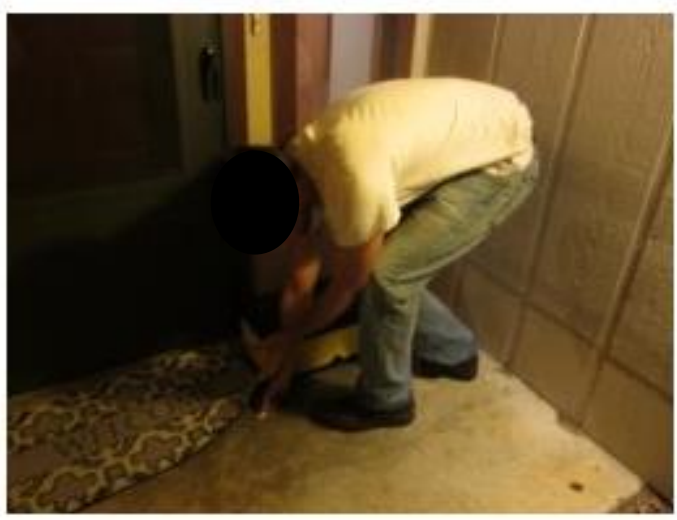

Slide Two

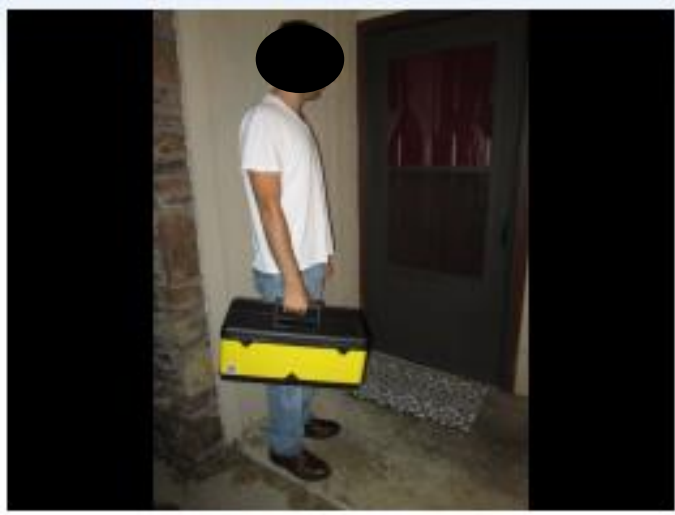

Contradictory Key Item A

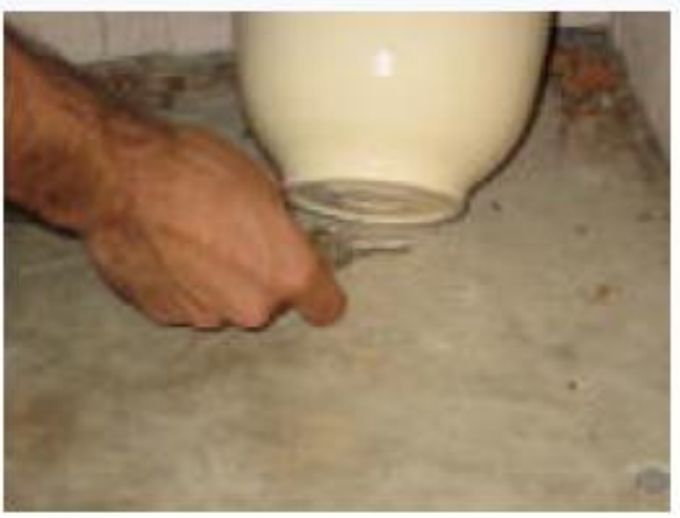

Contradictory Key Item B

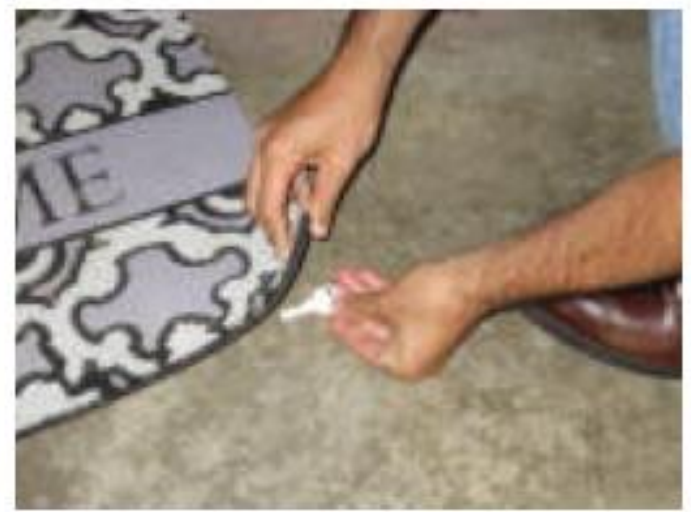

Pictures taken by Kara Moore at Dr. James Lampien's place of residence in Fayetteville, AR on October 28, 2013. 
Slide Three

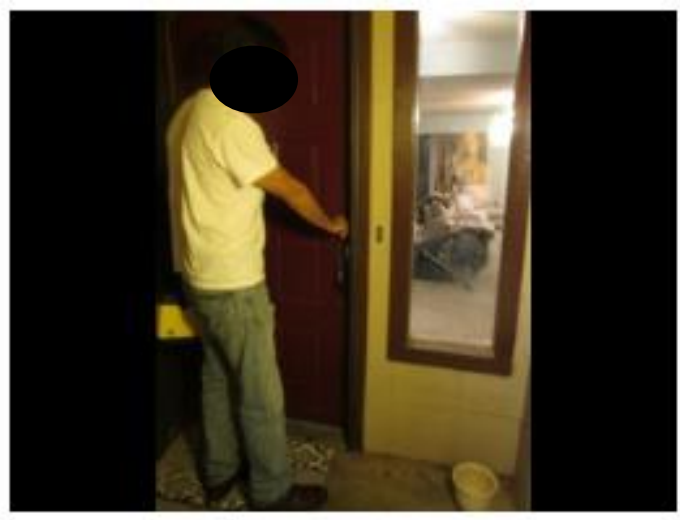

Slide Five

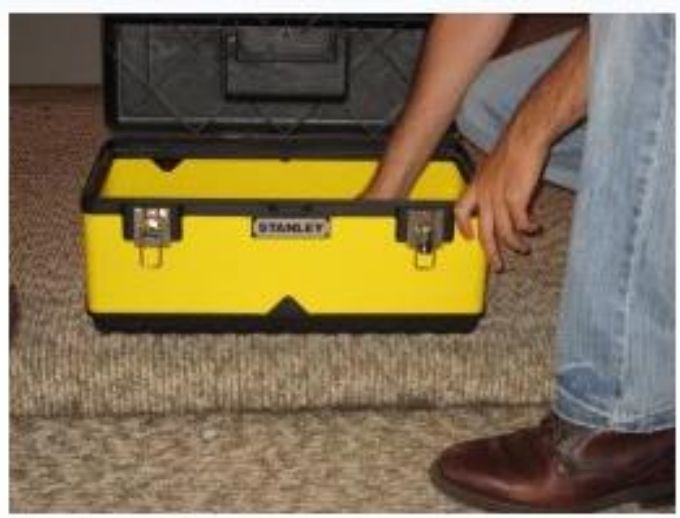

Contradictory Note Location Item B

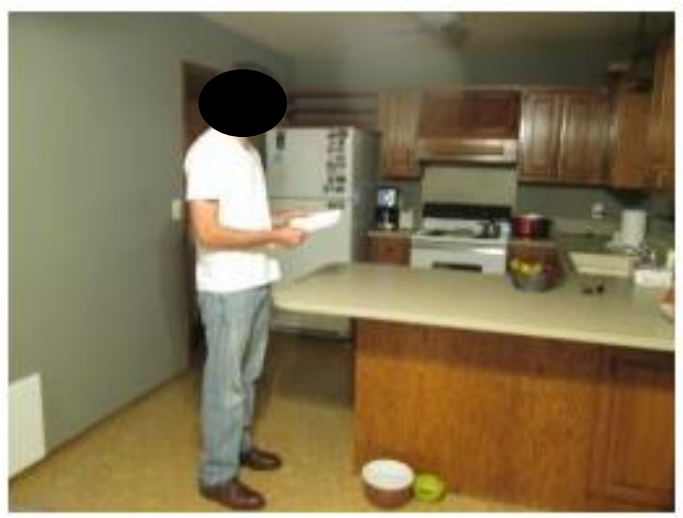

Slide Four

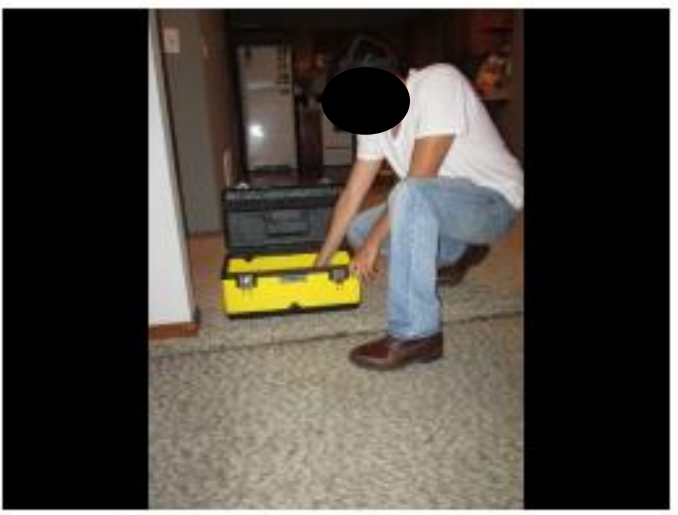

Contradictory Note Location Item A

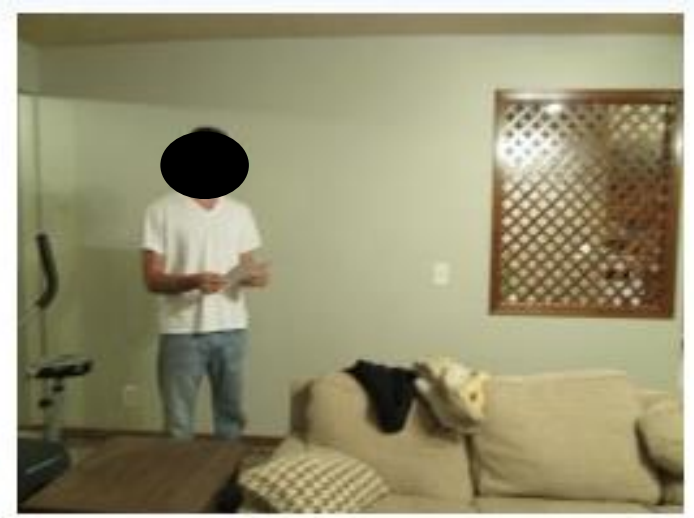

Slide Six

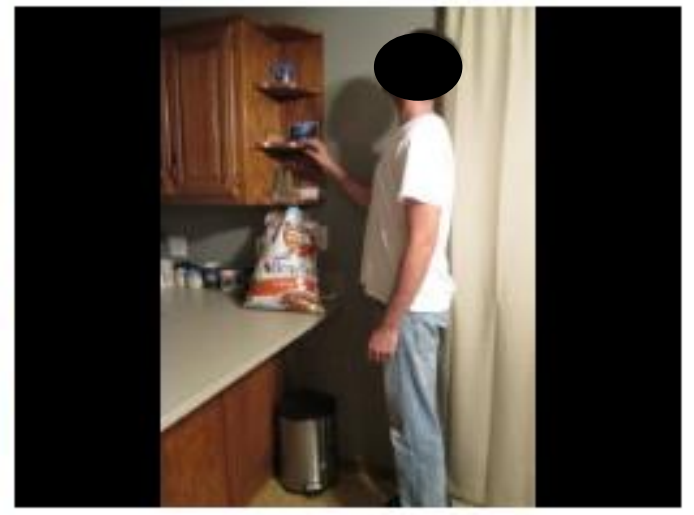

Pictures taken by Kara Moore at Dr. James Lampien's place of residence in Fayetteville, AR on October 28, 2013. 
Contradictory Fruit Item A

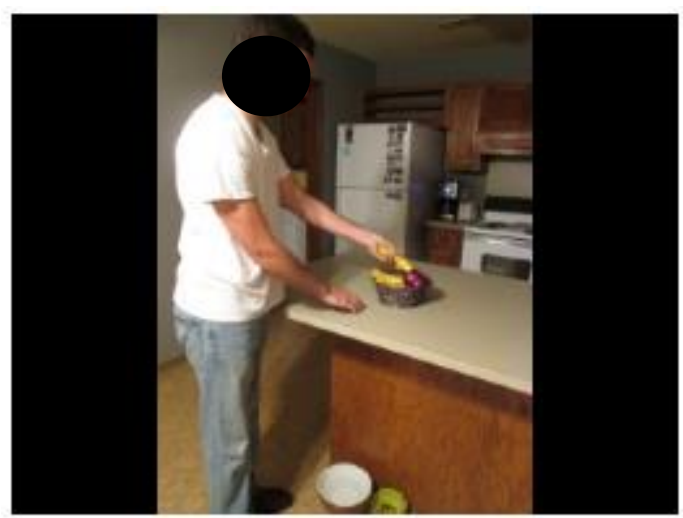

Contradictory Fruit Item B

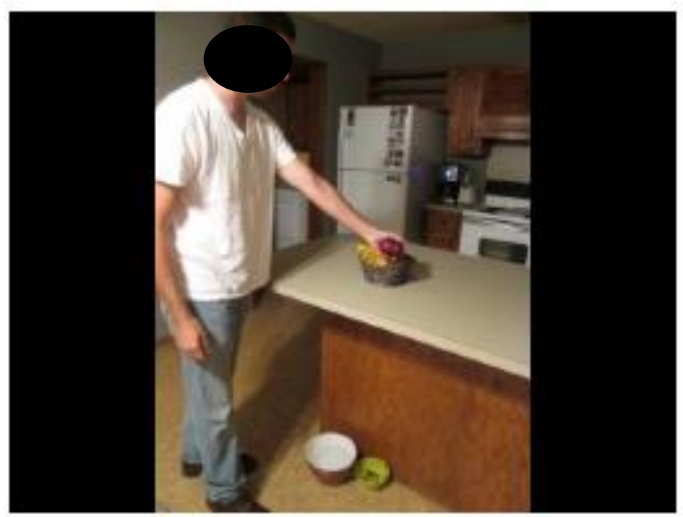

Slide Seven

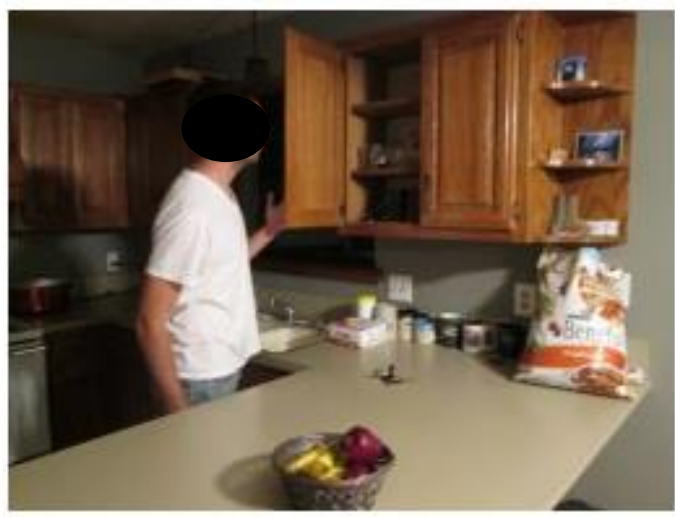

Contradictory Fruit Item A

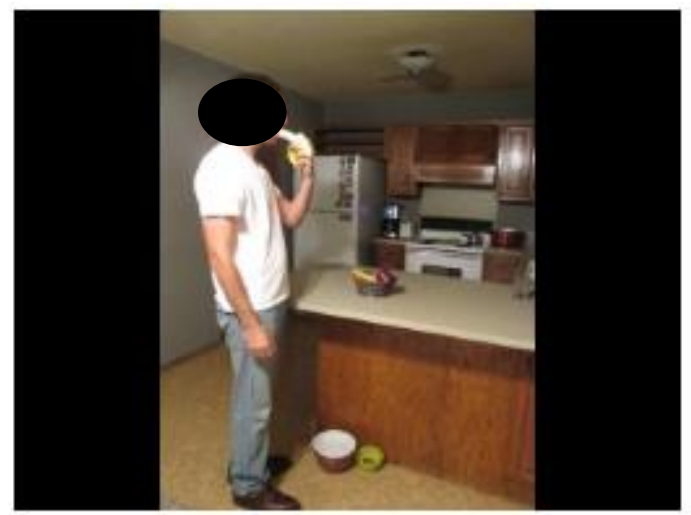

Contradictory Fruit Item B

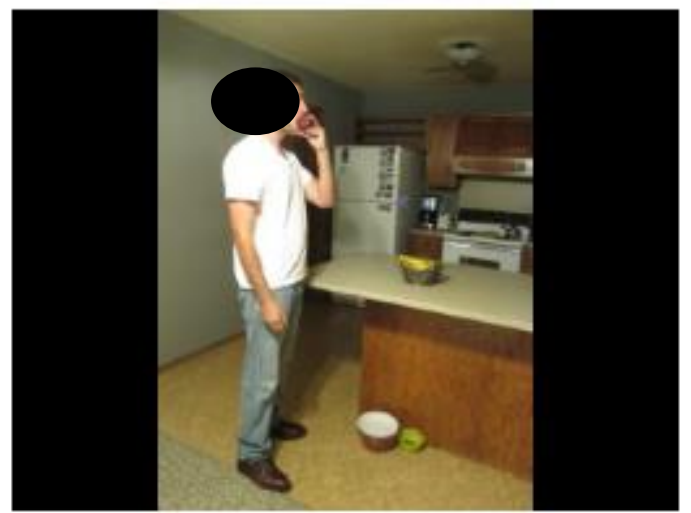

Slide Eight

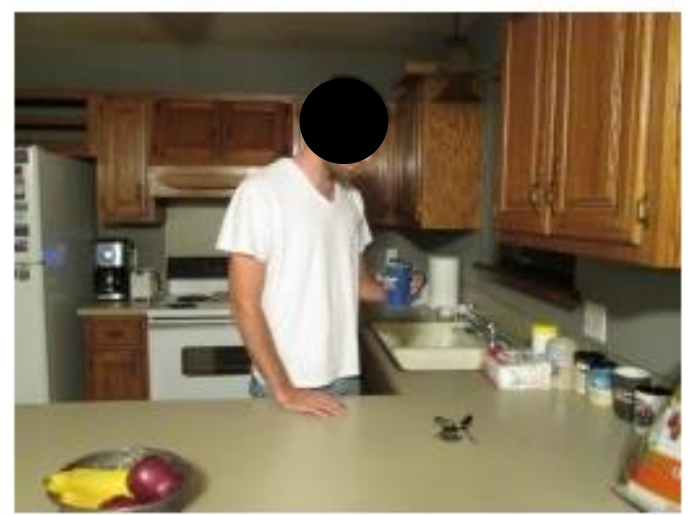

Pictures taken by Kara Moore at Dr. James Lampien's place of residence in Fayetteville, AR on October 28, 2013. 
Slide Nine

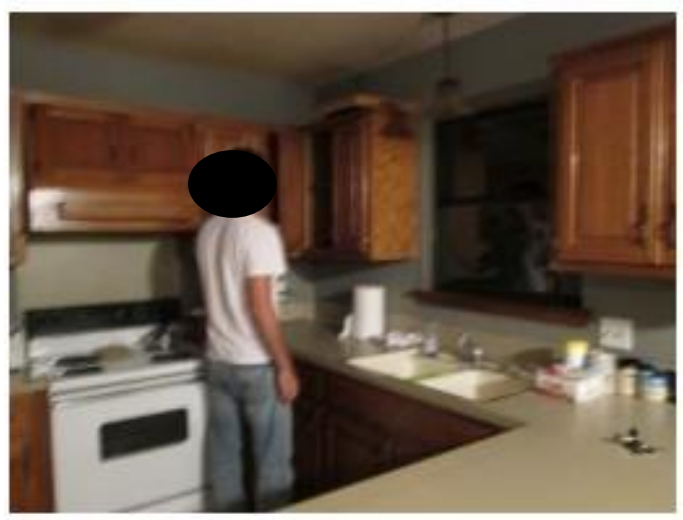

Slide Eleven

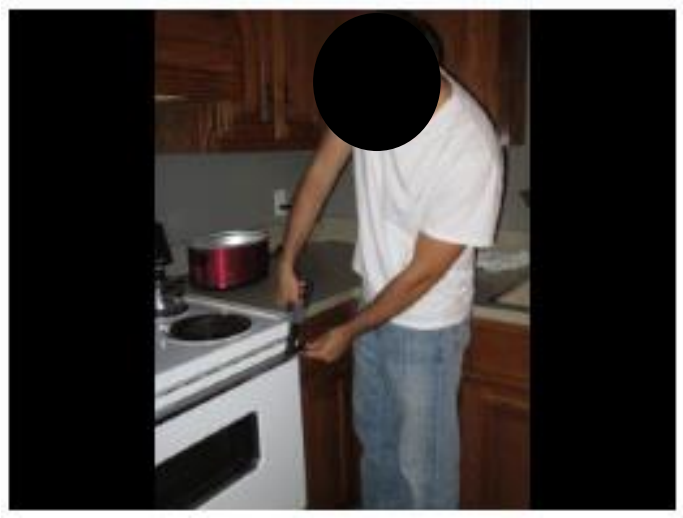

Contradictory Soda Item A

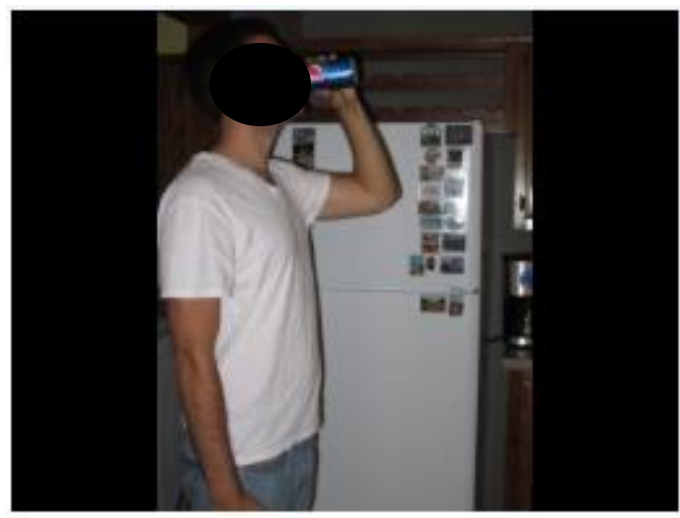

Slide Ten

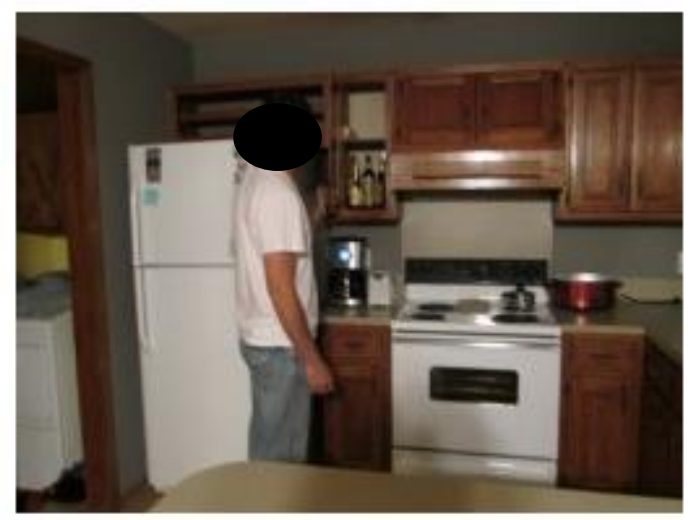

Slide Twelve

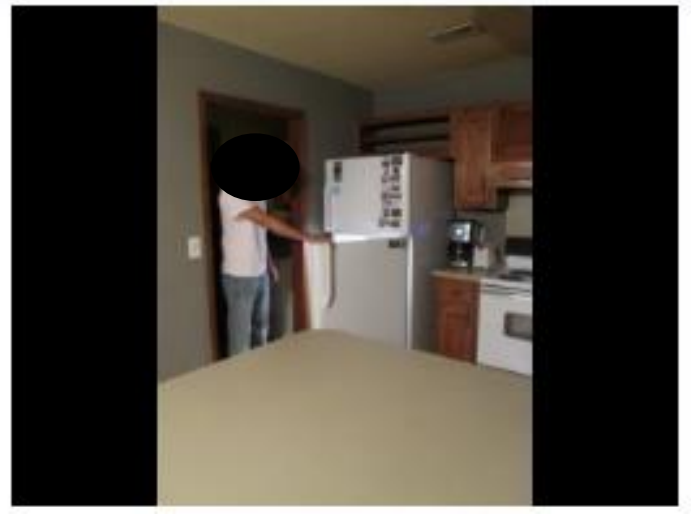

Contradictory Soda Item B

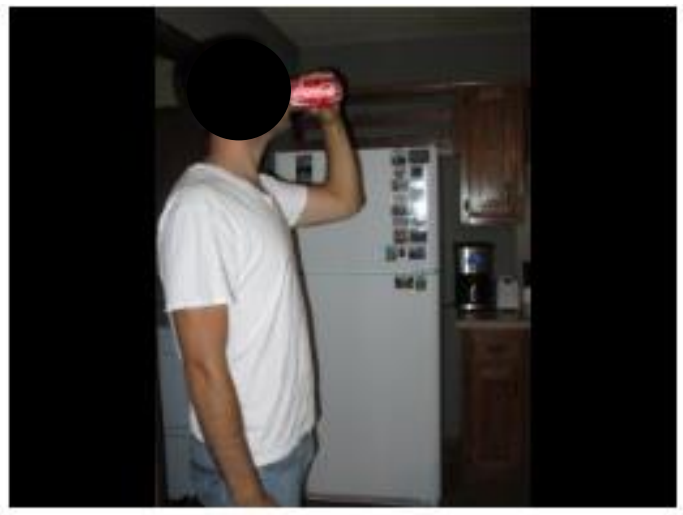

Pictures taken by Kara Moore at Dr. James Lampien's place of residence in Fayetteville, AR on

October 28, 2013. 
Slide Thirteen

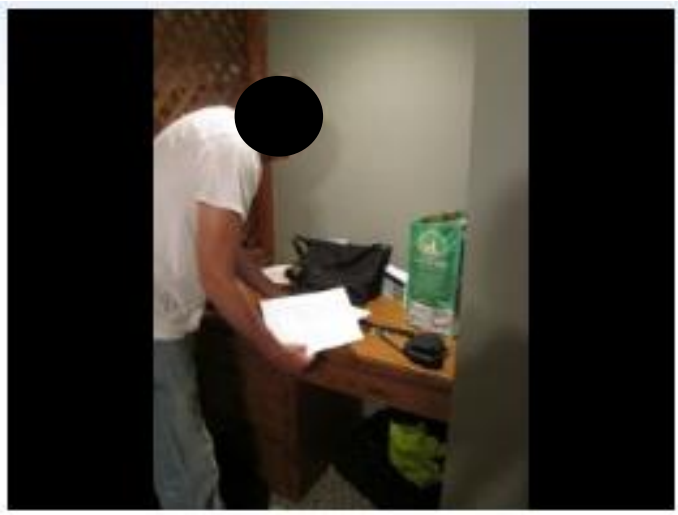

Slide Fifteen

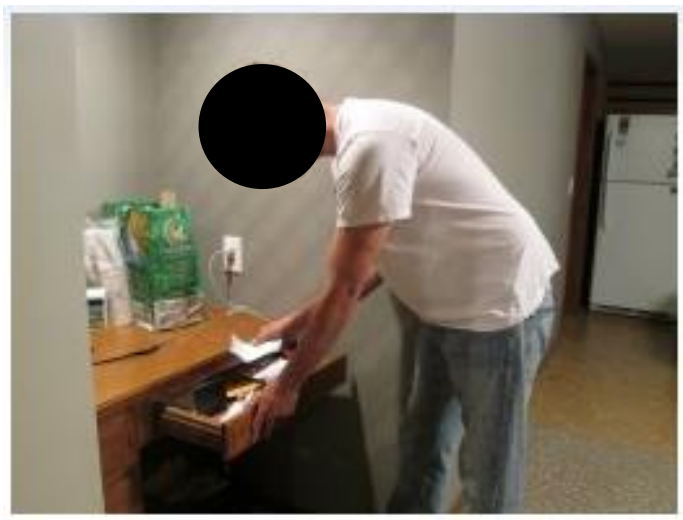

Slide Seventeen

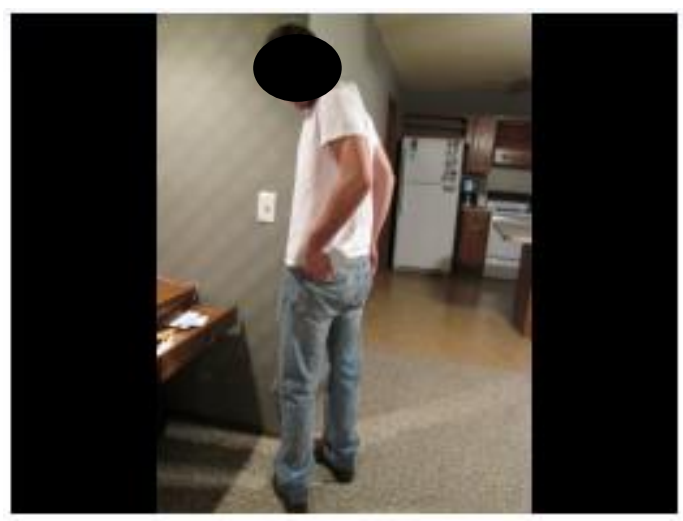

Slide Fourteen

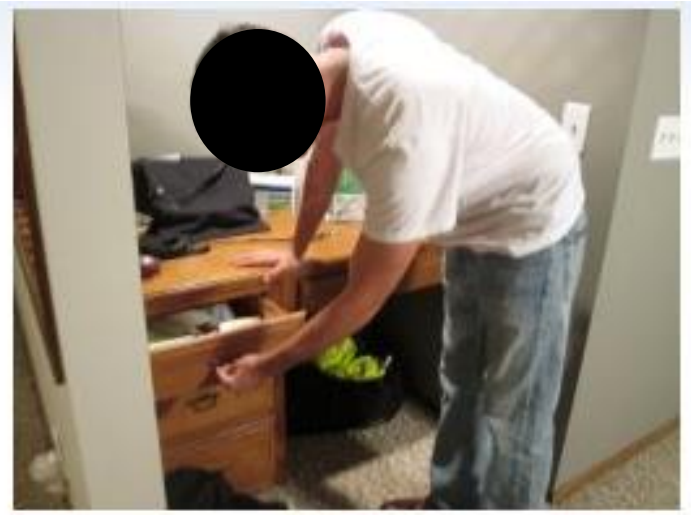

Slide Sixteen

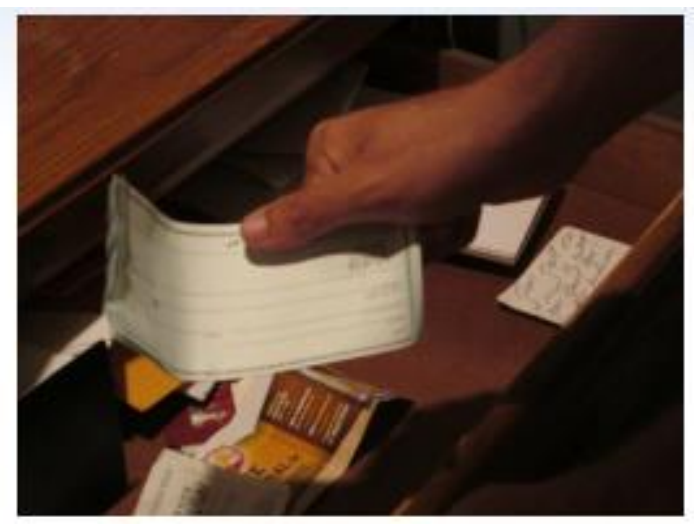

Slide Eighteen

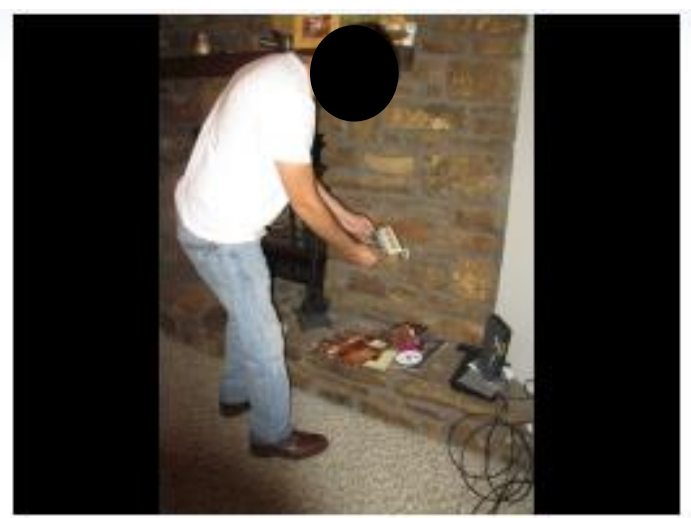

Pictures taken by Kara Moore at Dr. James Lampien's place of residence in Fayetteville, AR on October 28, 2013. 
Slide Nineteen

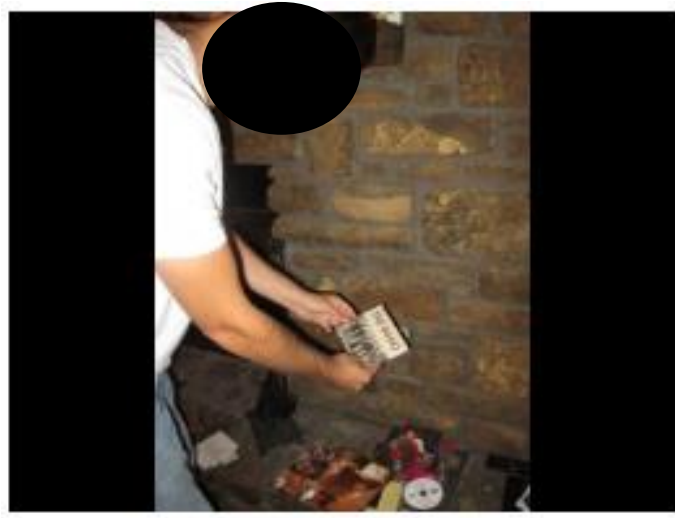

Contradictory Magazine Item A

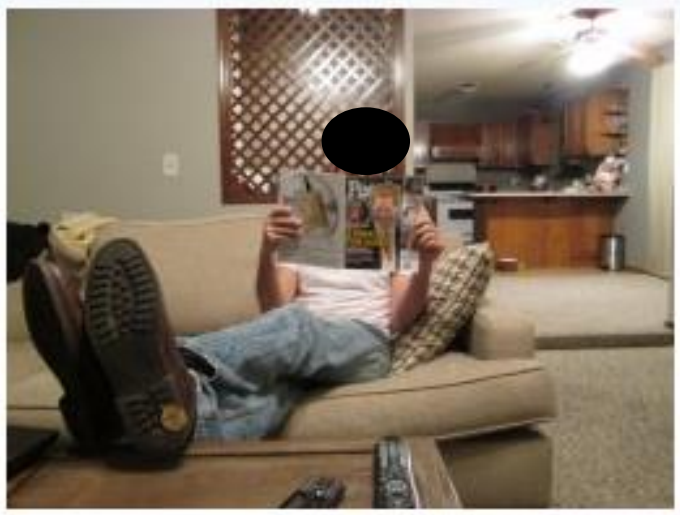

Slide Twenty One

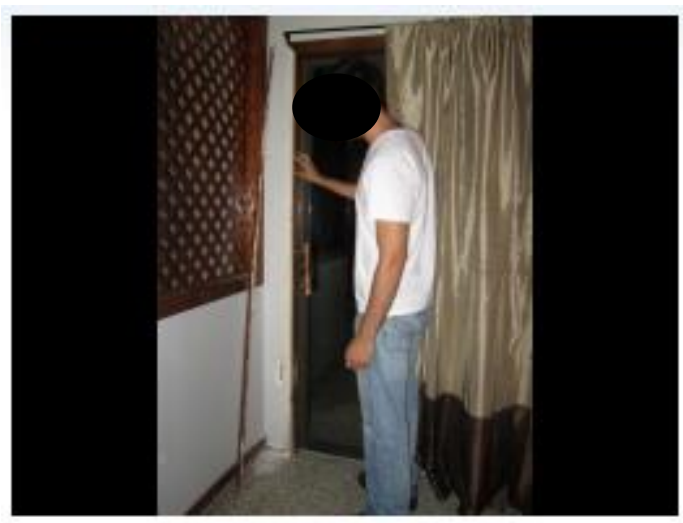

Slide Twenty

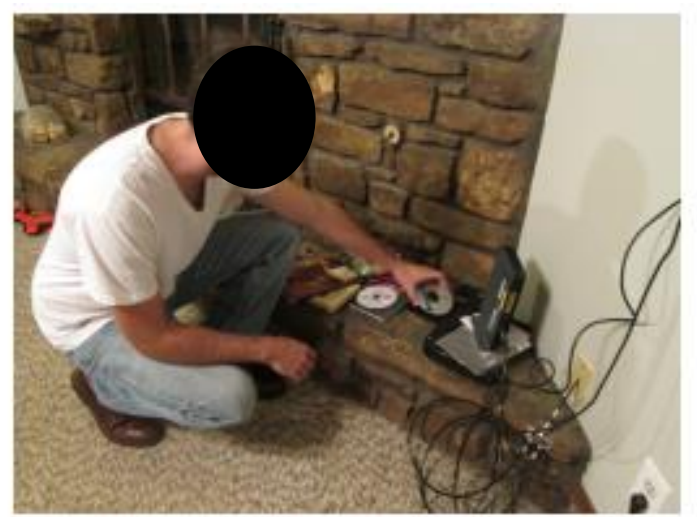

Contradictory Magazine Item B

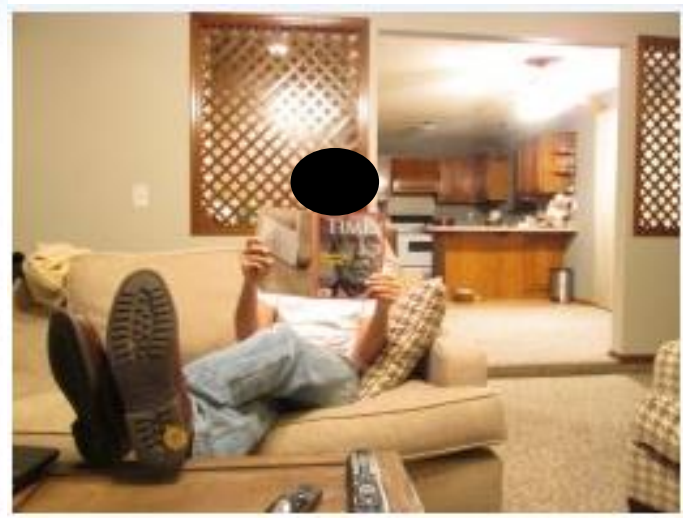

Slide Twenty Two

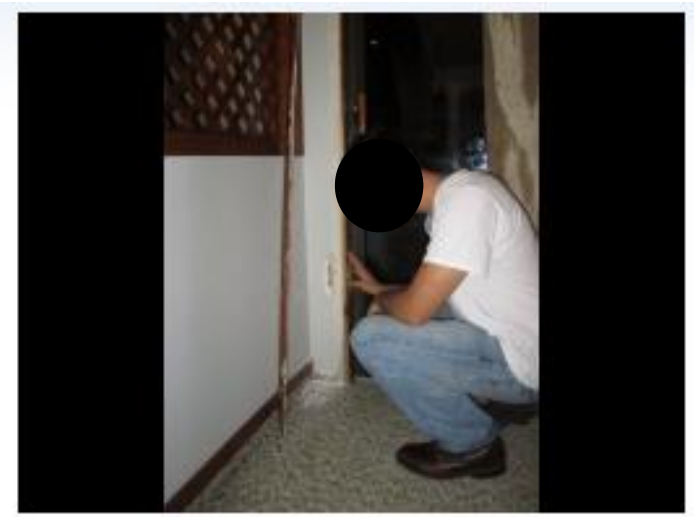

Pictures taken by Kara Moore at Dr. James Lampien's place of residence in Fayetteville, AR on October 28, 2013. 
Slide Twenty Three

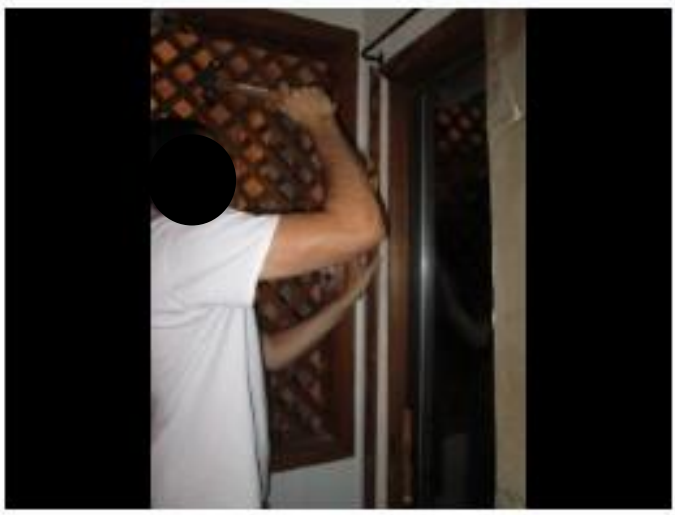

Slide Twenty Five

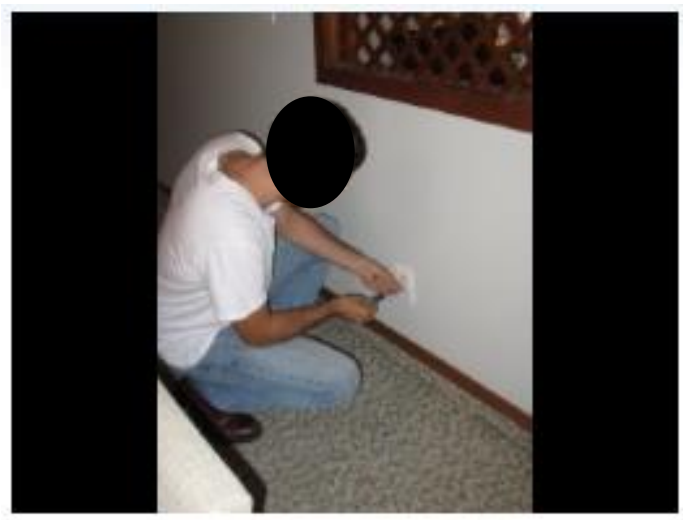

Slide Twenty Seven

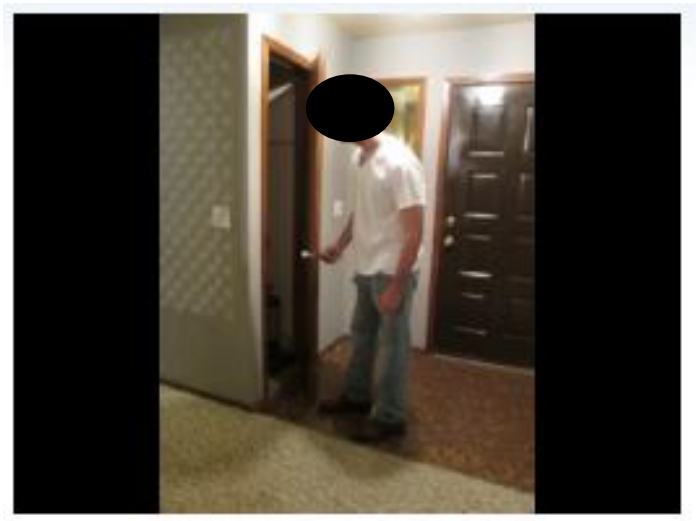

Slide Twenty Four

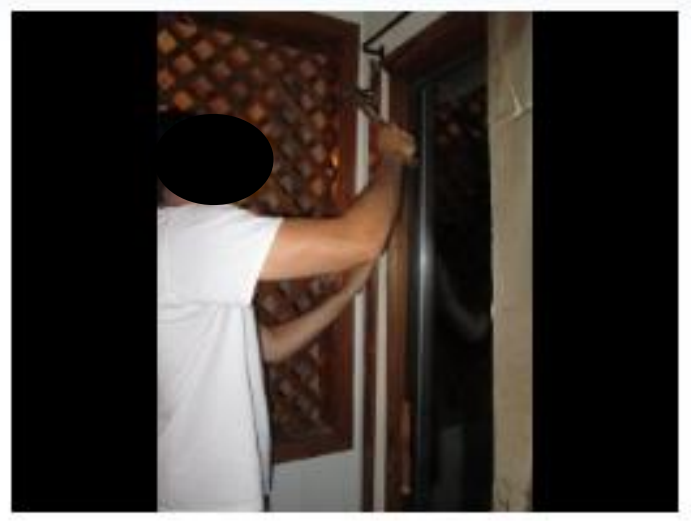

Slide Twenty Six

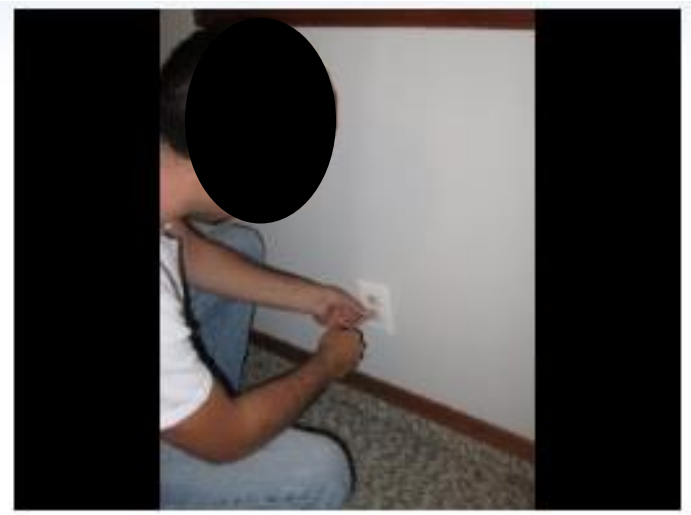

Contradictory Cap Item A

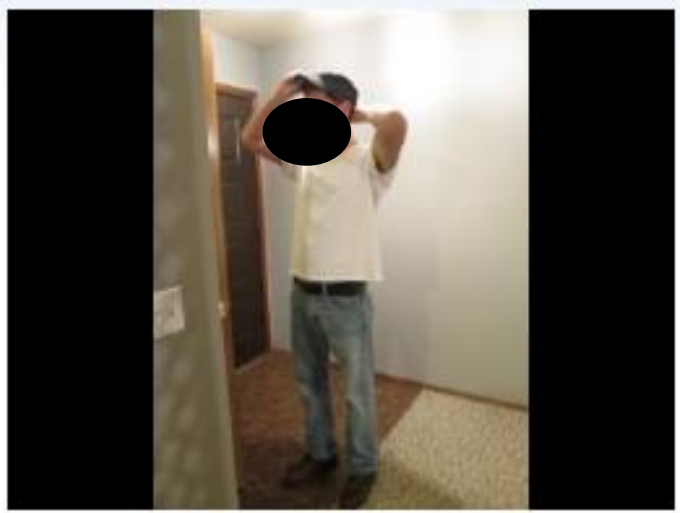

Pictures taken by Kara Moore at Dr. James Lampien's place of residence in Fayetteville, AR on October 28, 2013. 
Contradictory Cap Item B

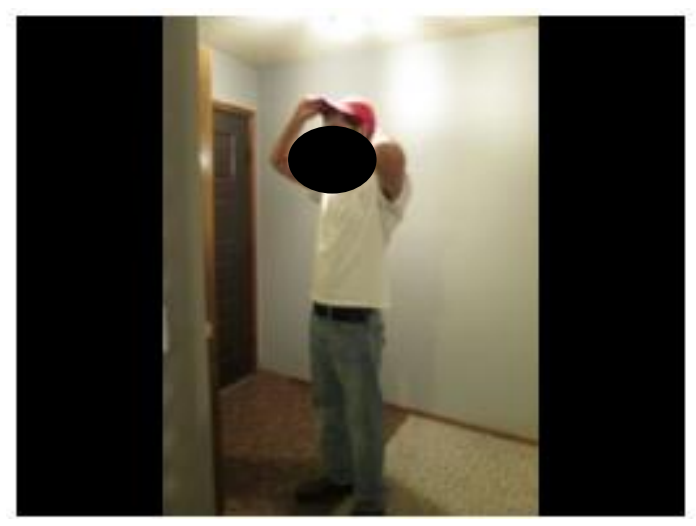

Slide Twenty Nine

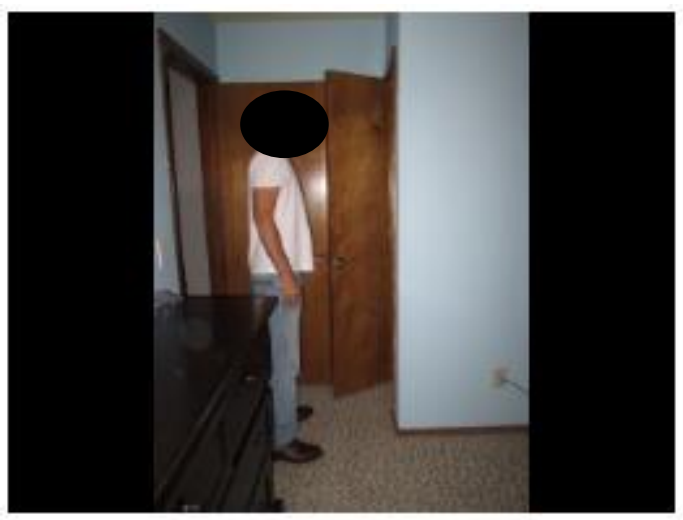

Contradictory Bed Item B

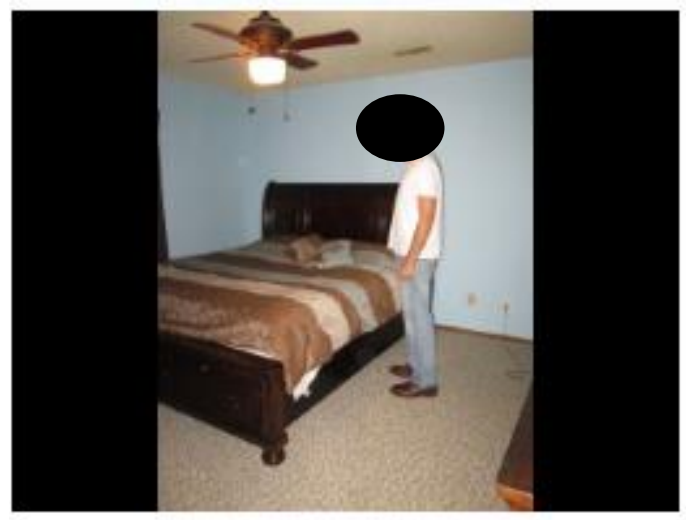

Slide Twenty Eight

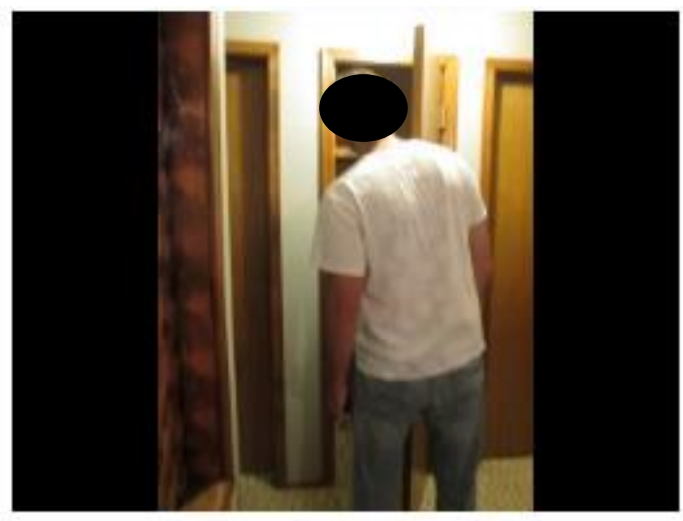

Contradictory Bed Item A

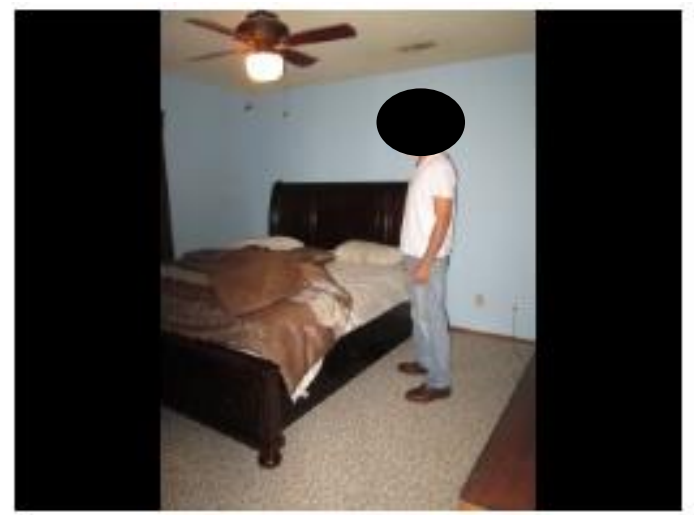

Slide Thirty

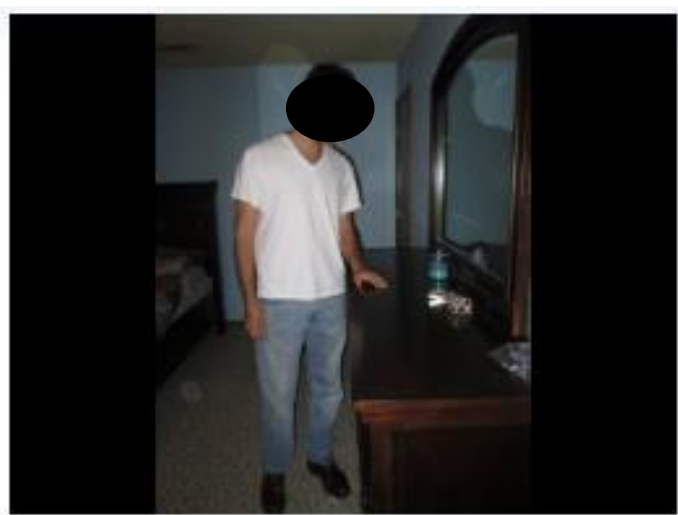

Pictures taken by Kara Moore at Dr. James Lampien's place of residence in Fayetteville, AR on October 28, 2013. 
Contradictory Jewelry Item A

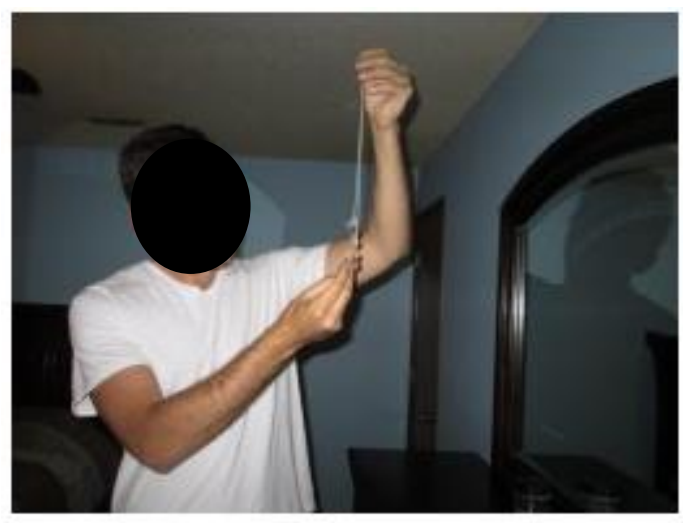

Contradictory Jewelry Item B

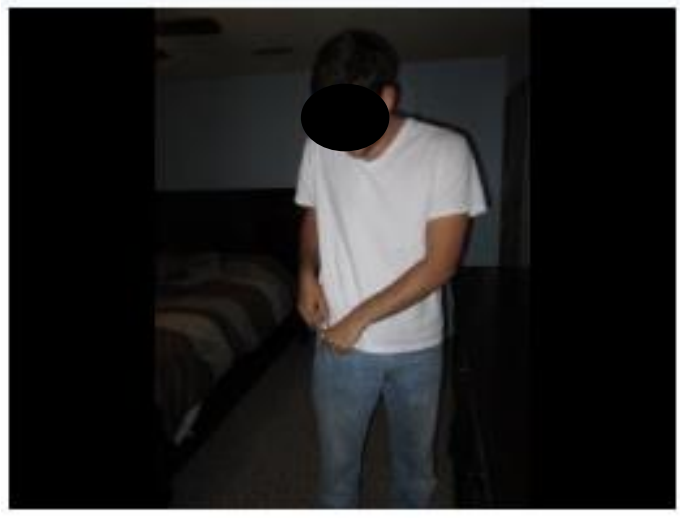

Contradictory Jewelry Item $2 \mathrm{~A}$

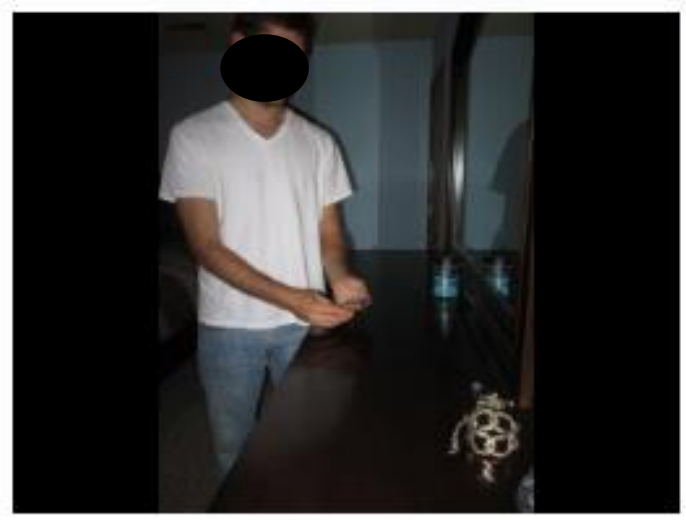

Contradictory Jewelry Item A

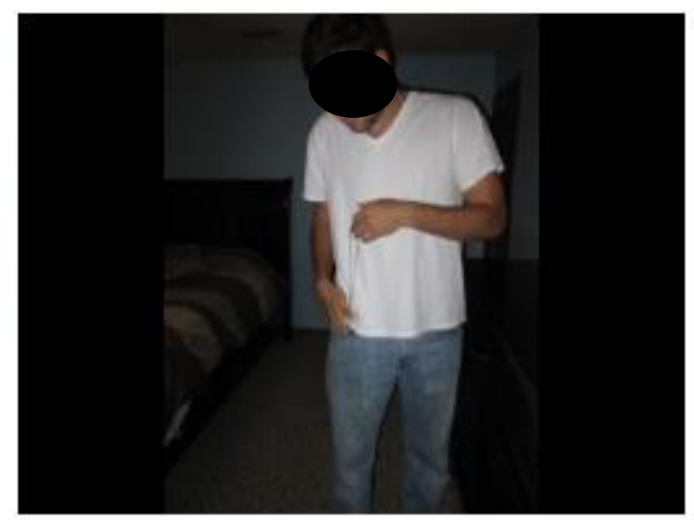

Contradictory Jewelry Item B

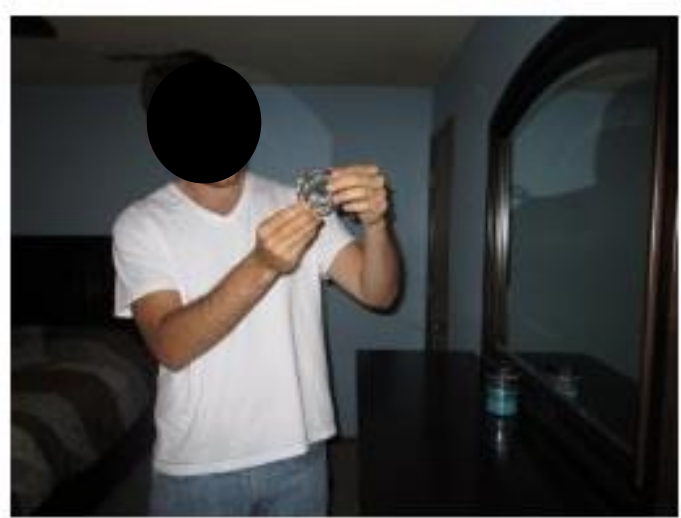

Contradictory Jewelry Item 2A

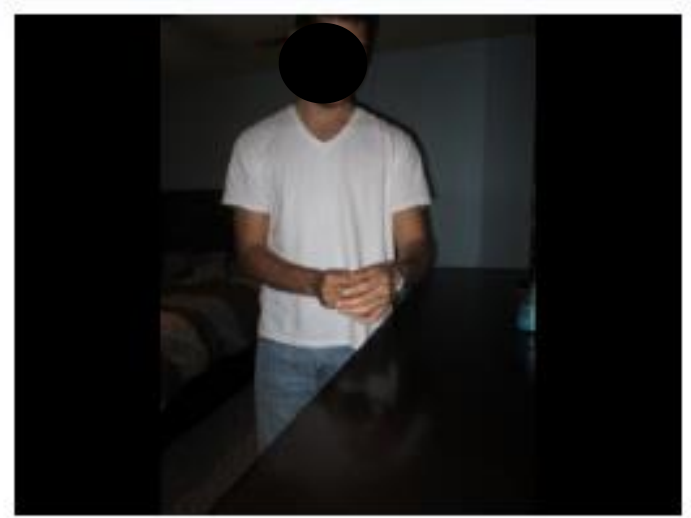

Pictures taken by Kara Moore at Dr. James Lampien's place of residence in Fayetteville, AR on October 28, 2013. 
Contradictory Jewelry Item 2B

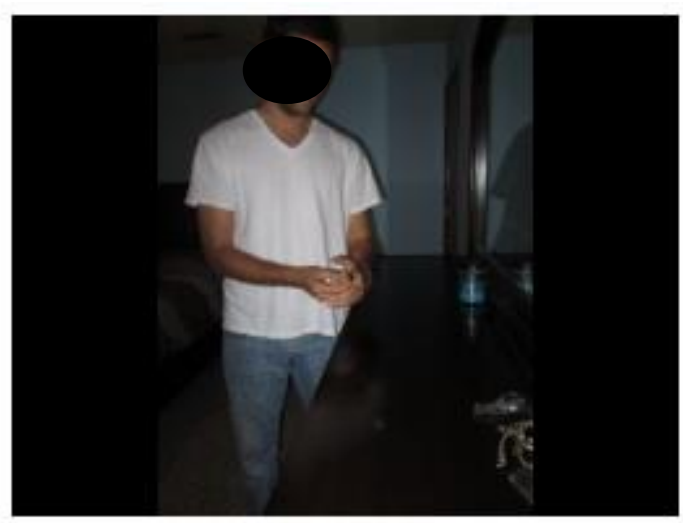

Slide Thirty One

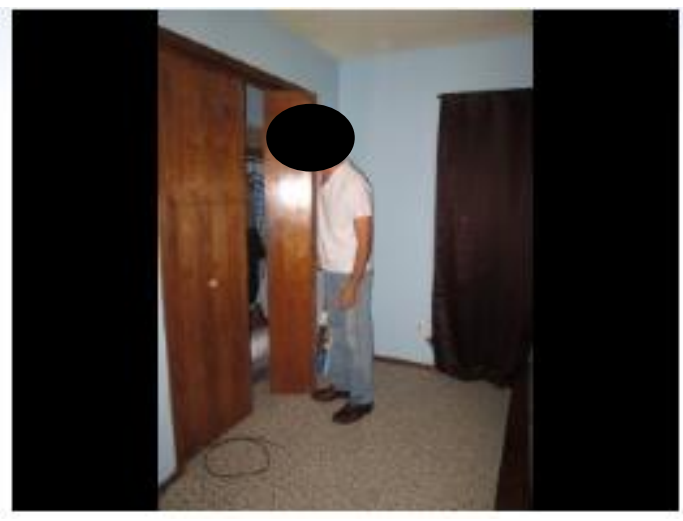

Slide Thirty Three

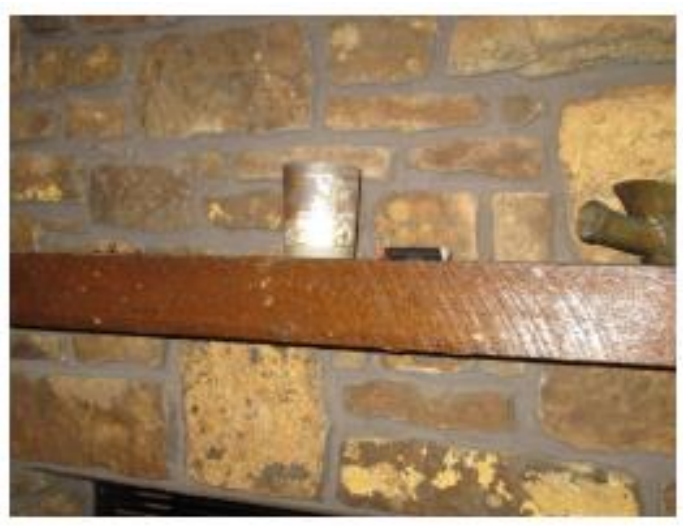

Contradictory Jewelry Item 2B

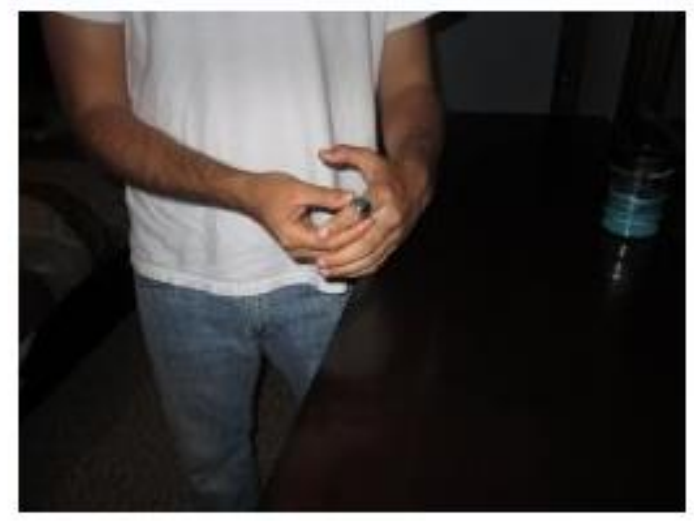

Slide Thirty Two

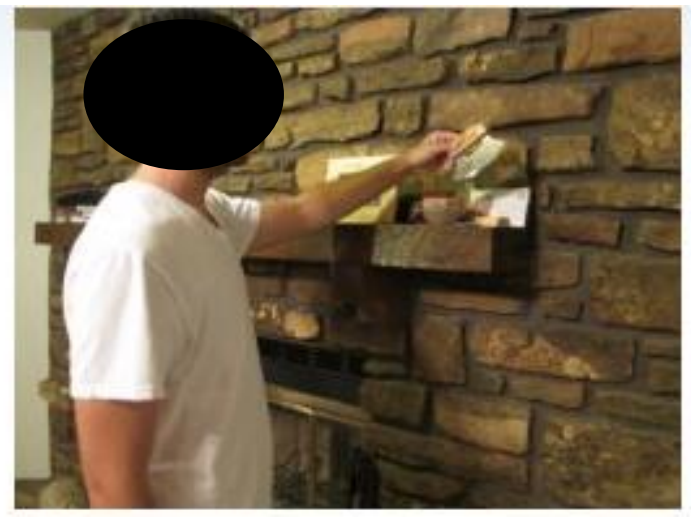

Slide Thirty Four

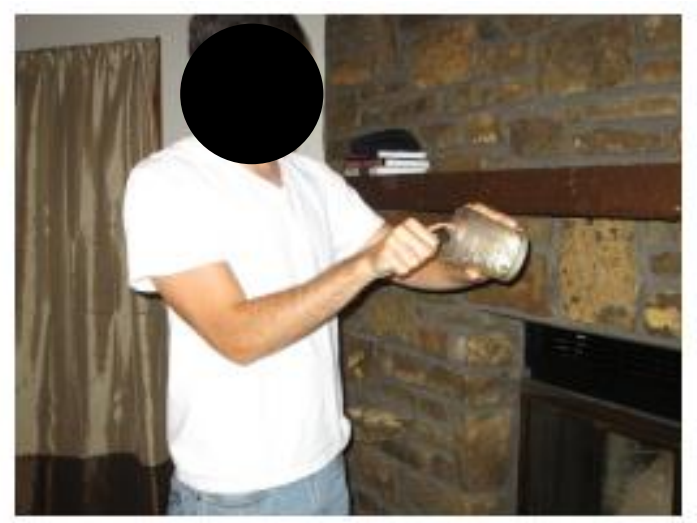

Pictures taken by Kara Moore at Dr. James Lampien's place of residence in Fayetteville, AR on October 28, 2013. 
Slide Thirty Five

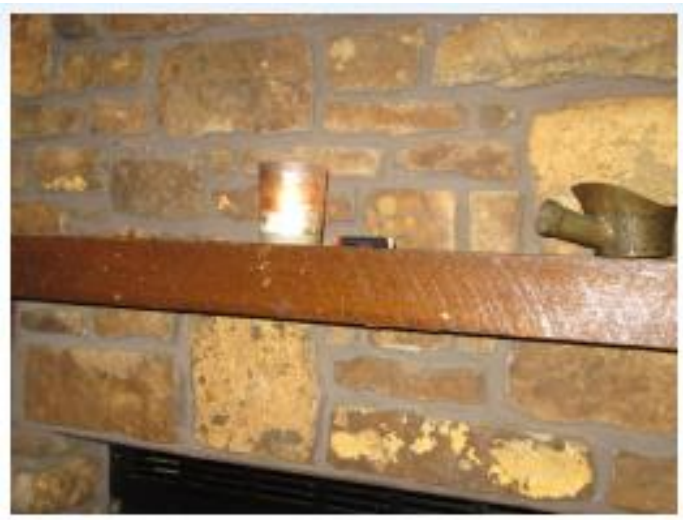

Slide Thirty Seven

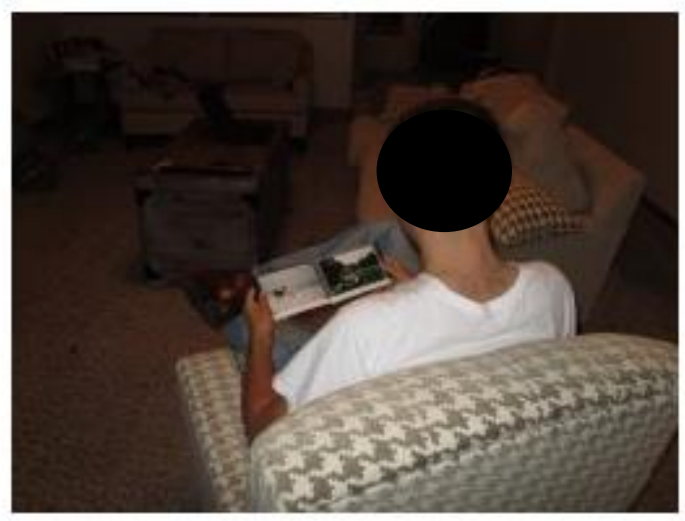

Slide Thirty Nine

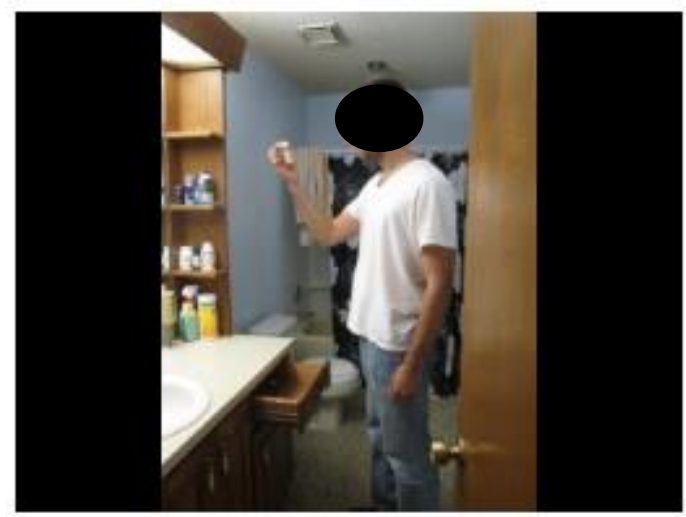

Slide Thirty Six

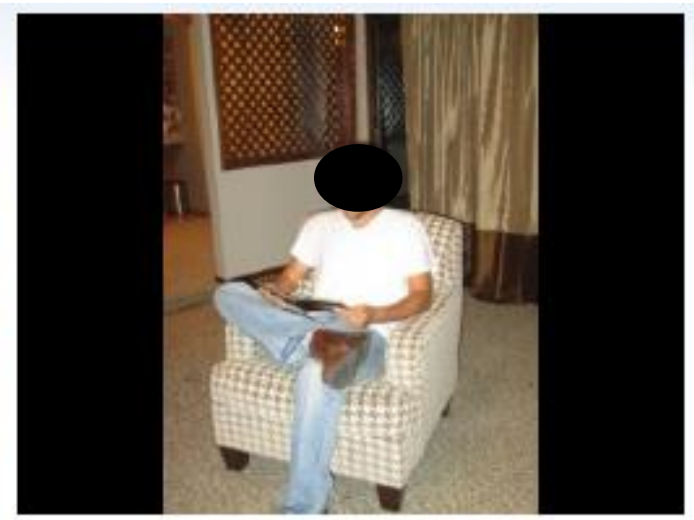

Slide Thirty Eight

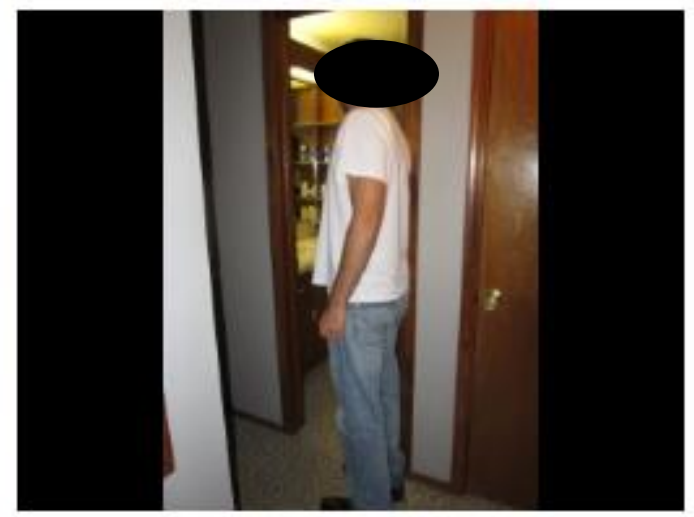

Slide Forty

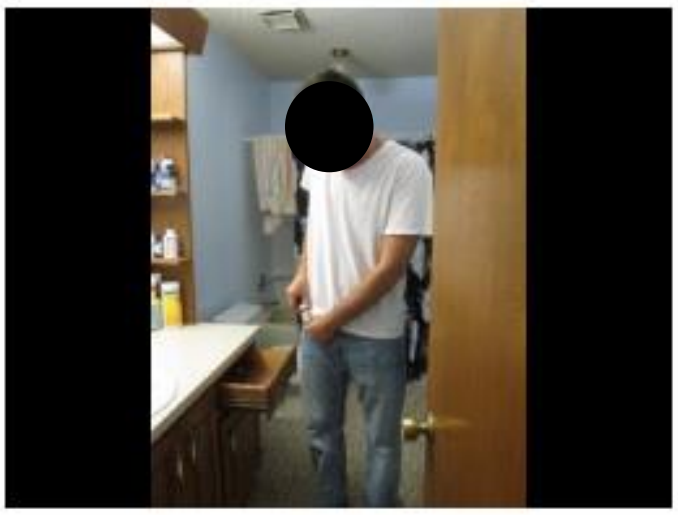

Pictures taken by Kara Moore at Dr. James Lampien's place of residence in Fayetteville, AR on October 28, 2013. 
Appendix C: Adult Information Form

\section{Adult Information Form}

You are participating in the 'Memory for Events' project. Section A asks for your birthdate. Section B asks you some questions about you. Section $C$ is to be filled out by the research assistant on the day you participate. Please complete the information in Sections A and B.

Section A. To Be Completed By You

Date of Birth:

Month:

Day:
Section B. To Be Completed By You

Are you male or female?

How would you describe your race/ethnicity?

What languages do you speak?

Are you a native English speaker?

Section C. To Be Completed By Research Assistant

Participant Number:

What condition is the participant in?

Note: Once all sessions are completed, Section A will be cut away from this form and shredded to preserve your confidentiality. 
Appendix D: Critical Item Counterbalance

\begin{tabular}{|l|l|l|l|l|l|}
\hline & Narrative 1 \& 4 & Narrative 2 \& 5 & Narrative 3 \& 6 & $\begin{array}{l}\text { Suggested } \\
(\mathrm{N} 1,2,3) \text { A }\end{array}$ & $\begin{array}{l}\text { Suggested } \\
(\mathrm{N} 4,5,6) \text { B }\end{array}$ \\
\hline Magazine & Unrelated & Additive & Contradictory & Time & People \\
\hline Tries On & Unrelated & Additive & Contradictory & Ring & Watch \\
\hline Key & Unrelated & Additive & Contradictory & Flower Pot & Doormat \\
\hline Bed & Additive & Contradictory & Unrelated & Made & Unmade \\
\hline $\begin{array}{l}\text { Note } \\
\text { Location }\end{array}$ & Additive & Contradictory & Unrelated & Kitchen & $\begin{array}{l}\text { Living } \\
\text { Room }\end{array}$ \\
\hline Fruit & Additive & Contradictory & Unrelated & Apple & Banana \\
\hline Soda & Contradictory & Unrelated & Additive & Coca-Cola & Pepsi \\
\hline Jewelry & Contradictory & Unrelated & Additive & Bracelet & Necklace \\
\hline $\begin{array}{l}\text { Baseball } \\
\text { cap }\end{array}$ & Contradictory & Unrelated & Additive & Red & Black \\
\hline
\end{tabular}




\section{Appendix E: Narratives}

Contradictory items are in bold and Additive items are underlined.

Narrative One

One afternoon, Eric Lewis, an average looking (although dishonest) guy with brown hair, had a job at a house in the city. Eric pulled up to the house and parked in the driveway. After getting his yellow tool box out of the van, Eric went to the front door.

He unlocked the door and walked into the house, where he found a note from the homeowner on the counter in the kitchen. After reading the note, Eric put his tool box down. Although being an electrician could get boring, one thing Eric liked about his job was that he could be nosy. He walked into the kitchen and began looking around. He saw a basket of fruit and, thinking he was hungry, he took an apple. After taking a bite, he continued looking around the kitchen but found nothing interesting in the kitchen cabinets. Thinking he should get down to work, Eric walked over to the broken oven and bent down to examine it. Eric took the pliers from his pocket and fixed the loose oven handle. Once his kitchen repair was finished, he was feeling thirsty so he helped himself to a Coca-Cola from the fridge. Always curious about the secret lives of his customers, Eric rummaged through a pile of papers next to a dog leash on the built-in desk, but there wasn't much interesting there either. In the drawers, Eric found blank checks and decided to pocket them.

Next, Eric walked into the living room and noticed some CDs lying out. He started to look through the pile of CDs. After selecting a CD by "The Band" that he knew he would enjoy, Eric placed it in the stereo, thinking he would listen to it while he finished his work in the living room. Eric decided to sit down on the couch. After a little time passed, Eric began to feel a little guilty and decided it was time to get back to work. He started by examining a piece of siding on the back door that had been torn down, perhaps by a dog. He retrieved his hammer and put the siding back up. Then he knelt down to fix one of the electrical sockets that the homeowners said was not working. Once that was done, Eric got up to have a look around the room.

He found a hall closet and opened it to examine its contents. He tried on a red cap and checked his reflection in the mirror, but he didn't really like the way it looked on him so he put it back. Next, Eric looked through another hall closet but it only contained towels.

Eric then headed to the master bedroom. He searched through one closet but found nothing interesting. He examined the bedspread on the nicely made-up bed. He thought he might like to get a bedspread like the one on the bed for himself. Eric checked out the items on the dresser, including some jewelry. He picked up a bracelet, which he inspected carefully and — thinking of his girlfriend's upcoming birthday_-slipped it into his pocket.

Since his work was done, Eric decided that he deserved to relax for a while. He headed back into the living room and looked around again. He found some interesting knick-knacks on the 
fireplace mantle and examined them. He also lit a candle that was on the fireplace mantle with a black lighter. He sat down on the patterned chair, finding a photo album that was lying on the wooden coffee table and flicked through it. Realizing he needed to get to his next job, Eric got up and turned the CD off. He retrieved the CD from the stereo and put it back. On his way out, Eric decided to have a quick look through the bathroom cabinet, where he pocketed some prescription pills that he thought he might be able to sell. By now, he was late for his next job, so Eric hurried to the door and closed it behind him as he left.

\section{Narrative Two}

One afternoon, Eric Lewis, an average looking (although dishonest) guy with brown hair, had a job at a house in the city. Eric pulled up to the house and parked in the driveway. After getting his yellow tool box out of the van, Eric went to the front door and retrieved the key that was left for him from under a flowerpot.

He unlocked the door and walked into the house, where he found a note from the homeowners on the counter in the kitchen. After reading the note, Eric put his tool box down. Although being an electrician could get boring, one thing Eric liked about his job was that he could be nosy. He walked into the kitchen and began looking around. He saw a basket of fruit and, thinking he was hungry, he took an apple. After taking a bite, he continued looking around the kitchen but found nothing interesting in the kitchen cabinets. Thinking he should get down to work, Eric walked over to the broken oven and bent down to examine it. Eric took the pliers from his pocket and fixed the loose oven handle. Once his kitchen repair was finished, he then looked in the fridge to see he could find anything to drink. Always curious about the secret lives of his customers, Eric rummaged through a pile of papers next to a dog leash on the kitchen bench, but there wasn't much interesting there either. In the drawers, Eric found blank checks and decided to pocket them.

Next, Eric walked into the living room and noticed some CDs lying out. He started to look through the pile of CDs. After selecting a CD by "The Band" that he knew he would enjoy, Eric placed it in the stereo, thinking he would listen to it while he finished his work in the living room. Eric sat down on the couch to read Time magazine, but found it boring, and tossed it back on the floor. After a little time passed, Eric began to feel a little guilty and decided it was time to get back to work. He started by examining a piece of siding on the back door that had been torn down, perhaps by a dog. He retrieved his hammer and put the siding back up. He knelt down to fix one of the electrical sockets that the homeowners said was not working. Once that was done, Eric got up to have a look around the room.

He found a hall closet and examined its contents. Eric did not find anything that interested him there. Next, Eric looked through another hall closet but it only contained towels. Then Eric headed to the master bedroom. He searched through one closet but found nothing interesting. He examined the bedspread on the nicely made-up bed. He thought he might like to get a bedspread 
like the one on the bed for himself. Eric checked out the items on the dresser, including some jewelry. He found a ring that fit him nicely and slipped it into his pocket.

Since his work was done, Eric decided that he deserved to relax for a while. He headed back into the living room and looked around again. He found some interesting knick-knacks on the fireplace mantle and examined them. He also lit a candle with a black lighter. He sat down on the patterned chair, finding a photo album that was lying on the wooden coffee table and flicked through it. Realizing he needed to get to his next job, Eric got up and turned the CD off. He retrieved the $\mathrm{CD}$ from the stereo and put it back. On his way out, Eric decided to have a quick look through the bathroom cabinet, where he pocketed some prescription pills that he thought he might be able to sell. By now, he was late for his next job, so Eric hurried to the door and closed it behind him as he left.

Narrative Three

One afternoon, Eric Lewis, an average looking (although dishonest) guy with brown hair, had a job at a house in the city. Eric pulled up to the house and parked in the driveway. After getting his yellow tool box out of the van, Eric went to the front door and retrieved the key that was left for him from under a flowerpot.

He unlocked the door and walked into the house. Eric put his tool box down. Although being an electrician could get boring, one thing Eric liked about his job was that he could be nosy. He walked into the kitchen and began looking around. He found nothing interesting in the kitchen cabinets. Thinking he should get down to work, Eric walked over to the broken oven and bent down to examine it. Eric took the pliers from his pocket and fixed the loose oven handle. Once his kitchen repair was finished, he was feeling thirsty so he helped himself to a Coca-Cola from the fridge. Always curious about the secret lives of his customers, Eric rummaged through a pile of papers next to a dog leash on the kitchen bench, but there wasn't much interesting there either. In the drawers, Eric found blank checks and decided to pocket them.

Next, Eric walked into the living room and noticed some CDs lying out. He started to look through the pile of CDs. After selecting a CD by "The Band" that he knew he would enjoy, Eric placed it in the stereo, thinking he would listen to it while he finished his work in the living room. Eric sat down on the couch to read Time magazine, but found it boring, and tossed it back on the floor. After a little time passed, Eric began to feel a little guilty and decided it was time to get back to work. He started by examining a piece of siding on the back door that had been torn down, perhaps by a dog. He retrieved his hammer and put the siding back up. He knelt down to fix one of the electrical sockets that the homeowners said was not working. Once that was done, Eric got up to have a look around the room.

He found a hall closet and examined its contents. He tried on a red cap and checked his reflection in the mirror, but he didn't really like the way it looked on him so he put it back. Next, Eric looked through another hall closet but it only contained towels. Then Eric headed to the master 
bedroom. He searched through one closet but found nothing interesting. He thought he might like to get a bedspread like the one on the bed for himself. Eric checked out the items on the dresser, including some jewelry. He picked up a bracelet, which he inspected carefully and — thinking of his girlfriend's upcoming birthday — slipped it into his pocket. He also found a ring that fit him nicely and slipped it into his pocket.

Since his work was done, Eric decided that he deserved to relax for a while. He headed back into the living room and looked around again. He found some interesting knick-knacks on the fireplace mantle and examined them. He also lit a candle with a black lighter. He sat down on the patterned chair, finding a photo album that was lying on the wooden coffee table and flicked through it. Realizing he needed to get to his next job, Eric got up and turned the CD off. He retrieved the $\mathrm{CD}$ from the stereo and put it back. On his way out, Eric decided to have a quick look through the bathroom cabinet, where he pocketed some prescription pills that he thought he might be able to sell. By now, he was late for his next job, so Eric hurried to the door and closed it behind him as he left.

\section{Narrative Four}

One afternoon, Eric Lewis, an average looking (although dishonest) guy with brown hair, had a job at a house in the city. Eric pulled up to the house and parked in the driveway. After getting his yellow tool box out of the van, Eric went to the front door.

He unlocked the door and walked into the house, where he found a note from the homeowners on the end table in the living room. After reading the note, Eric put his tool box down. Although being an electrician could get boring, one thing Eric liked about his job was that he could be nosy. He walked into the kitchen and began looking around. He saw a basket of fruit and, thinking he was hungry, he took a banana. After taking a bite, he continued looking around the kitchen but found nothing interesting in the kitchen cabinets. Thinking he should get down to work, Eric walked over to the broken oven and bent down to examine it. Eric took the pliers from his pocket and fixed the loose oven handle. Once his kitchen repair was finished, he was feeling thirsty so he helped himself to a Pepsi from the fridge. Always curious about the secret lives of his customers, Eric rummaged through a pile of papers next to a dog leash on the built-in desk, but there wasn't much interesting there either. In the drawers, Eric found blank checks and decided to pocket them.

Next, Eric walked into the living room and noticed some CDs lying out. He started to look through the pile of CDs. After selecting a CD by "The Band" that he knew he would enjoy, Eric placed it in the stereo, thinking he would listen to it while he finished his work in the living room. Eric decided to sit down on the couch. After a little time passed, Eric began to feel a little guilty and decided it was time to get back to work. He started by examining a piece of siding on the back door that had been torn down, perhaps by a dog. He retrieved his hammer and put the 
siding back up. Then he knelt down to fix one of the electrical sockets that the homeowners said was not working. Once that was done, Eric got up to have a look around the room.

He found a hall closet and opened it to examine its contents. He tried on a black cap and checked his reflection in the mirror, but he didn't really like the way it looked on him so he put it back. Next, Eric looked through another hall closet but it only contained towels.

Eric then headed to the master bedroom. He searched through one closet but found nothing interesting. He examined the bedspread on the unmade bed. He thought he might like to get a bedspread like the one on the bed for himself. Eric checked out the items on the dresser, including some jewelry. He picked up a necklace, which he inspected carefully and - thinking of his girlfriend's upcoming birthday_-slipped it into his pocket.

Since his work was done, Eric decided that he deserved to relax for a while. He headed back into the living room and looked around again. He found some interesting knick knacks on the fireplace mantle and examined them. He also lit a candle that was on the fireplace mantle with a black lighter. He sat down on the patterned chair, finding a photo album that was lying on the wooden coffee table and flipped through it. Realizing he needed to get to his next job, Eric got up and turned the CD off. He retrieved the CD from the stereo and put it back. On his way out, Eric decided to have a quick look through the bathroom cabinet, where he pocketed some prescription pills that he thought he might be able to sell. By now, he was late for his next job, so Eric hurried to the door and closed it behind him as he left.

Narrative Five

One afternoon, Eric Lewis, an average looking (although dishonest) guy with brown hair, had a job at a house in the city. Eric pulled up to the house and parked in the driveway. After getting his yellow tool box out of the van, Eric went to the front door and retrieved the key that was left for him from under a doormat.

He unlocked the door and walked into the house, where he found a note from the homeowners on the end table in the living room. After reading the note, Eric put his tool box down. Although being an electrician could get boring, one thing Eric liked about his job was that he could be nosy. He walked into the kitchen and began looking around. He saw a basket of fruit and, thinking he was hungry, took a banana. After taking a bite, he continued looking around the kitchen but found nothing interesting in the kitchen cabinets. Thinking he should get down to work, Eric walked over to the broken oven and bent down to examine it. Eric took the pliers from his pocket and fixed the loose oven handle. Once his kitchen repair was finished, he then looked in the fridge to see he could find anything to drink. Always curious about the secret lives of his customers, Eric rummaged through a pile of papers next to a dog leash on the kitchen bench, but there wasn't much interesting there either. In the drawers, Eric found blank checks and decided to pocket them. 
Next, Eric walked into the living room and noticed some CDs lying out. He started to look through the pile of CDs. After selecting a CD by "The Band" that he knew he would enjoy, Eric placed it in the stereo, thinking he would listen to it while he finished his work in the living room. Eric sat down on the couch to read People magazine, but found it boring, and tossed it back on the floor. After a little time passed, Eric began to feel a little guilty and decided it was time to get back to work. He started by examining a piece of siding on the back door that had been torn down, perhaps by a dog. He retrieved his hammer and put the siding back up. He knelt down to fix one of the electrical sockets that the homeowners said was not working. Once that was done, Eric got up to have a look around the room.

He found a hall closet and examined its contents. Eric did not find anything that interested him there. Next, Eric looked through another hall closet but it only contained towels. Then Eric headed to the master bedroom. He searched through one closet but found nothing interesting. He examined the bedspread on the unmade bed. He thought he might like to get a bedspread like the one on the bed for himself. Eric checked out the items on the dresser, including some jewelry. He found a watch that fit him nicely and slipped it into his pocket.

Since his work was done, Eric decided that he deserved to relax for a while. He headed back into the living room and looked around again. He found some interesting knick-knacks on the fireplace mantle and examined them. He also lit a candle with a black lighter. He sat down on the patterned chair, finding a photo album that was lying on the wooden coffee table and flicked through it. Realizing he needed to get to his next job, Eric got up and turned the CD off. He retrieved the $\mathrm{CD}$ from the stereo and put it back. On his way out, Eric decided to have a quick look through the bathroom cabinet, where he pocketed some prescription pills that he thought he might be able to sell. By now, he was late for his next job, so Eric hurried to the door and closed it behind him as he left.

\section{Narrative Six}

One afternoon, Eric Lewis, an average looking (although dishonest) guy with brown hair, had a job at a house in the city. Eric pulled up to the house and parked in the driveway. After getting his yellow tool box out of the van, Eric went to the front door and retrieved the key that was left for him from under a doormat.

He unlocked the door and walked into the house. Eric put his tool box down. Although being an electrician could get boring, one thing Eric liked about his job was that he could be nosy. He walked into the kitchen and began looking around. He found nothing interesting in the kitchen cabinets. Thinking he should get down to work, Eric walked over to the broken oven and bent down to examine it. Eric took the pliers from his pocket and fixed the loose oven handle. Once his kitchen repair was finished, he was feeling thirsty so he helped himself to a Pepsi from the fridge. Always curious about the secret lives of his customers, Eric rummaged through a pile of 
papers next to a dog leash on the kitchen bench, but there wasn't much interesting there either. In the drawers, Eric found blank checks and decided to pocket them.

Next, Eric walked into the living room and noticed some CDs lying out. He started to look through the pile of CDs. After selecting a CD by "The Band" that he knew he would enjoy, Eric placed it in the stereo, thinking he would listen to it while he finished his work in the living room. Eric sat down on the couch to read People magazine, but found it boring, and tossed it back on the floor. After a little time passed, Eric began to feel a little guilty and decided it was time to get back to work. He started by examining a piece of siding on the back door that had been torn down, perhaps by a dog. He retrieved his hammer and put the siding back up. He knelt down to fix one of the electrical sockets that the homeowners said was not working. Once that was done, Eric got up to have a look around the room.

He found a hall closet and examined its contents. He tried on a black cap and checked his reflection in the mirror, but he didn't really like the way it looked on him so he put it back. Next, Eric looked through another hall closet but it only contained towels. Then Eric headed to the master bedroom. He searched through one closet but found nothing interesting. He thought he might like to get a bedspread like the one on the bed for himself. Eric checked out the items on the dresser, including some jewelry. He picked up a necklace, which he inspected carefully and - thinking of his girlfriend's upcoming birthday — slipped it into his pocket. He also found a watch that fit him nicely and slipped it into his pocket.

Since his work was done, Eric decided that he deserved to relax for a while. He headed back into the living room and looked around again. He found some interesting knick-knacks on the fireplace mantle and examined them. He also lit a candle with a black lighter. He sat down on the patterned chair, finding a photo album that was lying on the wooden coffee table and flipped through it. Realizing he needed to get to his next job, Eric got up and turned the CD off. He retrieved the $\mathrm{CD}$ from the stereo and put it back. On his way out, Eric decided to have a quick look through the bathroom cabinet, where he pocketed some prescription pills that he thought he might be able to sell. By now, he was late for his next job, so Eric hurried to the door and closed it behind him as he left. 
Appendix F: Test One

Test for Narratives 1, 2, \& 3 .

You will now be asked some questions about the video you saw. We are testing your memory for this video.

Each question has three parts:

1) the first part asks you about a particular item from the video;

2) the second part asks you how confident you are about your answer.

3) the third part asks you to explain the reasons for your answer.

Please complete all three steps for every question.

WHEN YOU HAVE READ AND UNDERSTOOD HOW TO ANSWER THESE QUESTIONS, TURN OVER THE PAGE AND BEGIN THE TEST. 
1) The man read a Time magazine.

Yes

No

How confident are you that your answer is correct?

$\begin{array}{llll}1 & 2 & 3 & 4 \\ \text { Not at all } & \text { Somewhat } & \text { Moderately } & \text { Extremely } \\ \text { confident } & \text { Confident } & \text { Confident } & \text { Confident }\end{array}$

2) There was a bag of dog food on the kitchen counter.

Yes No

How confident are you that your answer is correct?

$\begin{array}{llll}1 & 2 & 3 & 4 \\ \text { Not at all } & \text { Somewhat } & \text { Moderately } & \text { Extremely } \\ \text { confident } & \text { Confident } & \text { Confident } & \text { Confident }\end{array}$

The man drank a Coca-Cola that he got from the

3) fridge.

Yes

No

How confident are you that your answer is correct?

$\begin{array}{llll}1 & 2 & 3 & 4 \\ \text { Not at all } & \text { Somewhat } & \text { Moderately } & \text { Extremely } \\ \text { confident } & \text { Confident } & \text { Confident } & \text { Confident }\end{array}$

4) The bed in the bedroom was made.

Yes

No

How confident are you that your answer is correct?

$\begin{array}{llll}1 & 2 & 3 & 4 \\ \text { Not at all } & \text { Somewhat } & \text { Moderately } & \text { Extremely } \\ \text { confident } & \text { Confident } & \text { Confident } & \text { Confident }\end{array}$

Please explain the reasons for your answer.
Please explain the reasons for your answer.
Please explain the reasons for your answer.
Please explain the reasons for your answer. 
5) The man sat in a patterned chair.

Yes

No

How confident are you that your answer is correct?

$\begin{array}{llll}1 & 2 & 3 & 4 \\ \text { Not at all } & \text { Somewhat } & \text { Moderately } & \text { Extremely } \\ \text { confident } & \text { Confident } & \text { Confident } & \text { Confident }\end{array}$

There was a white microwave on the kitchen

6) counter.

Yes

No

How confident are you that your answer is correct?

$\begin{array}{llll}1 & 2 & 3 & 4 \\ \text { Not at all } & \text { Somewhat } & \text { Moderately } & \text { Extremely } \\ \text { confident } & \text { Confident } & \text { Confident } & \text { Confident }\end{array}$

The man read a note from the homeowners in the

7) kitchen.

Yes

No

How confident are you that your answer is correct?

$\begin{array}{llll}1 & 2 & 3 & 4 \\ \text { Not at all } & \text { Somewhat } & \text { Moderately } & \text { Extremely } \\ \text { confident } & \text { Confident } & \text { Confident } & \text { Confident }\end{array}$

8) The man had blonde hair.

Yes No

How confident are you that your answer is correct?

$\begin{array}{llll}1 & 2 & 3 & 4 \\ \text { Not at all } & \text { Somewhat } & \text { Moderately } & \text { Extremely } \\ \text { confident } & \text { Confident } & \text { Confident } & \text { Confident }\end{array}$

Please explain the reasons for your answer.

Please explain the reasons for your answer.

Please explain the reasons for your answer.
Please explain the reasons for your answer. 
9) The man tried on a ring in the bedroom.

Yes

No

How confident are you that your answer is correct?

$\begin{array}{llll}1 & 2 & 3 & 4 \\ \text { Not at all } & \text { Somewhat } & \text { Moderately } & \text { Extremely } \\ \text { confident } & \text { Confident } & \text { Confident } & \text { Confident }\end{array}$

10) The man listened to a CD by "The Band".

Yes

No

How confident are you that your answer is correct?

$\begin{array}{llll}1 & 2 & 3 & 4 \\ \text { Not at all } & \text { Somewhat } & \text { Moderately } & \text { Extremely } \\ \text { confident } & \text { Confident } & \text { Confident } & \text { Confident }\end{array}$

11) The man stole a credit card from a drawer.

Yes

No

How confident are you that your answer is correct?

$\begin{array}{llll}1 & 2 & 3 & 4 \\ \text { Not at all } & \text { Somewhat } & \text { Moderately } & \text { Extremely } \\ \text { confident } & \text { Confident } & \text { Confident } & \text { Confident }\end{array}$

12) The man stole a bracelet.

Yes

No

How confident are you that your answer is correct?

$\begin{array}{llll}1 & 2 & 3 & 4 \\ \text { Not at all } & \text { Somewhat } & \text { Moderately } & \text { Extremely } \\ \text { confident } & \text { Confident } & \text { Confident } & \text { Confident }\end{array}$

Please explain the reasons for your answer.

Please explain the reasons for your answer.

Please explain the reasons for your answer.

Please explain the reasons for your answer. 
13) The man fixed an electrical socket.

Yes

No

How confident are you that your answer is correct?

1

Not at all

2

Somewhat

3

confident
Extremely
Confident

14) The man ate an apple.

Yes

No

How confident are you that your answer is correct?

1 2

3

4

Not at all

Somewhat

Moderately

Extremely

confident

Confident
Please explain the reasons for your answer.
Please explain the reasons for your answer.

15) The man looked through a photo album.

Yes

No

How confident are you that your answer is correct?

$\begin{array}{llll}1 & 2 & 3 & 4 \\ \text { Not at all } & \text { Somewhat } & \text { Moderately } & \text { Extremely } \\ \text { confident } & \text { Confident } & \text { Confident } & \text { Confident }\end{array}$

The man wore a white

16) shirt.

Please explain the

Yes

No

reasons for your answer.

How confident are you that your answer is correct?

$\begin{array}{llll}1 & 2 & 3 & 4 \\ \text { Not at all } & \text { Somewhat } & \text { Moderately } & \text { Extremely } \\ \text { confident } & \text { Confident } & \text { Confident } & \text { Confident }\end{array}$


17) The man stole pills from the bathroom.

Yes

No

How confident are you that your answer is correct?

$\begin{array}{llll}1 & 2 & 3 & 4\end{array}$

Not at all Somewhat Moderately Extremely

confident Confident Confident Confident

18) The man tried on a red cap.

Yes

No

How confident are you that your answer is correct?

$\begin{array}{llll}1 & 2 & 3 & 4\end{array}$

Not at all Somewhat Moderately Extremely

confident Confident Confident Confident

19) The man lit a candle with a black lighter.

Yes

No

How confident are you that your answer is correct?

$\begin{array}{llll}1 & 2 & 3 & 4\end{array}$

Not at all Somewhat Moderately Extremely

confident Confident Confident Confident

20) There was a treadmill in the living room.

Yes

No

How confident are you that your answer is correct?

$\begin{array}{llll}1 & 2 & 3 & 4 \\ \text { Not at all } & \text { Somewhat } & \text { Moderately } & \text { Extremely } \\ \text { confident } & \text { Confident } & \text { Confident } & \text { Confident }\end{array}$

Please explain the reasons for your answer.

Please explain the reasons for your answer.

Please explain the reasons for your answer.

Please explain the reasons for your answer. 
21) The man picked up a blue coffee mug.

Yes

No

How confident are you that your answer is correct?

$\begin{array}{llll}1 & 2 & 3 & 4 \\ \text { Not at all } & \text { Somewhat } & \text { Moderately } & \text { Extremely } \\ \text { confident } & \text { Confident } & \text { Confident } & \text { Confident }\end{array}$

The man used a hammer to fix the siding on the door

22) frame.

Yes

No

How confident are you that your answer is correct?

$\begin{array}{llll}1 & 2 & 3 & 4 \\ \text { Not at all } & \text { Somewhat } & \text { Moderately } & \text { Extremely } \\ \text { confident } & \text { Confident } & \text { Confident } & \text { Confident }\end{array}$

The man found the key to the door under a flower

23) pot.

Yes

No

How confident are you that your answer is correct?

$\begin{array}{llll}1 & 2 & 3 & 4 \\ \text { Not at all } & \text { Somewhat } & \text { Moderately } & \text { Extremely } \\ \text { confident } & \text { Confident } & \text { Confident } & \text { Confident }\end{array}$

24) The man carried a yellow tool box.

Yes

No

How confident are you that your answer is correct?

$\begin{array}{llll}1 & 2 & 3 & 4 \\ \text { Not at all } & \text { Somewhat } & \text { Moderately } & \text { Extremely } \\ \text { confident } & \text { Confident } & \text { Confident } & \text { Confident }\end{array}$

Please explain the reasons for your answer.

Please explain the reasons for your answer.

Please explain the reasons for your answer.

Please explain the reasons for your answer. 


\section{Appendix G: Test Two}

Test for Narratives 4, 5, \& 6 .

You will now be asked some questions about the video you saw. We are testing your memory for this video.

Each question has three parts:

1) the first part asks you about a particular item from the video;

2 ) the second part asks you how confident you are about your answer.

3 ) the third part asks you to explain the reasons for your answer.

Please complete all three steps for every question.

WHEN YOU HAVE READ AND UNDERSTOOD HOW TO ANSWER THESE QUESTIONS, TURN OVER THE PAGE AND BEGIN THE TEST. 
1) The man read a People magazine.

Yes

No

How confident are you that your answer is correct?

$\begin{array}{llll}1 & 2 & 3 & 4 \\ \text { Not at all } & \text { Somewhat } & \text { Moderately } & \text { Extremely } \\ \text { confident } & \text { Confident } & \text { Confident } & \text { Confident }\end{array}$

2) There was a bag of dog food on the kitchen counter. Yes No

How confident are you that your answer is correct?

$\begin{array}{llll}1 & 2 & 3 & 4 \\ \text { Not at all } & \text { Somewhat } & \text { Moderately } & \text { Extremely } \\ \text { confident } & \text { Confident } & \text { Confident } & \text { Confident }\end{array}$

3) The man drank a Pepsi that he got from the fridge. Yes No

How confident are you that your answer is correct?

$\begin{array}{llll}1 & 2 & 3 & 4 \\ \text { Not at all } & \text { Somewhat } & \text { Moderately } & \text { Extremely } \\ \text { confident } & \text { Confident } & \text { Confident } & \text { Confident }\end{array}$

4) The bed in the bedroom was unmade.

Yes

No

How confident are you that your answer is correct?

$\begin{array}{llll}1 & 2 & 3 & 4 \\ \text { Not at all } & \text { Somewhat } & \text { Moderately } & \text { Extremely } \\ \text { confident } & \text { Confident } & \text { Confident } & \text { Confident }\end{array}$

Please explain the reasons for your answer.

Please explain the reasons for your answer.

Please explain the reasons for your answer.

Please explain the reasons for your answer. 
5) The man sat in a patterned chair.

Yes

No

How confident are you that your answer is correct?

$\begin{array}{llll}1 & 2 & 3 & 4\end{array}$

Not at all Somewhat Moderately Extremely

confident Confident Confident Confident

6) There was a white microwave on the kitchen counter.

Yes

No

How confident are you that your answer is correct?

$\begin{array}{llll}1 & 2 & 3 & 4 \\ \text { Not at all } & \text { Somewhat } & \text { Moderately } & \text { Extremely } \\ \text { confident } & \text { Confident } & \text { Confident } & \text { Confident }\end{array}$

7) The man read a note from the homeowners in the living room.

Yes

No

How confident are you that your answer is correct?

$\begin{array}{llll}1 & 2 & 3 & 4 \\ \text { Not at all } & \text { Somewhat } & \text { Moderately } & \text { Extremely } \\ \text { confident } & \text { Confident } & \text { Confident } & \text { Confident }\end{array}$

8) The man had blonde hair.

Yes

No

How confident are you that your answer is correct?

$\begin{array}{llll}1 & 2 & 3 & 4 \\ \text { Not at all } & \text { Somewhat } & \text { Moderately } & \text { Extremely } \\ \text { confident } & \text { Confident } & \text { Confident } & \text { Confident }\end{array}$

Please explain the reasons for your answer.

Please explain the reasons for your answer.

Please explain the reasons for your answer.

Please explain the reasons for your answer. 
9) The man tried on a watch in the bedroom.

Yes

No

How confident are you that your answer is correct?

$\begin{array}{llll}1 & 2 & 3 & 4 \\ \text { Not at all } & \text { Somewhat } & \text { Moderately } & \text { Extremely } \\ \text { confident } & \text { Confident } & \text { Confident } & \text { Confident }\end{array}$

10) The man listened to a CD by "The Band".

Yes

No

How confident are you that your answer is correct?

$\begin{array}{llll}1 & 2 & 3 & 4 \\ \text { Not at all } & \text { Somewhat } & \text { Moderately } & \text { Extremely } \\ \text { confident } & \text { Confident } & \text { Confident } & \text { Confident }\end{array}$

11) The man stole a credit card from a drawer.

Yes

No

How confident are you that your answer is correct?

$\begin{array}{llll}1 & 2 & 3 & 4 \\ \text { Not at all } & \text { Somewhat } & \text { Moderately } & \text { Extremely } \\ \text { confident } & \text { Confident } & \text { Confident } & \text { Confident }\end{array}$

12) The man stole a necklace.

Yes

No

How confident are you that your answer is correct?

$\begin{array}{llll}1 & 2 & 3 & 4 \\ \text { Not at all } & \text { Somewhat } & \text { Moderately } & \text { Extremely } \\ \text { confident } & \text { Confident } & \text { Confident } & \text { Confident }\end{array}$

Please explain the reasons for your answer.

Please explain the reasons for your answer.

Please explain the reasons for your answer.

Please explain the reasons for your answer. 
13) The man fixed an electrical socket.

Yes

No

How confident are you that your answer is correct?

$\begin{array}{llll}1 & 2 & 3 & 4 \\ \text { Not at all } & \text { Somewhat } & \text { Moderately } & \text { Extremely } \\ \text { confident } & \text { Confident } & \text { Confident } & \text { Confident }\end{array}$

14) The man ate a banana.

Yes

No

How confident are you that your answer is correct?

$\begin{array}{llll}1 & 2 & 3 & 4 \\ \text { Not at all } & \text { Somewhat } & \text { Moderately } & \text { Extremely } \\ \text { confident } & \text { Confident } & \text { Confident } & \text { Confident }\end{array}$

15) The man looked through a photo album.

Yes

No

How confident are you that your answer is correct?

$\begin{array}{llll}1 & 2 & 3 & 4 \\ \text { Not at all } & \text { Somewhat } & \text { Moderately } & \text { Extremely } \\ \text { confident } & \text { Confident } & \text { Confident } & \text { Confident }\end{array}$

16) The man wore a white shirt.

Yes

No

How confident are you that your answer is correct?

$\begin{array}{llll}1 & 2 & 3 & 4 \\ \text { Not at all } & \text { Somewhat } & \text { Moderately } & \text { Extremely } \\ \text { confident } & \text { Confident } & \text { Confident } & \text { Confident }\end{array}$

Please explain the reasons for your answer.

Please explain the reasons for your answer.

Please explain the reasons for your answer.

Please explain the reasons for your answer. 
17) The man stole pills from the bathroom.

Yes

No

How confident are you that your answer is correct?

$\begin{array}{llll}1 & 2 & 3 & 4 \\ \text { Not at all } & \text { Somewhat } & \text { Moderately } & \text { Extremely } \\ \text { confident } & \text { Confident } & \text { Confident } & \text { Confident }\end{array}$

18) The man tried on a black cap.

Yes

No

How confident are you that your answer is correct?

$\begin{array}{llll}1 & 2 & 3 & 4 \\ \text { Not at all } & \text { Somewhat } & \text { Moderately } & \text { Extremely } \\ \text { confident } & \text { Confident } & \text { Confident } & \text { Confident }\end{array}$

19) The man lit a candle with a black lighter.

Yes

No

How confident are you that your answer is correct?

$\begin{array}{llll}1 & 2 & 3 & 4 \\ \text { Not at all } & \text { Somewhat } & \text { Moderately } & \text { Extremely } \\ \text { confident } & \text { Confident } & \text { Confident } & \text { Confident }\end{array}$

20) There was a treadmill in the living room.

Yes

No

How confident are you that your answer is correct?

$\begin{array}{llll}1 & 2 & 3 & 4 \\ \text { Not at all } & \text { Somewhat } & \text { Moderately } & \text { Extremely } \\ \text { confident } & \text { Confident } & \text { Confident } & \text { Confident }\end{array}$

Please explain the reasons for your answer.

Please explain the reasons for your answer.

Please explain the reasons for your answer.

Please explain the reasons for your answer. 
21) The man picked up a blue coffee mug. Yes

No

How confident are you that your answer is correct?

$\begin{array}{llll}1 & 2 & 3 & 4 \\ \text { Not at all } & \text { Somewhat } & \text { Moderately } & \text { Extremely } \\ \text { confident } & \text { Confident } & \text { Confident } & \text { Confident }\end{array}$

22) The man used a hammer to fix the siding on the door frame.

Yes No

How confident are you that your answer is correct?

$\begin{array}{llll}1 & 2 & 3 & 4 \\ \text { Not at all } & \text { Somewhat } & \text { Moderately } & \text { Extremely } \\ \text { confident } & \text { Confident } & \text { Confident } & \text { Confident }\end{array}$

23) The man found the key to the door under a door mat. Yes No

How confident are you that your answer is correct?

$\begin{array}{llll}1 & 2 & 3 & 4 \\ \text { Not at all } & \text { Somewhat } & \text { Moderately } & \text { Extremely } \\ \text { confident } & \text { Confident } & \text { Confident } & \text { Confident }\end{array}$

24) The man carried a yellow tool box.

Yes

No

How confident are you that your answer is correct?

$\begin{array}{llll}1 & 2 & 3 & 4 \\ \text { Not at all } & \text { Somewhat } & \text { Moderately } & \text { Extremely } \\ \text { confident } & \text { Confident } & \text { Confident } & \text { Confident }\end{array}$

Please explain the reasons for your answer.
Please explain the reasons for your answer.
Please explain the reasons for your answer.
Please explain the reasons for your answer. 
Appendix H: Test Keys

Counterbalance One: Test Key

\begin{tabular}{|r|l|l|l|}
\hline$\#$ & Item & Question & Answer \\
\hline 1 & Unrelated & The man read a Time magazine. & No \\
\hline 2 & Target & There was a bag of dog food on the kitchen counter. & Yes \\
\hline 3 & Contradictory & The man drank a Coca-Cola that he got from the fridge. & No \\
\hline 4 & Additive & The bed in the bedroom was made. & No \\
\hline 5 & Target & The man sat in a patterned chair. & Yes \\
\hline 7 & Additive & The man read a note from the homeowners in the kitchen. & No \\
\hline 8 & Foil & The man had blonde hair. & No \\
\hline 9 & Unrelated & The man tried on a ring in the bedroom. & No \\
\hline 10 & Target & The man listened to a CD by "The Band". & Yes \\
\hline 11 & Foil & The man stole a credit card from a drawer. & No \\
\hline 12 & Contradictory & The man stole a bracelet. & No \\
\hline 13 & Target & The man fixed an electrical socket. & Yes \\
\hline 14 & Additive & The man ate an apple. & No \\
\hline 15 & Target & The man looked through a photo album. & Yes \\
\hline 16 & Target & The man wore a white shirt. & Yes \\
\hline 17 & Target & The man stole pills from the bathroom & Yes \\
\hline 18 & Contradictory & The man tried on a red cap. & No \\
\hline 19 & Target & The man lit a candle with a black lighter. & Yes \\
\hline 20 & Foil & There was a treadmill in the living room. & No \\
\hline 21 & Target & The man picked up a blue coffee mug. & No \\
\hline 22 & Target & $\begin{array}{l}\text { The man used a hammer to fix the siding on the door } \\
\text { frame. }\end{array}$ \\
\hline 23 & Unrelated & The man found the key to the door under a flower pot. & Yes \\
\hline 24 & Target & The man carried a yellow tool box. & \\
\hline & & & Nounter \\
\hline
\end{tabular}


Counterbalance Two: Test Key

\begin{tabular}{|c|c|c|c|}
\hline \# & Item & Question & Answer \\
\hline 1 & Additive & The man read a Time magazine. & No \\
\hline 2 & Target & There was a bag of dog food on the kitchen counter. & Yes \\
\hline 3 & Unrelated & The man drank a Coca-Cola that he got from the fridge. & No \\
\hline 4 & Contradictory & The bed in the bedroom was made. & No \\
\hline 5 & Target & The man sat in a patterned chair. & Yes \\
\hline 6 & Foil & There was a white microwave on the kitchen counter. & No \\
\hline 7 & Contradictory & The man read a note from the homeowners in the kitchen. & No \\
\hline 8 & Foil & The man had blonde hair. & No \\
\hline 9 & Additive & The man tried on a ring in the bedroom. & No \\
\hline 10 & Target & The man listened to a CD by "The Band". & Yes \\
\hline 11 & Foil & The man stole a credit card from a drawer. & No \\
\hline 12 & Unrelated & The man stole a bracelet. & No \\
\hline 13 & Target & The man fixed an electrical socket. & Yes \\
\hline 14 & Contradictory & The man ate an apple. & No \\
\hline 15 & Target & The man looked through a photo album. & Yes \\
\hline 16 & Target & The man wore a white shirt. & Yes \\
\hline 17 & Target & The man stole pills from the bathroom & Yes \\
\hline 18 & Unrelated & The man tried on a red cap. & No \\
\hline 19 & Target & The man lit a candle with a black lighter. & Yes \\
\hline 20 & Foil & There was a treadmill in the living room. & No \\
\hline 21 & Foil & The man picked up a red coffee mug. & No \\
\hline 22 & Target & $\begin{array}{l}\text { The man used a hammer to fix the siding on the door } \\
\text { frame. }\end{array}$ & Yes \\
\hline 23 & Additive & The man found the key to the door under a flower pot. & No \\
\hline 24 & Target & The man carried a yellow tool box. & Yes \\
\hline
\end{tabular}


Counterbalance Three: Test Key

\begin{tabular}{|r|l|l|l|}
\hline$\#$ & Item & Question & Answer \\
\hline 1 & Contradictory & The man read a Time magazine. & No \\
\hline 2 & Target & There was a bag of dog food on the kitchen counter. & Yes \\
\hline 3 & Additive & The man drank a Coca-Cola that he got from the fridge. & No \\
\hline 4 & Unrelated & The bed in the bedroom was made. & No \\
\hline 6 & Farget & The man sat in a patterned chair. & Yes \\
\hline 7 & Unrelated & There was a white microwave on the kitchen counter. & No \\
\hline 8 & Foil & The man had a note from the homeowners in the kitchen. & No \\
\hline 9 & Contradictory & The man tried on a ring in the bedroom. & No \\
\hline 10 & Target & The man listened to a CD by "The Band". & No \\
\hline 11 & Foil & The man stole a credit card from a drawer. & Yes \\
\hline 12 & Additive & The man stole a bracelet. & No \\
\hline 13 & Target & The man fixed an electrical socket. & No \\
\hline 14 & Unrelated & The man ate an apple. & Yes \\
\hline 15 & Target & The man looked through a photo album. & No \\
\hline 16 & Target & The man wore a white shirt. & Yes \\
\hline 17 & Target & The man stole pills from the bathroom & Yes \\
\hline 18 & Additive & The man tried on a red cap. & Yes \\
\hline 19 & Target & The man lit a candle with a black lighter. & No \\
\hline 20 & Foil & There was a treadmill in the living room. & Yes \\
\hline 21 & Foil & The man picked up a red coffee mug. & No \\
\hline 22 & Target & $\begin{array}{l}\text { The man used a hammer to fix the siding on the door } \\
\text { frame. }\end{array}$ & No \\
\hline 23 & Contradictory & The man found the key to the door under a flower pot. & Yes \\
\hline 24 & Target & The man carried a yellow tool box. & Yes \\
\hline
\end{tabular}


Counterbalance Four: Test Key

\begin{tabular}{|r|l|l|l|}
\hline$\#$ & Item & Question & Answer \\
\hline 1 & Unrelated & The man read a People magazine. & No \\
\hline 2 & Target & There was a bag of dog food on the kitchen counter. & Yes \\
\hline 3 & Contradictory & The man drank a Pepsi that he got from the fridge. & No \\
\hline 4 & Additive & The bed in the bedroom was unmade. & No \\
\hline 5 & Target & The man sat in a patterned chair. & Yes \\
\hline 6 & Foil & There was a white microwave on the kitchen counter. & No \\
\hline 7 & Additive & $\begin{array}{l}\text { The man read a note from the homeowners in the living } \\
\text { room. }\end{array}$ & No \\
\hline 8 & Foil & The man had blonde hair. & No \\
\hline 9 & Unrelated & The man tried on a watch in the bedroom. & No \\
\hline 10 & Target & The man listened to a CD by "The Band". & Yes \\
\hline 11 & Foil & The man stole a credit card from a drawer. & No \\
\hline 12 & Contradictory & The man stole a necklace. & No \\
\hline 13 & Target & The man fixed an electrical socket. & Yes \\
\hline 14 & Additive & The man ate a banana. & No \\
\hline 15 & Target & The man looked through a photo album. & Yes \\
\hline 16 & Target & The man wore a white shirt. & Yes \\
\hline 17 & Target & The man stole pills from the bathroom & Yes \\
\hline 18 & Contradictory & The man tried on a black cap. & No \\
\hline 19 & Target & The man lit a candle with a black lighter. & Yes \\
\hline 20 & Foil & There was a treadmill in the living room. & No \\
\hline 21 & Foil & The man picked up a blue coffee mug. & No \\
\hline 22 & Target & The man used a hammer to fix the siding on the door frame. & Yes \\
\hline 23 & Unrelated & The man found the key to the door under a door mat. & No \\
\hline 24 & Target & The man carried a yellow tool box. & Yes \\
\hline & & & \\
\hline
\end{tabular}


Counterbalance Five: Test Key

\begin{tabular}{|r|l|l|l|}
\hline$\#$ & Item & Question & Answer \\
\hline 1 & Additive & The man read a People magazine. & No \\
\hline 2 & Target & There was a bag of dog food on the kitchen counter. & Yes \\
\hline 3 & Unrelated & The man drank a Pepsi that he got from the fridge. & No \\
\hline 4 & Contradictory & The bed in the bedroom was unmade. & No \\
\hline 5 & Target & The man sat in a patterned chair. & Yes \\
\hline 6 & Foil & There was a white microwave on the kitchen counter. & No \\
\hline 7 & Contradictory & $\begin{array}{l}\text { The man read a note from the homeowners in the living } \\
\text { room. }\end{array}$ & No \\
\hline 8 & Foil & The man had blonde hair. & No \\
\hline 9 & Additive & The man tried on a watch in the bedroom. & No \\
\hline 10 & Target & The man listened to a CD by "The Band". & Yes \\
\hline 11 & Foil & The man stole a credit card from a drawer. & No \\
\hline 12 & Unrelated & The man stole a necklace. & No \\
\hline 13 & Target & The man fixed an electrical socket. & Yes \\
\hline 14 & Contradictory & The man ate a banana. & No \\
\hline 15 & Target & The man looked through a photo album. & Yes \\
\hline 16 & Target & The man wore a white shirt. & Yes \\
\hline 17 & Target & The man stole pills from the bathroom & Yes \\
\hline 18 & Unrelated & The man tried on a black cap. & No \\
\hline 19 & Target & The man lit a candle with a black lighter. & Yes \\
\hline 20 & Foil & There was a treadmill in the living room. & No \\
\hline 21 & Foil & The man picked up a blue coffee mug. & No \\
\hline 22 & Target & The man used a hammer to fix the siding on the door frame. & Yes \\
\hline 23 & Additive & The man found the key to the door under a door mat. & No \\
\hline 24 & Target & The man carried a yellow tool box. & Yes \\
\hline & & & \\
\hline
\end{tabular}


Counterbalance Six: Test Key

\begin{tabular}{|r|l|l|l|}
\hline$\#$ & Item & Question & Answer \\
\hline 1 & Contradictory & The man read a People magazine. & No \\
\hline 2 & Target & There was a bag of dog food on the kitchen counter. & Yes \\
\hline 3 & Additive & The man drank a Pepsi that he got from the fridge. & No \\
\hline 4 & Unrelated & The bed in the bedroom was unmade. & No \\
\hline 5 & Target & The man sat in a patterned chair. & Yes \\
\hline 6 & Foil & There was a white microwave on the kitchen counter. & No \\
\hline 7 & Unrelated & $\begin{array}{l}\text { The man read a note from the homeowners in the living } \\
\text { room. }\end{array}$ & No \\
\hline 8 & Foil & The man had blonde hair. & No \\
\hline 9 & Contradictory & The man tried on a watch in the bedroom. & No \\
\hline 10 & Target & The man listened to a CD by "The Band". & Yes \\
\hline 11 & Foil & The man stole a credit card from a drawer. & No \\
\hline 12 & Additive & The man stole a necklace. & No \\
\hline 13 & Target & The man fixed an electrical socket. & Yes \\
\hline 14 & Unrelated & The man ate a banana. & No \\
\hline 15 & Target & The man looked through a photo album. & Yes \\
\hline 16 & Target & The man wore a white shirt. & Yes \\
\hline 17 & Target & The man stole pills from the bathroom & Yes \\
\hline 18 & Additive & The man tried on a black cap. & No \\
\hline 19 & Target & The man lit a candle with a black lighter. & Yes \\
\hline 20 & Foil & There was a treadmill in the living room. & No \\
\hline 21 & Foil & The man picked up a blue coffee mug. & No \\
\hline 22 & Target & The man used a hammer to fix the siding on the door frame. & Yes \\
\hline 23 & Contradictory & The man found the key to the door under a door mat. & No \\
\hline 24 & Target & The man carried a yellow tool box. & Yes \\
\hline & & & \\
\hline
\end{tabular}




\section{Appendix I: Self Report Survey}

1) Did you recognize the man in the video? If so, in what way (i.e., 'I've seen him around' or 'We're friends')?

2) Were you at all suspicious about being tricked during the study? If so, please explain and indicate when such suspicions took place.

3) Did you know about the misinformation effect prior to participating in this study?

4) If you answered yes to question 3, please briefly describe the misinformation effect.

5) If you answered yes to question 3, were you aware that this study was about the misinformation effect before we told you? 
Appendix J: Warning Scripts

Warning

Now, I am going have you answer some questions about the video you saw earlier. You may remember me telling you earlier that some of the details in the narrative were inaccurate. Keep this in mind when answering questions on the test. Respond according to what you saw in video. Make sure to read the instructions at the top of the page before beginning and complete every step asked of you. Please, try to be as accurate as possible.

Warning + RR

Now, I am going have you answer some questions about the video you saw earlier. You may remember me telling you earlier that some of the details in the narrative were inaccurate. You may be able to reject some of these inaccurate details by comparing what you saw in the video to other details when only one or the other could have occurred. For example, if you had seen the man arrive at the house in a taxi and the test asked if he drove a car you could reject the idea that he drove a car because you know he arrived in a taxi. Keep this in mind when answering questions on the test. Respond according to what you saw in video. Make sure to read the instructions at the top of the page before beginning and complete every step asked of you. Please, try to be as accurate as possible. 